\title{
WestVirginiaUniversity
}

THE RESEARCH REPOSITORY @ WVU

Graduate Theses, Dissertations, and Problem Reports

2021

\section{Three Essays on the Impact of Cuteness on Consumer Behavior}

Alexis Taeeun Yim

West Virginia University, ya0016@mix.wvu.edu

Follow this and additional works at: https://researchrepository.wvu.edu/etd

Part of the Advertising and Promotion Management Commons, Marketing Commons, and the Sales and Merchandising Commons

\section{Recommended Citation}

Yim, Alexis Taeeun, "Three Essays on the Impact of Cuteness on Consumer Behavior" (2021). Graduate Theses, Dissertations, and Problem Reports. 8087.

https://researchrepository.wvu.edu/etd/8087

This Dissertation is protected by copyright and/or related rights. It has been brought to you by the The Research Repository @ WVU with permission from the rights-holder(s). You are free to use this Dissertation in any way that is permitted by the copyright and related rights legislation that applies to your use. For other uses you must obtain permission from the rights-holder(s) directly, unless additional rights are indicated by a Creative Commons license in the record and/ or on the work itself. This Dissertation has been accepted for inclusion in WVU Graduate Theses, Dissertations, and Problem Reports collection by an authorized administrator of The Research Repository @ WVU.

For more information, please contact researchrepository@mail.wvu.edu. 


\title{
Three Essays on the Impact of Cuteness on Consumer Behavior
}

\author{
Alexis T. Yim \\ Dissertation submitted \\ to the John Chambers College of Business and Economics \\ at West Virginia University \\ in partial fulfillment of the requirements for the degree of \\ Doctor of Philosophy in \\ Business Administration-Marketing
}

\begin{abstract}
Annie P. Cui, Ph. D., Co-Chair
Stephen He, Ph. D., Co-Chair

Julian Givi, Ph.D.

Brad Price, Ph.D.

Department of Marketing

Morgantown, West Virginia

2021
\end{abstract}

Keywords: Cuteness, risk preference, sales, personal selling, consumer engagement, babyface, voice

Copyright: 2021 Alexis T. Yim 


\title{
ABSTRACT \\ Three Essays on the Impact of Cuteness on Consumer Behavior
}

\begin{abstract}
Alexis T. Yim
Over the last decade, the world has seen a rise in the popularity of cute stimuli. Adorable baby pictures, fluffy puppy videos, and whimsical emojis seem ever-present in social media news feeds and friends' posts. In addition, products marketed toward adults that feature cute characters drive sales worth billions of dollars. The growing presence of cute stimuli in our daily lives is accompanied by emerging research on their social and behavioral impacts. Correspondingly, the current dissertation consists of three essays that contribute to the literature on cuteness by empirically testing the impacts of cuteness in the marketplace. To extend the literature on cuteness, the first essay examines the effects of exposure to cute images on risk-seeking behavior, the second essay tests the effect of salespeople's cute facial features (i.e., babyface) on online consumer engagement, and the third essay proposes a novel construct that induces the perception of cuteness through auditory cuteness cues: cute voice.

The first essay aims to consolidate seemingly contradictory findings in the emerging research on cuteness. While some studies on cuteness have shown that cuteness evokes caring and careful behavior, other research has found that cuteness causes aggressive and indulgent behavior. Thus, the first essay asks a more fundamental question of whether cute stimuli affect consumers' risk preference. The first essay develops a conceptual framework of a dual process to consolidate the contradictory findings from previous studies and demonstrates the positive effect of cuteness on risk-seeking behavior in various risk domains. Across four experimental studies, the first essay shows that exposure to cuteness reduces consumers' level of conscientiousness and, therefore, enhances their risk-seeking behaviors.
\end{abstract}


Next, the second essay fills the gap in the sales literature by exploring the effects of babyface on online consumer engagement. Literature has shown that salespeople's appearance plays an important role their sales performance and consumer evaluations. Still, little is known about how the extent to which a salesperson possesses babyish facial features (i.e., 'babyface') affects consumer engagement. Thus, the second essay fills this gap by exploring the effects of babyface on consumer engagement in an online environment. Real-world observational data from an online real estate marketplace is utilized to test whether babyface impacts online consumer engagement. In addition, an experimental study was conducted to test the effect in a controlled setting. Findings of these two studies reveal that babyface (vs. mature face) induces less online consumer engagement when consumers are highly involved in their purchase decision-making process. This research contributes to the sales literature by providing an initial exploration of babyface's impact on online consumer engagement while simultaneously investigating theoretically-relevant and practically-important moderators.

Lastly, going beyond the perception of cuteness generated through visual stimuli, the third essay introduces and defines the construct of cute voice and two types of auditory stimuli that induce the perception of cuteness. Although how consumers perceive cuteness through their sense of sight has been defined and studied since the early 1940s, how they perceive cuteness through their sense of hearing has not been explored yet. Thus, the third essay develops and validates the perception of cute voice and proposes two antecedents. This work will be the first to introduce, define and demonstrate cute voice. 


\section{DEDICATION}

I dedicate this work to my loving and supportive family and friends. 


\section{ACKNOWLEDGEMENTS}

I would like to thank my committee members and professors who have shown endless trust, unlimited support, utmost kindness, and guidance during every stage of my doctoral journey. Especially, I would like to thank Dr. Annie Cui and Dr. Stephen He for always being there for me during this journey and teaching me how to be a better researcher. Without their time, knowledge sharing, and enormous efforts, I would not be able to be here. I am especially thankful for my co-chairs who have closely worked with me since the first year I moved to West Virginia. Dr. Annie Cui and Dr. Stephen He have always supported, taught, and led me in the right direction to be able to be a better researcher and person. They have been not only my dissertation co-chairs, but also my role models. Having Dr. Annie Cui as my faculty mentor ever since I started the program has been the best thing that has happened to me during my doctoral journey. She has provided invaluable care and guidance for me, and has always been there for my teaching, research, and even personal concerns. Dr. Stephen He has taught me how to think critically and organize thoughts in systematic ways, which I would never have been able to gain by myself. He also has taught me how to run experimental studies and analyze data from the beginning, and write papers with compelling stories to convince readers more efficiently. Dr. Julian Givi has helped strengthen the dissertation enormously, and write it more concisely and clearly. He also has taught me how to structure a research paper by providing me his constructive and valuable comments. Dr. Brad Price has always been extremely supportive, welcomed my visit anytime when I needed his advice on programming and data analyses. Although I was not familiar with the programming, he has guided me with patience through the journey, and provided tremendous support. I am deeply grateful to all of my dissertation committee members for their unconditional support, valuable time, and insightful feedback. Lastly, there are no words 
to describe how much I appreciate all of the professors in the Department of Marketing at West Virginia University. I am looking forward to being a professor who can pass down their knowledge and wisdom to my students. 


\section{TABLE OF CONTENTS}

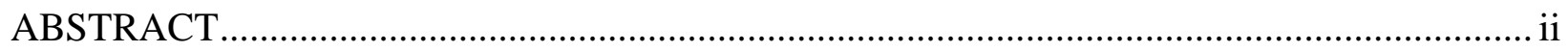

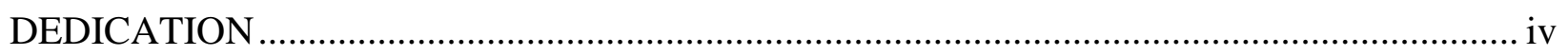

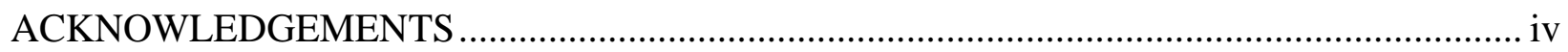

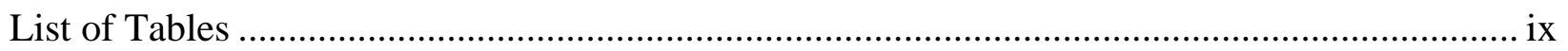

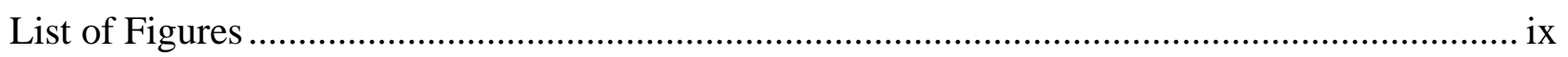

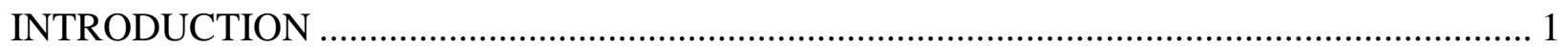

1. Overview of Research Context ................................................................................ 1

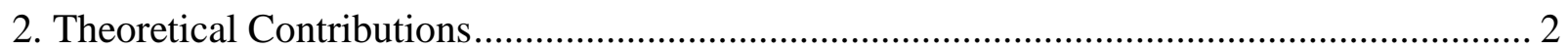

3. Structure of the Dissertation........................................................................................ 4

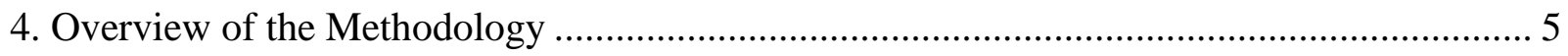

Essay 1: The Power of Aww: A Dual-process Approach to Cuteness-affected Risk Decision-

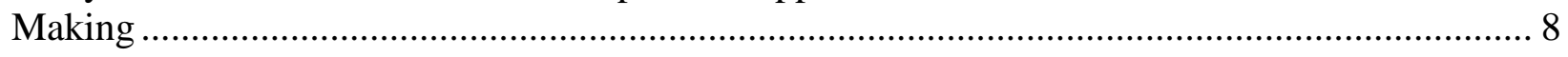

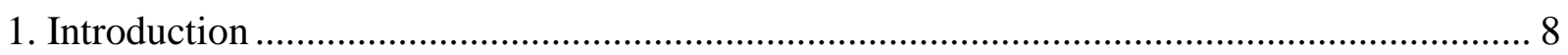

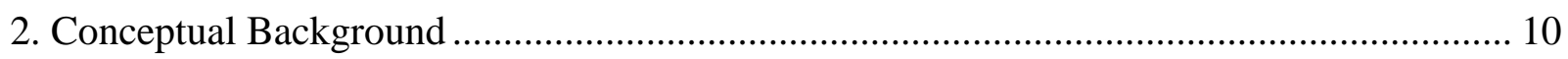

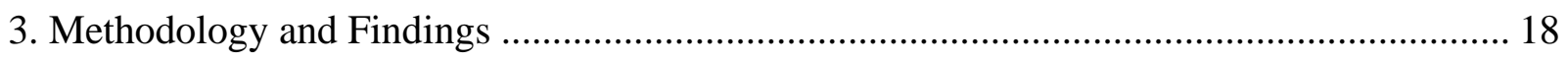

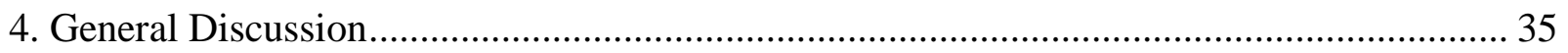

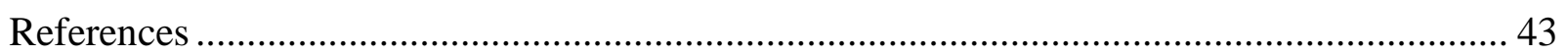

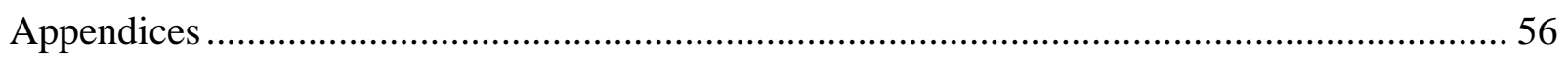

Essay 2: The Harmful Effect of Salesperson Babyface on Online Consumer Engagement......... 65

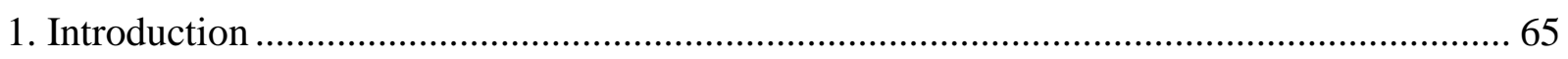

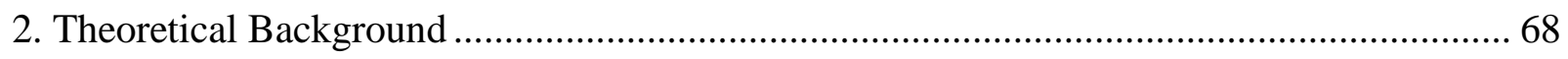

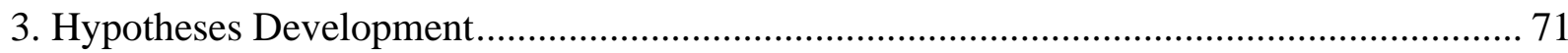

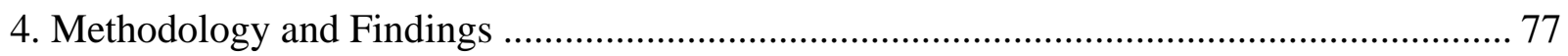

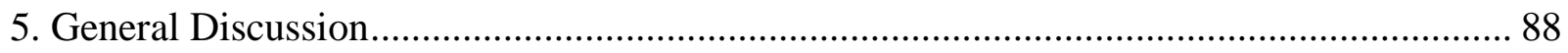

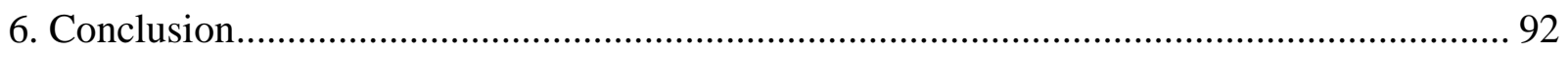

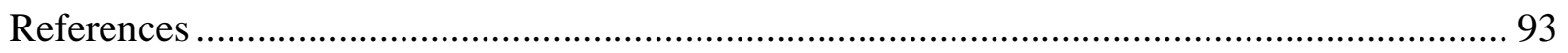

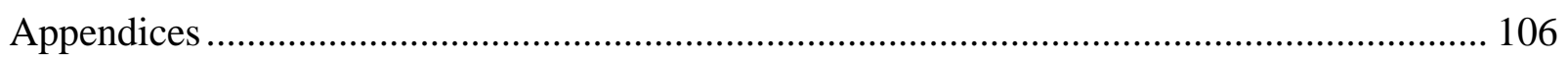

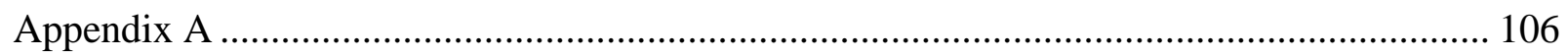

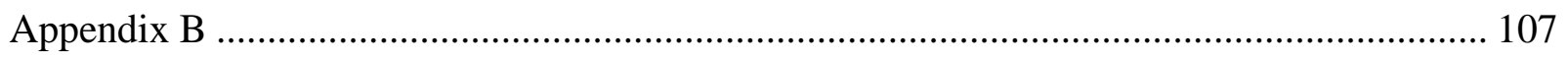

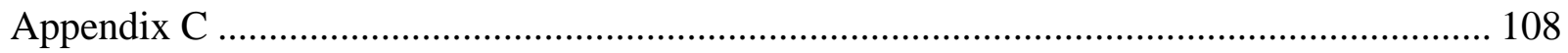

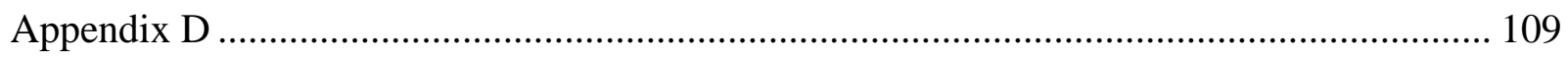

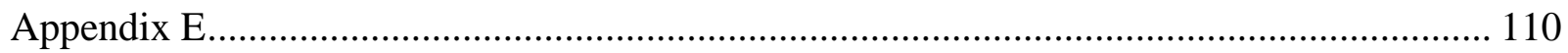

Essay 3: Cute Voice: Definition and Conceptualization................................................... 111 


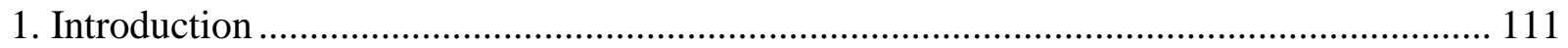

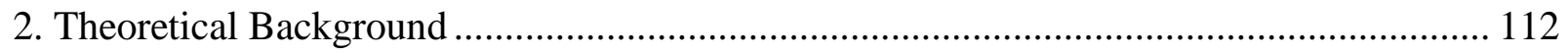

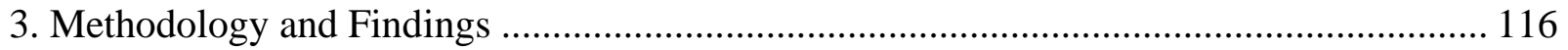

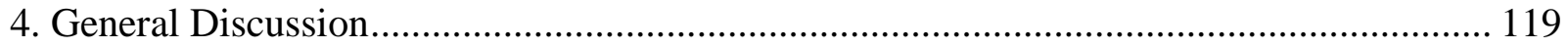

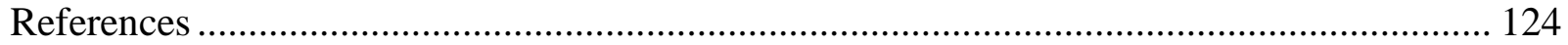




\section{List of Tables}

Table 1. Summary of prior research on effects of cuteness on risk preference ......................... 14

Table 2. Literature review on facial appearance in marketing .............................................. 70

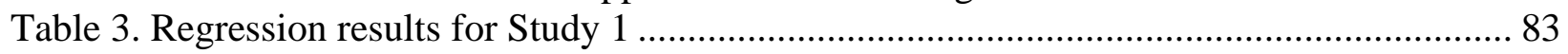

\section{List of Figures}

Figure 1. Study 1: The effect of cuteness on risky food consumption .................................. 21

Figure 2. Study 2: The effect of cuteness on risk-preference .............................................. 25

Figure 3. Study 3: The effect of cuteness on risk-preference ............................................... 29

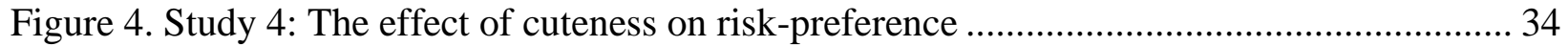

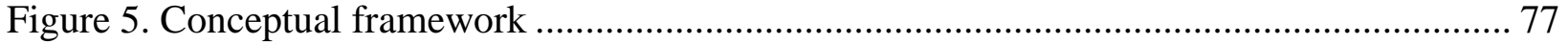

Figure 6. Study 2: Experimental study stimuli ............................................................... 86

Figure 7. Study 2: Moderation effect of involvement on the relationship between salesperson

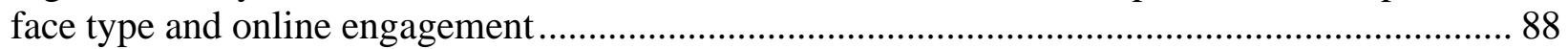

Figure 8. Study 1: The effect of pitch on the perception of cute voice.................................. 118

Figure 9. Study 1: The effect of tempo on the perception of cute voice................................. 118 


\section{INTRODUCTION}

\section{Overview of Research Context}

Cuteness refers to being attractive in an endearing and adorable way (Nenkov and Scott 2014; Merriam Webster 2020). Cuteness has a strong root in evolutionary imperatives, as it is key to offspring survival (Little 2012). Thus, regardless of animal species, babies have developed similar features that induce the perception of cuteness to gain help and support from adults (Glocker et al. 2009), and adults respond to them accordingly to secure the survival of the species (Lobmaier et al. 2010; Kringelbach et al. 2016). Therefore, cuteness has been an important topic of study because of its behavioral and biological significance for evolutionary function (Borgi and Cirulli 2016; Buckley 2016). For example, body temperature increases when individuals view cute stimuli, which indicates enhanced positive emotion and attention toward the cute stimuli (Esposito et al. 2014). In addition, exposure to cute stimuli encourages people to behave in more prosocial, careful and caring ways (Nittono 2012; Wang et al. 2017). Moreover, neuroscience studies have shown that seeing cute stimuli activates the orbitofrontal cortex, the part of the brain related to emotional pleasure and attachment (Kringelbach et al. 2008). However, consumers' responses to marketing strategies incorporating cute stimuli have rarely been examined in marketing literature, despite the discursive significance of cuteness and its popularity on marketing practices (Nenkov and Scott 2014; Scott and Nenkov 2016). Thus, the current dissertation aims to extend the literature on cuteness in marketing.

The current dissertation aims to answer the overarching question of how cuteness affects consumer behavior in three essays. More specifically, the first essay examines whether exposure to visual cuteness stimuli influences consumers' risk preference. Then, the second essay explores 
whether salespeople's cuteness impacts online consumer engagement. Lastly, the third essay defines a novel construct, cute voice.

\section{Theoretical Contributions}

The current dissertation makes many important contributions. First, the current dissertation contributes to the emerging cuteness research (Buckley 2016; Steinnes et al. 2019; Wang et al. 2017). This dissertation explicates the effects of cuteness on consumers' risk preference, the relationships between cute salespeople and online consumer engagement, and the antecedents of auditory cuteness stimuli. Importantly, the first essay proposes and examines a dual-process to resolve the conflicting findings from the cuteness literature (Glocker et al. 2009; Nenkov and Scott 2014; Nittono et al. 2012; Scott and Nenkov 2016). The first essay shows the positive effect of visual cuteness stimuli on risk-seeking behavior with four experimental studies in various risk domains. However, caring motivation reverses this positive effect. Then, the second essay shows the negative relationship between salespeople's cute face (i.e., babyfaced salespeople) and online consumer engagement. Building on the babyface overgeneralization effect (Zebrowitz et al. 2003; Zebrowitz et al. 2007), the second essay finds that cute face induces less online consumer engagement in a high involvement sales context. Additionally, the second essay proposes and tests important moderators (i.e., salespeople's gender and the level of consumer involvement) to enrich the literature on cuteness. Lastly, the third essay is first to introduce a novel construct, cute voice that induces the perception of cuteness through auditory stimuli.

Second, the current dissertation contributes to the literature on risk preference by demonstrating that exposure to cute stimuli increases people's risk-seeking behavior (Havlena and DeSarbo1991; Zhang and Hou 2017). Understanding consumer risk preference has 
been one of the most important topics in marketing literature, as risk preference is associated with various types of consumer decision-making (National Research Council 1982). For instance, consumers often deal with risks such as adopting a new product or service, and any purchasing decision can possibly lead to an adverse consequence (Murthy and Djamaludin 2002). Although previous studies have shown the effects of cuteness on consumer behavior to be somewhat associated with risk (Aragon et al. 2015; Glocker et al. 2009; Nenkov and Scott 2014; Nittono et al. 2012), none of the previous studies has explored a direct relationship between cuteness as an environmental cue and risk preference across various domains. Some previous studies have found that exposure to cute stimuli leads to careful and caretaking behavior, which is associated with risk-averse (Glocker et al. 2009; Nittono et al. 2012). On the other hand, a stream of literature on cuteness has shown that exposure to cute stimuli leads to indulgent and aggressive behavior which might be more relevant to risk-seeking behavior (Aragon et al. 2015; Nenkov and Scott 2014). Thus, the current dissertation answers calls for the systematic analysis of the relationship between exposure to cuteness and risk preference.

Third, the current dissertation extends sales literature. Contrary to the conventional notion that cute-looking salespeople (i.e., babyfaced salespeople) might have more advantages than their counterparts (i.e., mature-faced salespeople), the second essay demonstrates that salespeople with cute faces can actually induce less consumer engagement. This essay contributes to the sales literature by building on the babyface overgeneralization effect in which people often perceive childlike traits in babyfaced individuals (Zebrowitz et al. 2003; Zebrowitz et al. 2007). The findings from the current dissertation show that the babyface overgeneralization effect also prevails in a sales context. 


\section{Structure of the Dissertation}

Each essay aims to answer the main question in a different context: How does cuteness affect consumer behavior? In particular, the first essay examines the effects of visual cuteness stimuli such as cartoon characters on risk preference, the second essay examines the effects of salespeople's cute face (i.e., babyface) on online consumer engagement, and the third essay proposed and defined auditory cuteness cues.

The purpose of the first essay is to consolidate seemingly contradictory findings in the emerging literature on cuteness (Aragón et al. 2015; Glocker et al. 2009; Nittono et al. 2012). In addition, while marketers often integrate cute stimuli such as Disney characters into marketing materials (Poniewozik 2019; Tracey 2020; Woodford 2018), research on cute stimuli as an environmental cue (i.e., cute mascots on marketing materials) rather than a cute entity itself (i.e., cute panda cookies) has been scarce (Nenkov and Scott 2014; Wang et al. 2017). Therefore, the first essay proposes a dual-process approach, and examines whether subtle exposure to various types of cute stimuli influences risk preference. However, the first essay is limited to assessing the effects of cuteness solely generated by visual stimuli, although consumers might perceive cuteness through multiple senses. In addition, the first essay did not examine the direct effects of cuteness in sales contexts. Therefore, the second essay examines whether salespeople's cuteness affects online consumer engagement in a real-world context, and the third essay explores whether consumers perceive cuteness through their sense of hearing.

The purpose of the second essay is to examine whether salespeople's cute face (i.e., babyfaced salespeople) impacts online consumer engagement. Some might assume that being cute would be beneficial for every circumstance, but the second essay shows that salespeople's cute face could induce less online consumer engagement due to the babyface overgeneralization 
effect (Zebrowitz et al. 2003; Zebrowitz et al. 2007) when consumers are highly involved in their purchase process. Although the second essay sheds light on the negative effect of being cute in a sales context, the second essay still has a limitation, because it only examines the effect of visual cuteness stimuli, just as the first essay does. Therefore, the third essay extends the literature on cuteness by conceptualizing auditory cuteness stimuli and exploring their effects.

The purpose of the third essay is to explore whether individuals perceive a certain voice as cute and to conceptualize and define cute voice that induces the perception of cuteness. To do so, the third essay proposes and empirically tests a higher (vs. lower) pitch and a faster (slower) tempo as the antecedents of cute voice.

\section{Overview of the Methodology}

Essay 1 used four experiments to test the causal relationship between exposure to cute stimuli and risk preference.

(1) The first experiment aims to examine the positive effect of exposure to cuteness on risk-seeking behavior in a real-world situation. This study uses respondents' choice between a scorpion candy and a normal candy to assess their risk preference. Participants received a cardboard box containing both a priming stimulus and two candy options. Depending on the condition, participants viewed either a drawing of a cute scorpion or a drawing of a noncute scorpion in the candy box. To measure their risk-seeking behavior, I asked participants to choose either to taste a blue lollipop that has a real scorpion in it, or to taste an ordinary blue lollipop, or not to taste any candy.

(2) The second experiment tried to replicate the positive effect of exposure to cuteness on risk-seeking behavior by utilizing cute characters that are commonly-used cute stimuli in the marketplaces. This study used classical gambling games to measure participants' risk preference 
with finances (Porcelli and Delgado 2009). In this study, I examined whether participants make risky choices (i.e., safe options vs. risky options) more frequently after exposure to cute characters.

(3) The third experimental study tested the mediator role of low conscientiousness on the effect of cuteness on risk-seeking behavior. This study used the classical gambling game identical to the second experimental study. In addition, the study examined whether the effects of cuteness were moderated by different dimensions of cuteness (i.e., whimsical cuteness vs. baby cuteness) by using images of the same person with different facial expressions.

(4) The fourth experimental study examined the moderating role of caring motivation. This study used a real-world news article featuring a real mass-shooting incident and tested if participants are more willing to take a life-threatening risk during a mass-shooting. Depending on the condition, participants were exposed to an image of a cute cartoon character, a noncute cartoon character, a cute baby wipes advertisement, or a noncute baby wipes advertisement, or they did not view any image in the background of the news article.

Essay 2 used a real-world observational study and an experimental study to test how salespeople's cute face (i.e., babyface) affects online consumer engagement.

(1) The observational study in essay 2 examined the harmful effect of babyface by using real-world data from a leading online real estate marketplace, Zillow.com. Especially, essay 2 utilized an artificial intelligence facial recognition program to analyze a thousand online profile images of real estate agents from Zillow.com systematically.

(2) The experimental study in essay 2 tested the moderating role of consumer involvement in the effects of babyface on online consumer engagement. The experiment tested the effects by using morphed headshots of a salesperson and two types of service that consumers 
have either high or low involvement with. Participants read a description of a service, viewed a headshot of a salesperson, and indicated their willingness to write online reviews for the salesperson.

Lastly, essay 3 explored the antecedents of cute voice with an experimental study. This study manipulated the pitch and the tempo of voices to test their effects on the perception of cute voice. The study used a text-to-speech software, NaturalReader, to obtain the voices. After obtaining the voices, I used a cross-platform audio software, Audacity, to manipulate the pitch of each voice to be $15 \%$ higher (vs. lower) and the tempo of it to be $20 \%$ faster (vs. slower). Participants listened to twenty-four manipulated voice clips and indicated which voices sounded cuter. 


\section{Essay 1: The Power of Aww: A Dual-process Approach to Cuteness-affected Risk Decision- Making}

\section{Introduction}

Over the last decade, the world has seen a growing interest in cuteness (Myrick 2015; Stavropoulos 2019). Adorable baby pictures, fluffy puppy videos, and whimsical emojis seem ever-present in social media news feeds and marketing materials (Poniewozik 2019; Woodford 2018). For example, countries, including Japan, and Mexico have used cute characters to educate the public about COVID -19 guidance (Tracey 2020). In marketplaces, products featuring cute characters that appeal to adults drive sales worth billions of dollars (Tait 2019). When Nintendo launched Pokémon GO, a mobile game app featuring the well-known collection of cute pet monsters, it added $\$ 7.5$ billion (a $200 \%$ increase) to the market value of Nintendo in just two days (Funke 2016; Tait 2019). It is not surprising that a wide variety of marketing communications, including product packages, web banners, and logos also adopt cuteness as a theme to elicit positive responses from consumers (Olenski 2016). The Pillsbury Doughboy, Wells Fargo's puppy, and Baidu's bear paw are just a few examples in the marketplace (Appendix A).

The growing presence of cuteness in our daily life is accompanied by emerging research on their social and behavioral impacts (Buckley 2016; Steinnes et al. 2019). For instance, some research has found that exposure to cuteness makes individuals more careful and behave in caring ways (Glocker et al. 2009a; Nittono et al. 2012). On the other hand, other research has documented that exposure to cuteness leads individuals to be more aggressive (Aragón et al. 2015) and to indulge in foods and products (Nenkov and Scott 2014; Scott and Nenkov 2016). To consolidate these seemingly contradictory effects, I investigate a more fundamental question 
shared by these phenomena: will cuteness trigger more or less preference for risk? To address this question, I introduce a conceptual framework for the newly proposed dual-process approach and empirically investigate it with four experiments. Importantly, I establish the dual-process effects of cuteness on risk preference in various risk domains.

By providing evidence of the effect of cuteness on consumers' risk preference, the current paper contributes to consumer behavior literature in the following ways: First, this research sheds light on the topic of cuteness in the marketing literature (Wang et al. 2017; Zhipeng et al. 2018). Marketing literature on the subject of cuteness has been scarce despite the popularity of cuteness in marketing practice and the importance of biological and psychological changes evoked by cuteness (Glocker et al. 2009a). Importantly, the current research tries to consolidate the contradictory findings on the effects of exposure to cuteness on risk preference by examining a newly proposed dual-process model moderated by consumers' caring motivation. The dual-process model proposes that exposure to cuteness makes individuals become more (vs. les) likely to take risk when cute stimuli are not the focal points and caretaking motivation is absent (vs. salient).

Some scholars found the positive relationship between exposure to cuteness and riskseeking behavior (Aragón et al. 2015; Nenkov and Scott 2014), whereas others found the opposite direction (Glocker et al. 2009; Nittono et al. 2012). To resolve these contradictory findings, I propose caring motivation as a moderator and show that it indeed moderates the effects of cuteness on risk-seeking behavior. Moreover, this research contributes to the literature on cuteness by investigating the potential effects of cuteness as a subtle environmental cue on risk preference in marketplaces. Understanding cuteness as an environmental cue in the background rather than a focal point is especially important, as cute pictures and emojis prevail 
online, and consumers are consistently exposed to marketing campaigns with a subtle presence of cuteness (Myrick 2015).

Second, this research will extend the literature on risk preference (Esteky et al. 2018; Shen et al. 2014). Consumer risk preference is one of the most important topics in the marketing literature because consumers deal with risks and uncertainties as a part of their everyday decision-making (Murthy and Djamaludin 2002). Even though consumers make decisions involving risks every day and are consistently surrounded by cuteness, I am unaware of any existing study investigating how subtle exposure to cuteness in the background shapes consumers' risk preference across various risk domains (Li and Yan 2021; Poniewozik 2019). Therefore, the present study attempts to fill this theoretical gap.

In the next section, I discuss the conceptual background, including a literature review. Three research hypotheses for the main effect, the mediation effect, and the boundary condition of the main effect follow. The subsequent section presents the methodology for the four empirical investigations in the different risk domains. Finally, the theoretical contributions, practical implications for marketers and consumers, limitations, and future research directions conclude the article.

\section{Conceptual Background}

\section{Exposure to Cuteness}

Consistent with the previous literature on cuteness, the current study defines cuteness as the quality of being attractive in a pretty or endearing way by reflecting baby schema (Hellen and Sääksjärvi 2013). Nobel Laureate Konrad Lorenz (1943) proposed baby schema (i.e.,

kindchenschema) that describes the composition of childlike physical features, including big and round eyes, a small body-to-face ratio, and chubby cheeks (Nittono and Ihara 2017). 
Evolutionary theory supports the notion that younglings have developed baby schema that induces the perception of cuteness to gain support and attention from adults (Miseler et al. 2011; Saad 2013). Thus, regardless of animal species (i.e., babies, kittens, and puppies), younglings have baby schema in common to gain help for survival (Luo et al. 2011). Moreover, humans have evolved to be sensitive to cute stimuli that have the baby schema (Lehmann et al. 2013).

Early studies on cuteness have focused on the understanding of the antecedents of the perception of cuteness (Alley 1983; Lorenz 1943; Sternglanz et al. 1977). After many studies on cuteness have consistently shown that baby schema induces the perception of cuteness, more recent studies have proposed various consequences of exposure to cuteness (Holly et al. 2017; Zickfeld et al. 2018). Prior studies have found that exposure to cuteness influences numerous human behaviors, emotions, and brain activities (Dale 2016; Kringelbach et al. 2016), as it plays an important evolutionary role for offspring survival. For example, exposure to cuteness triggers observers' positive affective response (Miesler et al. 2011), attention (Nittono et al. 2012) and pleasure (Rossbach and Wilson 1992), and activates the brain regions associated with the reward system and attachment (Glocker et al. 2009b; Minagawa-Kawai et al. 2009; Stoeckel et al. 2014).

Regarding the association between cuteness and risk preference, two groups of research on cuteness have pointed out opposite consequences resulting from exposure to cuteness. One group of scholars has shown that individuals who view cute images become more aggressive and indulgent (Aragón et al. 2015; Nenkov and Scott 2014), which seems to suggest that cuteness may lead to more risk-seeking behavior. On the other hand, another group of scholars has found that people who view cute stimuli become more careful during subsequent behaviors (Nittono et 
al. 2012; Sherman et al. 2009), a phenomenon that could be extrapolated to argue that cuteness may foster risk-averse behavior.

Risk-aversion vs. Risk-seeking - A Dual-process Approach

In the current study, I aim to consolidate the mixed findings in the literature by proposing two competing processes triggered by cuteness. Though it is unclear whether exposure to cuteness might lead individuals to be risk-seeking or risk-averse, the literature on cuteness has consistently supported the important evolutionary function of cuteness for offspring survival (Aragón et al. 2015; Glocker et al. 2009a; Sherman et al. 2013). Hence, I propose a dual-process approach to consolidate these mixed findings by suggesting a new moderator, caregiving motivation. The first process is that exposure to cuteness facilitates risk-aversion because of cute entities' needs to be taken care of (Glocker et al. 2009b). On the other hand, the second process is that exposure to cuteness facilitates risk-seeking because individuals attracted by cute entities often instinctively approach them (Golle et al. 2013; Sternglanz et al. 1977; Wang et al. 2017).

A group of scholars has tested the first process (Nittono et al. 2012; Sherman et al. 2009; Sherman et al. 2013). More specifically, in the experimental studies conducted by Nittono et al. (2012) and Sherman et al. (2009), participants improved their performance on the tasks that required carefulness after viewing cute stimuli. Similarly, Fischer and Hills (2012), Sherman et al. (2013), and Li and Yan (2021) have shown that exposure to cuteness leads to risk-avoidance behavior solely for women because of their maternal instincts towards offspring (Berman 1980). Parental caretaking behaviors are closely related to cuteness, in which younglings have developed baby schema that induces the perception of cuteness to gain support and attention from adults (Luo et al. 2011; Saad 2013). Correspondingly, adults identify entities with a high level of baby schema as cute and respond to them with care (Gross 1997; Volk et al. 2007). The 
previous studies were more likely to obtain risk-aversion results in their experimental studies when cute stimuli were focal points, when they measured participants' behavior with operation tasks, and when participants were women who are more naturally oriented to caring than men. In those experimental set-ups, the caring motivation outweighed risk-seeking behavior (Fischer and Hills 2012; Li and Yan 2021; Nittono et al. 2012; Sherman et al. 2009) (See table 1).

Contrarily, another group of scholars has shown that when individuals view cute stimuli, they are more likely to squeeze targets, clench hands and teeth, and indulge in ice cream (Aragón et al. 2015; Nenkov and Scott 2014). More specifically, Aragón et al. (2015) and Stavropoulos and Alba (2018) have shown that individuals become more aggressive, which is consistent with an approach intention (Lott 1974). In addition, Nenkov and Scott $(2014,2016)$ have argued that exposure to cuteness leads individuals to make more indulging consumption, which is another form of risk-seeking behavior since consumers often engage in risky experiences for pleasure (Creyer et al. 2003). The previous studies were more likely to obtain risk-seeking results in their experimental studies when cute stimuli were not necessarily babies, when they measured participant's behavior with aggression questionnaires or consumption, and when both men and women participated in their studies. In those experimental set-ups, the risk-seeking behavior outweighed risk-avoidant behavior (Aragón et al. 2015; Nenkov and Scott 2014; Stavropoulos and Alba 2018) (See table 1). 
Table 1. Summary of prior research on effects of cuteness on risk preference

\begin{tabular}{llll}
\hline Risk preference & Author(s) & $\begin{array}{l}\text { Experimental } \\
\text { Studies }\end{array}$ & Dependent variable measure(s) \\
\hline Risk-seeking & Nenkov and Scott & Study1 & Ice cream consumption \\
& (2014) & Study2 & Stapler usage \\
& & Study3 & Movie choice \\
Cookie consumption
\end{tabular}


Despite some speculations, there has not been any study in either the risk literature or the cuteness literature that has consistently shown a robust effect of cuteness exposure on risk preference across different decision contexts. The current paper fills this research gap by proposing the dual-process model documenting such an effect. I conceptualize the dual-process model by suggesting that consumers are more or less likely to take risks after exposure to cuteness depending on the salience of caring motivation. The dual-process model suggests that consumers are more likely to take a risk-averse process after exposure to cuteness when their caring motivation is salient. In other words, when baby schema stimuli activate caring motivation, individuals are less likely to take a risk that might cause any potential hazards (Li and Yan 2021). On the other hand, when caring motivation is absent, exposure to cuteness leads to a risk-seeking process because cute entities are attractive and trigger approaching tendency (Alley 1981). Risk-seeking behavior is closely linked to approach behavior, as any approach could be potentially harmful or dangerous.

In the current paper, I am particularly interested in examining the risk-seeking process because it does not require cuteness to be the focal point of attention (Riessland 1998). That is, when individuals are exposed to cute entities placed in the background, caring motivation should become irrelevant (de Braal 2010). When caring motivation becomes irrelevant, the risk-seeking process should be the dominant process (Aragón et al. 2015; Nenkov and Scott 2014; Stavropoulos and Alba 2018). Cute stimuli often serve as spokespersons or illustrations in the background rather than a focal point, and the individuals who viewed them would not necessarily have the desire to take care of them. For example, consumers are often exposed to cute characters such as Kung Fu Panda on cereal boxes at grocery stores, although the cute characters are not their focal point. Moreover, based on previous studies, individuals are more likely to be 
risk-seeking than risk-averse (Powell and Ansic 1997; Weber and Chapman 2005). Thus, I note that the risk-seeking process is probably also the process that is easier to manifest in both genders and to be generalized to a variety of decision contexts. Therefore, my first hypothesis is framed as a simple main effect.

\section{H1. Exposure to cuteness increases customers' risk-seeking behavior.}

While the underlying mechanism of the risk-averse process is straightforward and has been supported by a lot of studies — baby schema triggers motivation to offer care for younglings - the newly proposed risk-seeking process needs more explanation. Although cute stimuli are often associated with positive mood (Aragón et al. 2015), which could lead to more risk-seeking because of optimism towards risk (Stanton et al. 2014), I speculate that there are additional mechanisms driving risk-seeking beyond positive mood. I propose that exposure to cuteness increases individuals' risk-seeking behavior because baby schema might also lower people's guard by making them less conscientious.

Conscientiousness refers to being attentive, careful, and planful towards risk and safety (Barrick and Mount 1991). Conscientiousness involves planning and thinking seriously before making any decision or taking any course of action, thus preventing individuals from taking risks (Dudley et al. 2006). In other words, individuals with a high level of conscientiousness are more likely to exhibit safety behaviors (Barrick and Mount 2000; Wallace and Vodanovich 2003). However, exposure to cuteness that evokes heartwarming emotion might reduce individuals' level of conscientiousness by lowering individuals' attentiveness and guards towards cute entities (Steinnes et al. 2019). Individuals with a low conscientiousness level are more likely to take risk because they are less alert and careless towards risk. Besides, Junglas et al. (2008) has shown that low conscientious individuals are less concerned about adverse outcomes caused by 
taking risk. Therefore, I propose that people do not need to be highly conscientious around cute entities, as cute entities are not dangerous and approachable, which causes less scrutiny of potential risks.

\section{H2. Low conscientiousness mediates the effect of exposure to cuteness on risk- seeking behavior.}

As I have discussed earlier, many factors could dampen the risk-seeking process and facilitate the risk-averse process, causing the effect of cuteness to disappear or even take the opposite direction (Nittono et al. 2012; Sherman et al. 2009). In the current research, I examine both processes by testing caring motivation as a moderator (Lobmaier et al. 2010; Maestripieri and Pelka 2002). Caring motivation refers to the tendency to nurture and help others (Mayseless 2015). When individuals are highly motivated to be caring, they are less likely to take a risk, as they become cautious to minimize any potential risky outcomes that might affect the entities they care for (Li and Yan 2021).

The dual-process approach would suggest that individuals either follow the risk-averse process or the risk-seeking process when they are exposed to cute entities, depending on the salience of caring motivation. More specifically, individuals take the risk-seeking process when exposure to cute entities does not induce caring motivation, but it reduces viewers' guards and makes them become less conscientious (Nenkov and Scott 2014; Tan et al. 2017). However, the dual-process approach would suggest that the risk-averse process will dominate when exposure to cute stimuli evokes viewers' caring motivation (Kringelbach et al. 2016), resulting in them being more risk-averse (Fischer and Hills 2012; Sternglanz et al. 1977).

\section{H3. Caring motivation moderates the effect of exposure to cuteness on risk-seeking behavior.}




\section{Methodology and Findings}

In the following sections, I describe four studies conducted to investigate the aforementioned hypotheses in laboratory and simulation studies across various risk domains. I expect that exposure to cute stimuli makes individuals take more risks by lowering their conscientiousness. Across the four experiments, I have participants view cute stimuli on different interfaces to show robust results.

Study 1 seeks initial evidence with a risky food choice that has real consequences in a laboratory experiment. Studies 2 and 3 provide convergent support for the effects of cuteness on risk-seeking behavior in a series of classical gambling games. Study 2 conceptually replicates the effect and provides evidence that cuteness leads individuals to take more risks. Next, study 3 provides evidence for low conscientiousness being the fundamental mechanism that links cuteness and risk-seeking behavior. Furthermore, study 3 examines the frequency of riskseeking behavior by comparing the participants' likelihood of choosing riskier options in four different conditions (i.e., whimsical babies vs. neutral babies vs. whimsical adults vs. neutral adults) in order to rule out whimsicality as an alternative explanation. Study 4 replicates riskaverse results from previous studies (Nittono et al. 2012; Sherman et al. 2013) and demonstrates risk-seeking choice when caring motivation is absent.

\section{Study 1}

Study 1 seeks initial evidence for the main hypothesis that exposure to cuteness increases people's risk-seeking, using choices that have real consequences. In this study, participants are given a box that contained two different types of candy, and asked to choose one to taste and evaluate. I predict that participants who are exposed to cute stimuli will be more likely to choose the riskier candy option to taste than those exposed to noncute stimuli. 


\section{Method}

Eighty-eight university students participated in the study for extra course credits. In an on-campus behavioral lab, participants sat at individual tables where a cardboard box and a survey booklet that detailed instructions were placed. The cardboard box contained both the priming stimuli and two candy options. All participants were randomly assigned to one of two between-subjects conditions (cuteness priming: cute vs. noncute). Depending on the condition, participants either found a cute scorpion drawing or a noncute scorpion drawing inside the box (Methodological Details Appendix A) before they made their candy choice.

Cuteness Manipulation. I conducted a pretest of the cuteness manipulation (the same student pool, drawing from people who were not involved in the current study; $N=81 ; 49 \%$ female; $\left.M_{\text {age }}=21.4\right)$. Pretest participants viewed a cute scorpion image and a noncute scorpion image and rated the extent to which the characters were cute, adorable, and endearing adapted from Nenkov and Scott (2014). All items were measured on a 7-point scale $(1=$ not at all, $7=$ extremely). Responses to the three items were averaged later. The cute scorpion image was rated as significantly cuter than the noncute scorpion image $\left(M_{\text {cute }}=5.32\right.$ vs. $M_{\text {noncute }}=1.56 ; t(80)=$ 21.39, $p<.001)$.

Risky Choice Manipulation. I conducted a pretest of the perceived risk of candy options $\left(N=81 ; 49 \%\right.$ female; $\left.M_{\text {age }}=21.4\right)$. Pretest participants viewed candy options and indicated whether they agreed with four risk-related statements adapted from Bond, He, and Wen (2019) ( 1 = strongly disagree, $5=$ strongly agree) 1$)$ "I am uncertain whether this candy would taste good or not;" 2) "If I am given the chance to try this candy for free, whether or not to actually try it is a difficult decision;" 3) "I am concerned about the potential risks involved in consuming this candy;" 4) "The thought of trying this candy makes me feel uncomfortable." Responses to the 
four items were averaged later. Pretest participants rated the scorpion candy to be riskier than the ordinary candy $\left(M_{\text {scorpion }}=3.53\right.$ vs. $\left.M_{\text {ordinary }}=2.21 ; t(80)=9.35, p<.001\right)$.

Risky Choice. To assess risk preference, I asked participants to choose between two candy options for tasting and evaluation. They may also choose not to take any candy. The risky option, always placed on the right-hand side of the candy box, was a blue lollipop that contained a whole visible scorpion while the riskless option, a normal blue lollipop, was always placed on the left-hand side (Methodological Details Appendix B).

Control Variables. Upon arrival, participants indicated their hunger level $(1=$ not hungry at all, $7=$ very hungry). They evaluated the chosen candy on nine dimensions (good, sweet, tasty, delicious, safe, threatening, worrisome, fearful, dangerous) on 7-point scales, which were later averaged to form a measure for participants' attitudes toward the chosen candy. Participants also reported their gender, age, the likelihood of them trying new food items, and the likelihood of trying food items with insect ingredients ( $1=$ not at all likely, $7=$ extremely likely). Age and gender were included as control variables, as previous literature has shown that these two variables affect risk decision-making (LaGrange and Ferrar 1989; Rhodes and Pivik 2011). However, I did not find that these two variables affect risk-seeking behavior in a consistent way across the studies.

\section{Results and Discussion}

Two participants were excluded from the analysis because their dietary restrictions prevented them from choosing any candy, resulting in a usable sample of 86 participants (63\% female; $\left.M_{\text {age }}=21.66\right)$. Among these participants, everyone picked a candy—either the scorpion lollipop or the ordinary lollipop- to taste and evaluate. 
If exposure to cuteness indeed increases people's risk preference, I should find more participants choosing the risky option in the cute condition than in the noncute condition. As predicted, more participants chose the seemingly riskier option scorpion lollipop after being exposed to a cute scorpion drawing (34.1\%) compared to those are exposed to a noncute scorpion drawing $\left(11.9 \% ; \chi^{2}(1, N=86)=5.93, p=.02\right.$, odds ratio $\left.=3.83\right)$ (see Figure 1$)$.

Figure 1. Study 1: The effect of cuteness on risky food consumption

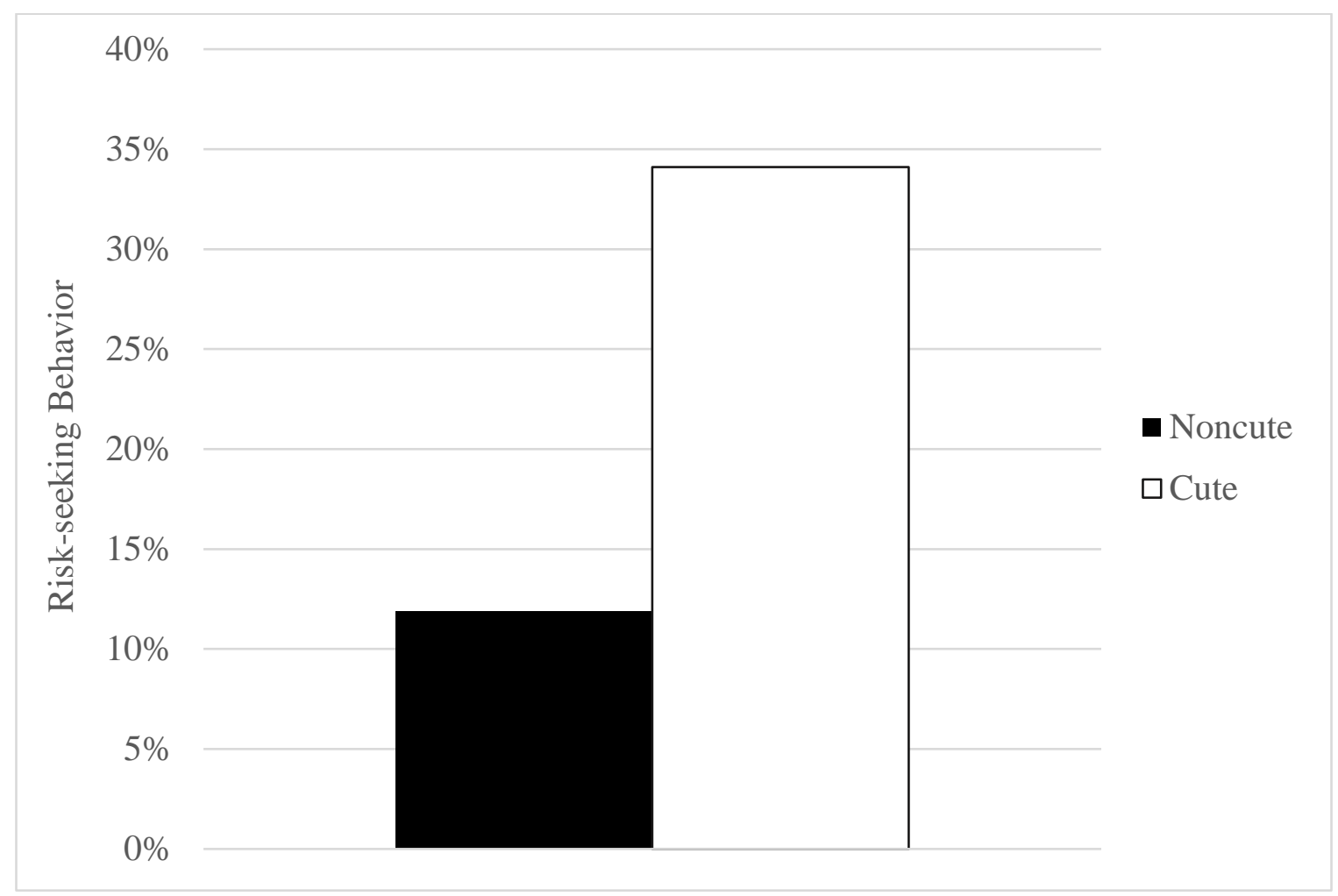

Participants' choice was further examined via a binary logistic regression including the cuteness factor, controlling for participants' gender, hunger level, attitude toward the chosen candy, likelihood of trying new food items, and likelihood of trying food items with insect ingredients. Analyses revealed a main effect of cuteness $\left(b=1.40, \mathrm{SE}=.62, \chi^{2}(1, N=86)=\right.$ $5.07, p=.02$, odds ratio $=4.06$ ), such that participants in the cute condition were significantly more likely to choose the risky option compared to those in the noncute condition. 
In a real food consumption setting that features an obviously scary scorpion lollipop and its ordinary counterpart, participants in the cute condition are $20 \%$ more likely to take risks than those in the noncute condition. These results demonstrate that exposure to cute stimuli has real downstream implications for consumers' risky decision-making process, in support of H1. While I argue that cuteness has a unique influence beyond simply putting people in a better mood, study 1 cannot speak to this concern because it did not take mood measures. Thus the next study will try to replicate the results of study 1 with a series of classical gambling games while controlling for participant's moods. In Study 1, I did not include a condition that participants do not view any image (i.e., no image condition) as a baseline. To fill this gap, study 2 employed no image condition as a baseline and tested the effect in the financial risk domain.

\section{Study 2}

Study 2 aims to replicate the effect of cuteness on risk preference in which implications of cuteness play a major role in marketplaces. I choose three different cute characters as focal stimuli in the current study, as consumers are constantly exposed to cute characters as parts of marketing campaigns (Tracey 2020). Consistent with the extent risk preference literature (Porcelli and Delgado 2009), I test the effect of cuteness on risk preference by using a series of gambling games, which should provide strong evidence of the causal relationship between cute stimuli and risk preference. I predict that participants who view cute characters during the gambling games will be more likely to choose the risky options (vs. safe options) than those who do not view them.

\section{Method}

One hundred sixty-nine undergraduate students at a U.S. University participated in the study for course credit and to enter to win gift cards (33.7 \% female; $\left.M_{\text {age }}=21.99\right)$. I first 
indicated to participants that their performance in the game links to a final reward, and if their total earning is ranked among the top $10 \%$ of all participants, they will automatically enter into a random draw to win the $\$ 20$ gift card to encourage their actual behavior toward risks. After the instruction, participants played the gambling games that priming stimuli embedded within. All participants were randomly assigned to one of two between-subjects conditions (cuteness priming: cute vs. neutral). Depending on the condition, participants either view images of cute characters or did not view them (Methodological Details Appendix C) while they make their gambling choices.

Cuteness Manipulation. I conducted a pretest of cuteness manipulation (US participants from MTurk; $N=61 ; 39 \%$ female; $M_{a g e}=34.8$ ). Pretest participants viewed the images of three characters and rated the cuteness of the characters rated the extent to which the faces are cute (1 $=$ not cute at all, $7=$ very cute). The result confirmed that the images of the three characters were rated as significantly cuter than the middle value $\left(M_{\text {cute }}=4.4\right.$ vs. $M_{\text {middlevalue }}=4, t(60)=$ $2.18, p=.03)$.

Risky Choice. To access risk preference, I asked participants to choose one of two options (risky option vs. safe option) twelve times (Porcelli and Delgado 2009). In particular, participants faced a choice between two options with an equal expected winning value calculated by multiplying the dollar amount by the probability of winning. Each participant played six trials within both the loss and gain domains for two sets with a reversed order of three probabilities (Methodological Details Appendix D).

Control Variables. A growing body of risk research has documented the profound influence of positive emotions on risk preference (Loewenstein et al. 2001). Thus, I measured participants' moods on four dimensions (good/bad, unpleasant/pleasant, happy/sad, 
negative/positive) on 7-point scales, and averaged them later. In addition, financial risk preference and resource scarcity is closely related, as people with lower resource scarcity are more likely to take risks than those with higher resource scarcity (Griskevicius et al. 2011). Thus, I asked participants to rate their resource scarcity adapted from Griskevicius et al. (2013) (1= strongly disagree, $7=$ strongly agree) and average them later: 1) "I have enough money to buy things I want;" 2) "I don't need to worry too much about paying my bills;" 3) "I feel relatively wealthy these days". Lastly, participants reported their gender and age.

\section{Results and Discussion}

If exposure to cuteness increases people's preference for risky choices in gambling games, I should find participants choosing the risky options (vs. safe options) in the cute condition than in the noncute condition. As predicted, an analysis of covariance (ANCOVA) including the risky choice as the dependent variable, cuteness as the independent variable, and age, gender, mood, resource scarcity as control variables revealed a marginally significant main effect of cuteness $\left(F(1,163)=3.1, p=.08, \eta_{\mathrm{p}}{ }^{2}=.02\right)$. In particular, participants who viewed cute images chose more risky options than those who viewed no image $\left(M_{\text {cute }}=6.84\right.$ vs. $M_{\text {neutral }}=$ 6.15) (See Figure 2). 
Figure 2. Study 2: The effect of cuteness on risk-preference

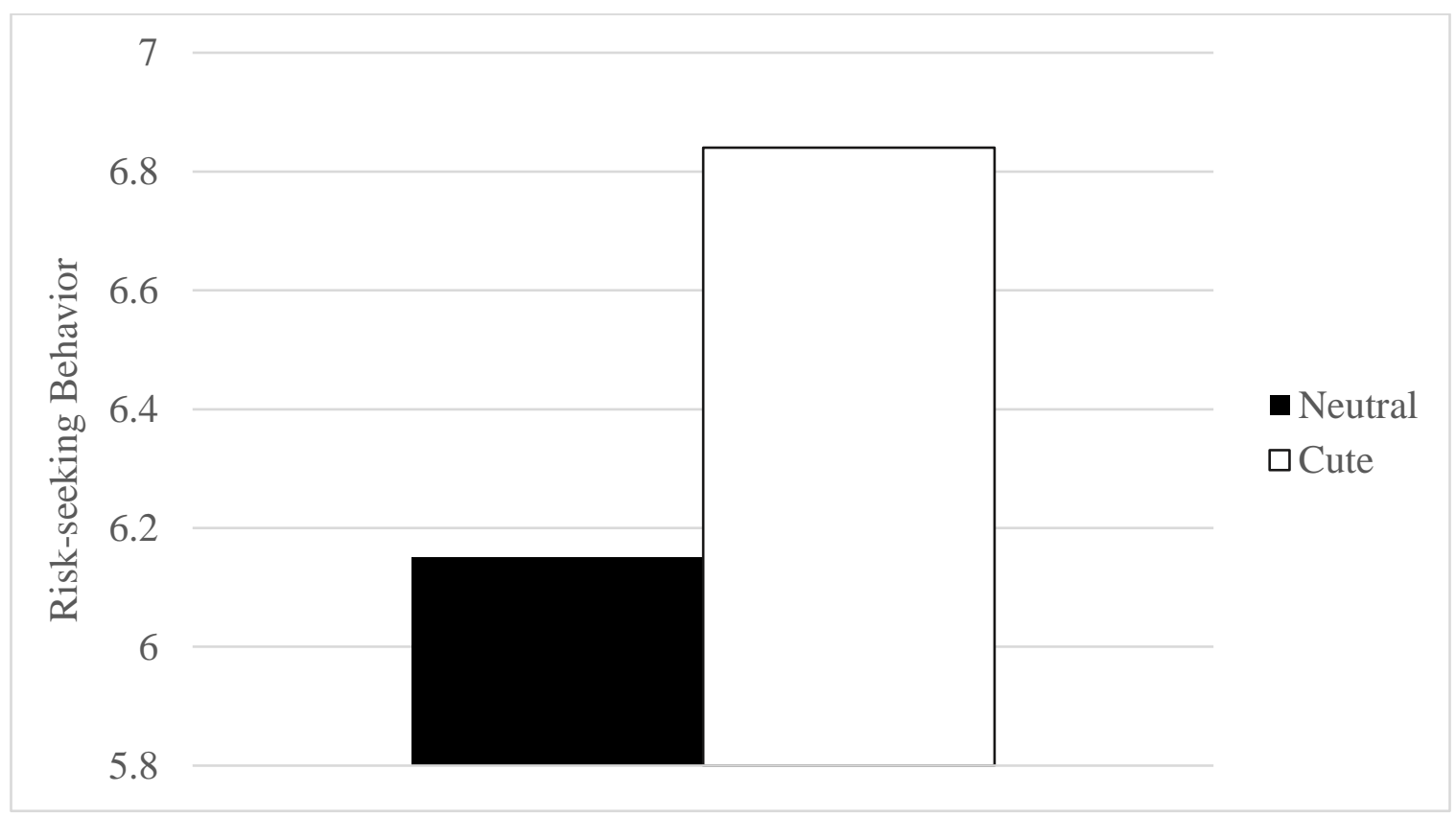

Using a classical gambling game setting (Porcelli and Delgado 2009), study 2 robustly demonstrated that simply being exposed to cute characters increases risk-seeking behavior, in support of the H1. Previous studies have shown that positive emotion also encourages riskseeking behavior (Loewenstein et al. 2001; Loewenstein and Lerner 2003; Stanton et al. 2014). Therefore, the results of those studies could raise the question of whether cute stimuli lead to risk-seeking behavior simply due to the positive emotions that cute stimuli might elicit. However, the effect of cuteness on risk preference is sustained even after controlling for mood measures in study 2 . The next study will identify its underlying mechanism and continue to test the effect of cuteness on risk preference by using different types of cute stimuli. In addition, the next study will rule out whimsicality as an alternative explanation, as whimsicality is closely associated with one of the specific dimensions of cuteness (Nenkov and Scott 2014).

\section{Study 3}


The goal of study 3 is to provide evidence that low conscientiousness is the underlying mechanism of the effect of cuteness on risk-seeking behavior. Additionally, study 3 seeks to explore whether the cuteness effect is caused by whimsicality rather than cuteness by using images of baby faces and adult faces with either whimsical or neutral facial expressions. More specifically, participants view one of the four different types of facial images that consist of whimsical baby faces, whimsical adult faces, neutral baby faces, neutral adult faces, and play the gambling game identical to those of study 2. Consistent with the theorization, I predict that participants who are exposed to cuteness are more likely to choose the riskier options than those who are not exposed to cuteness despite the whimsicality of the stimuli.

\section{Method}

Two hundred and thirty-two U.S. adults participated in study 3 in exchange for payment through Amazon Mechanical Turk (38\% female; $\left.M_{\text {age }}=34.1\right)$. Similar to study 2 , I first indicated participants that their performance in the game links to a final reward. Depending on the condition, participants viewed one of four types of images embedded in the series of gambling games while playing the game. All participants were randomly assigned to one of four betweensubjects conditions (cuteness priming: neutral non-cuteness condition vs. whimsical non-cuteness condition vs. neutral cuteness condition vs. whimsical cuteness condition). In particular, I placed images of adult faces right above gambling options for the noncute condition. In contrast, I placed images of baby faces replacing adult faces for the cute condition (Methodological Details Appendix E).

Cuteness Manipulation. I conducted a pretest of the cuteness manipulation (US participants from MTurk; $N=61 ; 39 \%$ female; $\left.M_{a g e}=34.8\right)$. Pretest participants viewed images of faces and rated the extent to which the faces are cute, adorable, and endearing. All items were 
measured on a 7 -point scale $(1=$ not at all, $7=$ very $)$. The result confirmed that images of baby faces were rated as significantly cuter than the images of adult faces $\left(M_{\text {baby }}=5.58 \mathrm{vs}\right.$. $M_{\text {adult }}=$ 4.13, $t(60)=8.47, p<.001)$.

Whimsicality Manipulation. To manipulate whimsicality, I used the images of the same babies and adults with either neutral facial expressions or whimsical facial expressions (Methodological Details Appendix E). I conducted a pretest of whimsicality manipulation (US participants from MTurk; $N=61 ; 39 \%$ female; $\left.M_{a g e}=34.8\right)$. The pretest participants viewed images of faces and rated the extent to which the faces are amusing, whimsical, and playful. All items were measured on a 7-point scale $(1=$ not at all, $7=$ very $)$. The result confirmed that the images of whimsical adults and babies are significantly more whimsical than the images of neutral adults and babies $\left(M_{\text {whimsical }}=4.9\right.$ vs. $\left.M_{\text {neutral }}=3.45, t(63)=9.19, p<.001\right)$.

Risky Choice. To access risk preference, participants played the gambling game identical to those of study 2 (Porcelli and Delgado 2009).

Conscientiousness. Participants indicated whether they agreed with the following four statements adapted from John and Srivastava (1999) (1 = strongly disagree, 5 = strongly agree): 1) "I am taking things seriously at this moment;" 2) "I am comfortable with not having good reasons for my own actions;" (reverse coded) 3) "I am concerned with doing things correctly;" 4) "I can be somewhat careless now." (reverse coded) $(\alpha=.59)$. Responses to the reverse coded statements were recoded and the four items were averaged.

Control Variables. Previous literature has shown that a sense of certainty increases riskseeking behavior (Mather et al. 2012; Tiedens and Linton 2001). Thus, I asked participants to indicate the extent to which the outcomes of those gambling games seem to be certain with the three bipolar responses (not at all certain/completely; not at all predictable/completely 
predictable; not at all expected/completely expected) on 7-point scales, and averaged them later to rule out certainty an alternative explanation. Lastly, participants reported their mood, gender, and age.

I also measured perceived threat to rule it out as an alternative explanation. As predicted, the difference in participants' level of perceived threat between the conditions (cute vs. noncute vs. noimage) was nonsignificant $\left(M_{\text {cute }}=4.21\right.$ vs. $M_{\text {noncute }}=4.39$ vs. $M_{\text {noimage }}=4.21, F(2,202)=$ $7.15, p=.6)$.

Results and Discussion

An analysis of covariance (ANCOVA) with risky choice as the dependent variable, cuteness as the independent variable, and gender, age, certainty, and mood as the control variables revealed a marginally significant main effect of cuteness $(F(1,226)$

$\left.=2.98, p=.09, \eta_{\mathrm{p}}^{2}=.01\right)$. As predicted, participants exposed to cute images chose risky options more often than those exposed to noncute images $\left(M_{\text {noncute }}=5.36\right.$ vs. $\left.M_{\text {cute }}=5.94\right)($ See Figure $3)$. 
Figure 3. Study 3: The effect of cuteness on risk-preference

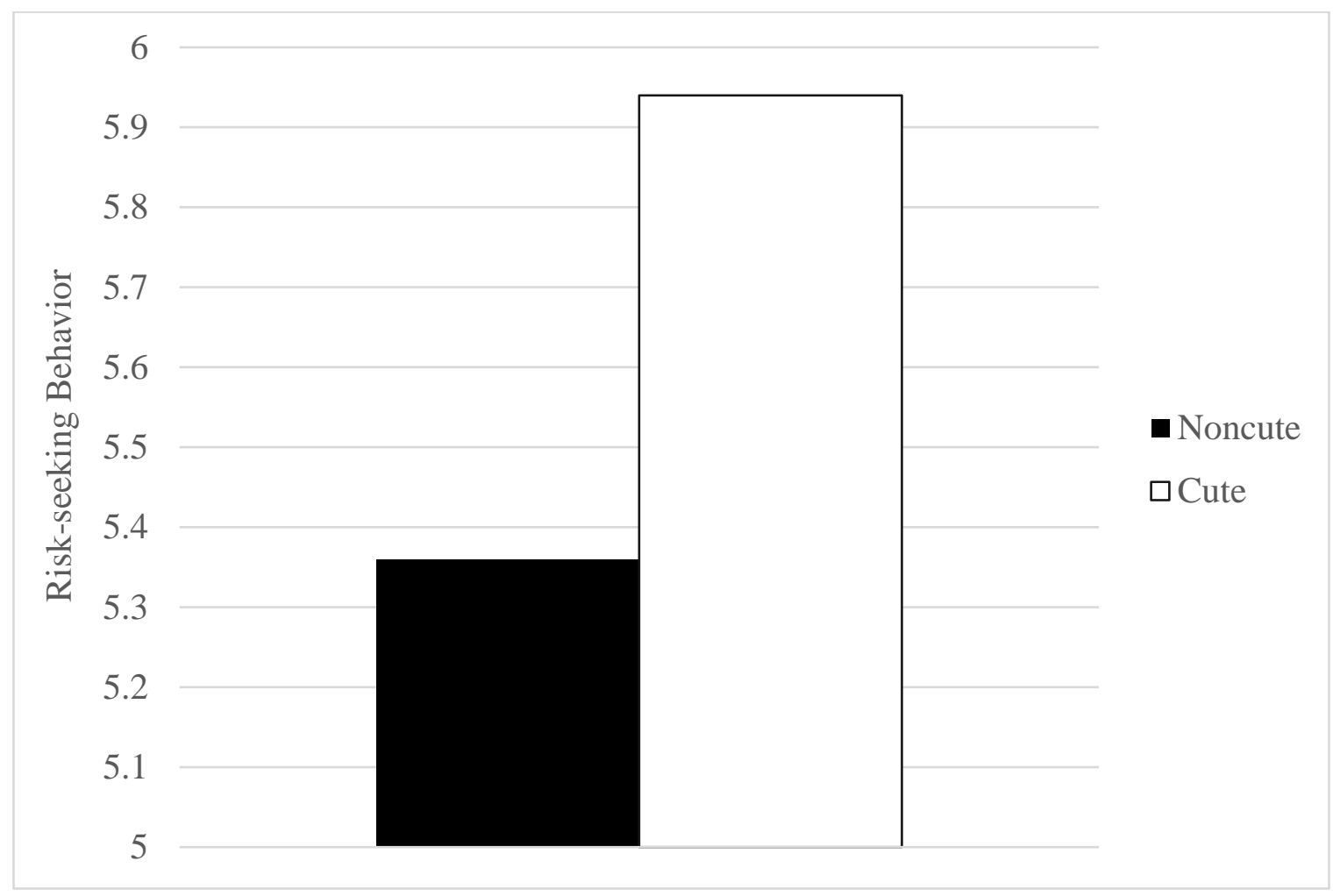

If whimsicality is not an alternative explanation for the effects of cuteness on riskseeking behavior, I should find that whimsicality does not interact with cuteness, and it does not affect risk-seeking behavior. To explore the interaction effect of whimsicality and cuteness, I conducted an additional ANCOVA with risky choice as the dependent variable, whimsicality (neutral vs. whimsical), cuteness (baby vs. adult), and their interaction as the independent variables, and age, gender, certainty, and mood as the control variables. The two-way interaction between cuteness and whimsicality was nonsignificant $(F(1,226)=.02, p=.88)$. In particular, participants who viewed whimsical baby images did not choose the risky options more frequently than participants who viewed neutral baby images $\left(M_{\text {whimsical baby }}=5.55\right.$ vs. $M_{\text {neutral baby }}=5.76$, $F(1,226)=.43, p=.51)$. Moreover, participants who viewed whimsical adult images did not 
choose the risky options more frequently than participants who viewed neutral adult images $\left(M_{\text {whimsical adult }}=5.28\right.$ vs. $\left.M_{\text {neutral adult }}=5.46, F(1,226)=.17, p=.68\right)$.

The priming effect of cuteness on low conscientiousness was tested with an analysis of covariance (ANCOVA). Conscientiousness was the dependent variable, cuteness was the independent variable, and age, gender, mood, and certainty were control variables. The ANCOVA revealed the significant effect of cuteness on conscientiousness $(F(1,226)=$ $7.98, p=.01)$. As expected, participants who viewed facial images of babies reported significantly lower conscientiousness than participants who viewed facial images of adults $\left(M_{\text {cute }}\right.$ $=3.69$ vs. $M_{\text {noncute }}=3.92$ ). Thus, the proposed underlying mechanism for the effect of cuteness on risk-seeking behavior was supported.

I ran a mediation model to analyze the mediation further (Process model 4; Hayes 2013). I tested whether low conscientiousness mediates the effect of cuteness on risk-seeking behavior. In the model, cuteness was the independent variable (facial images of babies vs. facial images of adults), conscientiousness was the mediator, risk-seeking behavior (choosing risky options over safe options) was the dependent variable, and gender, age, certain, and mood were the control variables. Boot-strapping analysis with 5,000 resamples did not include zero for the proposed indirect mediation path (effect $=.1573,95 \%$ confidence interval: .0113 to .3671$)$. Thus, the mediation analysis confirmed the indirect effect of low conscientiousness on risk-seeking behavior, supporting $\mathrm{H} 2$.

Importantly, study 3 assists me to test the mediating role of low conscientiousness, and once again to show that cute stimuli lead individuals to take risks, in support of $\mathrm{H} 1$ and $\mathrm{H} 2$. Furthermore, I demonstrate that the effect of cuteness on risk preference despite the whimsicality of the stimuli. Therefore, the findings of study 3 rule out whimsicality as an 
alternative explanation and provide evidence for the underlying mechanism of the effect of cuteness on risk-seeking behavior. The next study tests the moderating role of caring motivation. Additionally, study 4 tests the effect in the high-stake risk situation, while study 2 and 3 test the effect in the low-stake risk situation.

\section{Study 4}

Study 4 seeks evidence for the proposed moderation effect on whether caring motivation attenuates the effect of cuteness on risk-seeking behavior. Unlike the previous study, study 4 utilizes a real-world mass shooting news article to examine whether cuteness increases risk-seeking intention in a life-or-death situation. In this study, participants are asked to indicate their willingness to take a risk to save others in a mass shooting. I predict that participants exposed to cute stimuli are more likely to take a risk than those exposed to noncute stimuli, whereas the prediction is reversed when caring motivation is present.

\section{Method}

Two hundred twelve U.S. participants were recruited from Amazon MTurk to participate in study $4\left(46 \%\right.$ female; $\left.M_{\text {age }}=35.25\right)$. All participants were randomly assigned to one of five between-subjects conditions (conditions: nocare_cute vs. nocare_noncute vs. care_cute vs. care_noncute vs. no image). Depending on the condition, participants were exposed to one of four images or were not exposed to any image in the background of the recent mass shooting news article (Methodological Details Appendix F). The news article included a visual stimulus and detailed information about the shooting incident such as the date, death toll, and location of the mass shooting (Methodological Details Appendix G). After participants read the recent realworld mass shooting news article, they indicate their thought on it. 
Cuteness Manipulation. To manipulate cuteness, I used images possessing a high level of baby schema or images possessing a low level of baby schema. Pretest participants (US participants from MTurk; $N=61,30 \%$ female; $\left.M_{\text {age }}=36.28\right)$ rated the extent to which images were cute, adorable, and endearing. All items were measured on a 7 -point scale $(1=$ not at all, 7 $=$ very $)$. The result confirmed the image of the cute cartoon character was rated as significantly cuter than the image of the noncute cartoon character $\left(M_{\text {cute }}=4.95\right.$ vs. $M_{\text {noncute }}=2.0 ; F(60)=$ 108.63, $p<.001$ ) (Methodological Details Appendix F).

Caring Motivation Manipulation. To manipulate caring motivation, I used the images of a baby wipe advertisement for the care conditions, and the images of a cartoon character for the nocare conditions (Methodological Details Appendix F). I expect that the images of a baby wipes advertisement induces more caring motivation than the images of a cartoon character by reminding them of caregivers' role (Roh et al. 2017). Pretest participants (US participants from MTurk; $N=61,30 \%$ female; $\left.M_{\text {age }}=36.28\right)$ viewed the images of a baby wipe advertisement and the images of a cartoon character, and rated the extent to which images induce caring motivation adapted from Glocker et al. (2009a) (1 = not at all, 7 = very much): 1) "How much does what you see in the picture above make you feel that you would like to take care of it;" 2) How much does what you see in the picture above make you feel that you would like to take care of kids in general?". Responses to the two items were averaged later. The result confirmed that the images of baby wipes ads induced significantly higher caring motivation than the images of the cartoon character $\left(M_{\text {care }}=4.38\right.$ vs. $\left.M_{\text {nocare }}=2.93 ; F(60)=55.63, p<.001\right)$.

Risky Choice. Participants indicated the extent to which they would take a risk in a mass shooting $(1=$ not likely at all, 7 = extremely likely): "In mass shootings, some people step up to 
stop shooters and save others' lives, sometimes at the expense of their own. How likely would you be to take the risk?."

Control Variable. Participants indicated how easily they could relate to those victims in the mass shooting news article $(1=$ not at all, $7=$ very much $)$, and their attitudes toward guns adapted from Branscombe et al. (1991) (Methodological Details Appendix H). Next, participants answered questions about their mood, gender, and age.

\section{Results and Discussion}

If exposure to cuteness increases people's willingness to take a risk in a high-risk situation, I should find that participants exposed to cute stimuli are more likely to indicate that they would take a risk in a mass shooting than participants who were not exposed to such stimuli. An analysis of covariance (ANCOVA) with a risky choice as the dependent variable, condition as the independent variables, gender, age, mood, attitudes toward guns, and victim-related as the control variables revealed a significant effect of conditions on risky choice $(F(2,202)=$ $3.23, p=.01)$. The difference between the cute vs. the noncute conditions within the care condition vs. the nocare condition ((nocare_cute vs. nocare_noncute) vs. (care_cute vs. care_noncute)) was also significant $(F(2,202)=7.15, p=.01)$.

As predicted, for the nocare conditions, participants exposed to a cute cartoon character were marginally more likely to take a risk in a mass shooting than those exposed to a noncute cartoon character $\left(M_{\text {nocare_noncute }}=3.51\right.$ vs. $M_{\text {nocare_cute }}=4.13, F(2,202)=3.43, p$ $=.07)$. Moreover, pairwise comparisons analysis showed that participants exposed to the cute cartoon character were marginally more likely to take a risk in a mass shooting than those who did not view any character $(p=.05)$, or those exposed to the noncute cartoon character $(p=.07)$ (See Figure 4). 
On the other hand, for the care conditions, participants exposed to the cute baby wipes advertisement were less likely to take a risk in a mass shooting than those exposed to the nontcute baby wipes advertisement $\left(M_{\text {care_noncute }}=3.58\right.$ vs. $M_{\text {care_cute }}=2.93, F(2,202)=$ $3.95, p=.05)$. Moreover, pairwise comparisons analysis showed that participants exposed to the cute baby wipes advertisement were marginally less likely to take a risk in a mass shooting than those who did not view any character $(p=.1)$, or those exposed to the noncute baby wipes advertisement $(p=.05)$ (See Figure 4$)$.

Figure 4. Study 4: The effect of cuteness on risk-preference

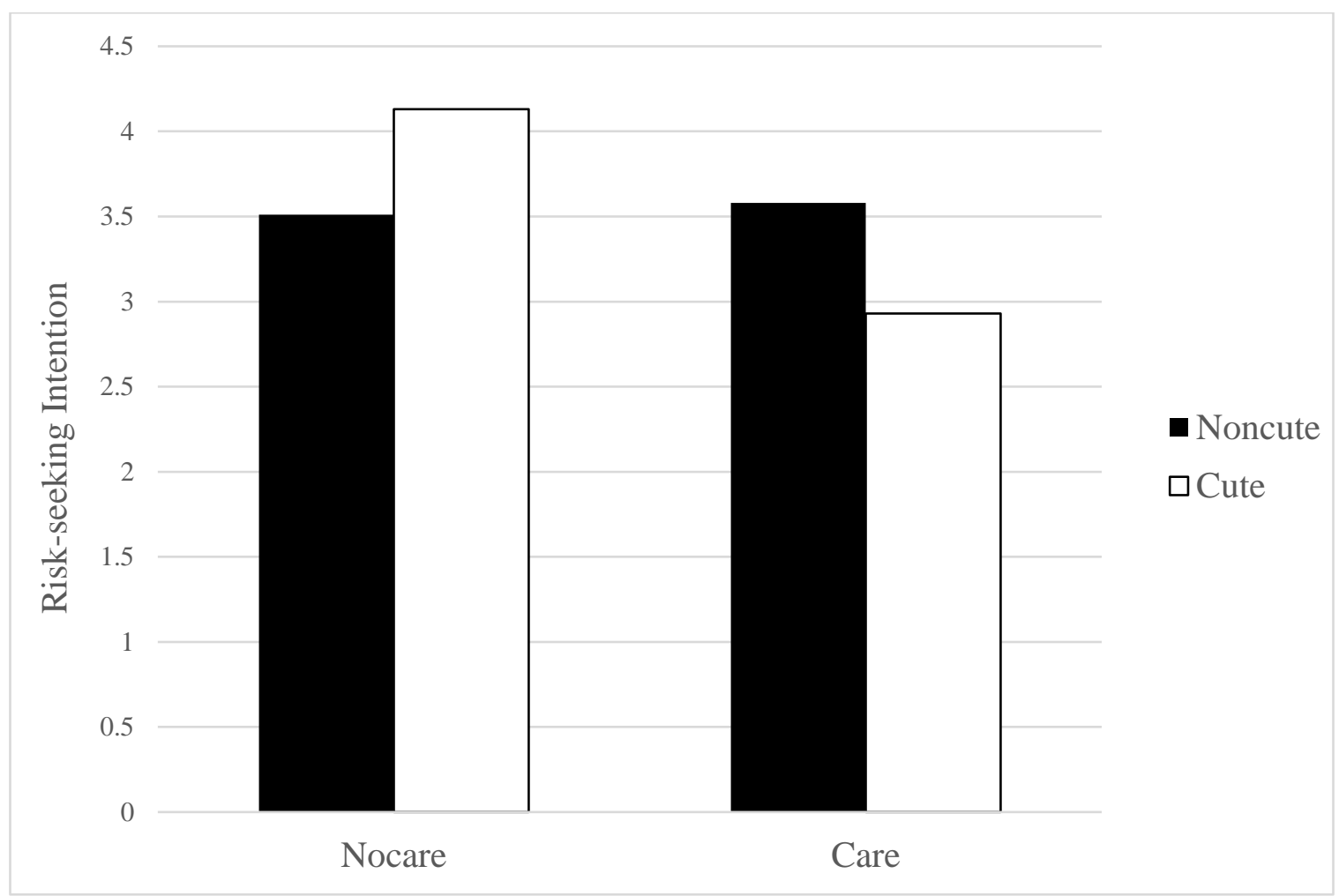

Furthermore, to explore the interaction effect of caring motivation and cuteness, I conducted an additional ANCOVA with risky choice as the dependent variable, caring motivation (care vs. nocare), cuteness (cute vs. noncute vs. no image), and their interaction as the independent variables, and gender, age, mood, attitudes toward guns, and victim-related as the 
control variables. As expected, the two-way interaction between cuteness and caring motivation was significant $(F(1,226)=6.84, p=.01)$, supporting $\mathrm{H} 3$.

Using a real-world context, study 4 replicates risk-averse results documented in previous research by using the images that facilitate caring motivation (Nittono et al. 2012; Sherman et al. 2009). Furthermore, Study 4 demonstrates risk-seeking choices when caring motivation is absent.

\section{General Discussion}

Whereas the usage of cute characters (e.g., Hello Kitty, Pikachu, Pusheen), puppies, and kittens are pervasive in online and offline marketing materials, extent marketing research offers surprisingly few insights regarding consumer behavior and cuteness. Whereas previous research on cuteness in marketing has solely focused on the direct influences of a cute entity itself (Gorn et al. 2008; Schnurr 2019), this essay focuses on the influence of cuteness in the background. Companies often use cuteness in the background rather than a focal point, as many consumers are obsessed with cuteness (Stavropoulos 2019). For example, Trader Joe's places cute stuffed animals in aisles sporadically to engage shoppers in their retail stores (Wida 2019), and Wells Fargo displays images of a puppy on the digital payments network webpage (Appendix A).

The relationship between exposure to cuteness and risk preference is a worthwhile endeavor, especially given that consumer decision-making often involves various risks (Blekheret al. 2020; Leonhardt et al. 2011). On the one hand, some may suggest exposure to cuteness might lead consumers to become more risk-seeking, as individuals become more aggressive after exposure to cuteness (Aragón et al. 2015). On the other hand, others may suggest the opposite effect, as individuals become more physically careful after exposure to cuteness (Glocker et al. 2009a; Nittono et al. 2012). Whereas previous studies have investigated 
the effects of cuteness on aggression, indulgent consumption and careful behavior (Aragón et al. 2015; Nittono et al. 2012; Nenkov and Scott 2014; Stavropoulos and Alba 2018), I aim to answer a more fundamental question related to all these behaviors. Thus, I propose a dual-process to resolve the seemingly contradictory results in the literature, and systematically explore when and why cuteness shapes consumers' risk preference.

I develop a conceptual framework and demonstrate the positive impact of cuteness on risk-seeking behavior. I argued that when individuals are exposed to cuteness, they are more likely to take risks as a result of low conscientiousness. I showed the effect within various risk contexts including food consumption (study 1), gambling games (Study 2 and 3), and a mass shooting (Study 4). Consistent with the predictions, four experimental studies reveal that participants exposed to cuteness are less likely to be conscientious, which in turn leads them to take more risks. However, the effect of exposure to cuteness on risk-seeking behavior attenuates when caring motivation outweighs approaching tendency.

\section{Theoretical Contributions}

This research enhances the literature on cuteness by proposing a dual-process model that reconciles the mixed findings from the previous studies (Nenkov and Scott 2014; Aragón et al. 2015). On the one hand, some may suggest that exposure to cuteness might lead consumers to be more risk-seeking, as they become more aggressive after exposure to cuteness. On the other hand, others might suggest that the opposite effect, as individuals become more careful after exposure to cuteness. Hence, the dual-process model suggests that caring motivation moderates the effect of exposure to cuteness on risk-seeking behavior. Despite previous studies have looked at caring motivation as an important consequence of exposure to cuteness, they have not looked at how it interacts with cute stimuli (Li and Yan 2021; Sanefuji et al. 2007; Sherman and Haidt 
2011). Moreover, this research contributes to the literature on cuteness by investigating how exposure to cute stimuli in the background rather than as a focal point affects consumers' risk preference. Additionally, the study extends the literature on cuteness by linking overall cuteness to risk-seeking behavior in various risk domains including health, finance and safety ( $\mathrm{Li}$ and Yan 2017; Stavropoulous and Alba 2018). Thus, the findings add to the literature on cuteness by showing that the effect of cuteness on risk preference is not limited to direct influences of a cute entity itself, observers' gender, a certain dimension of cuteness, or a particular risk context (Fischer and Hills 2012; Nenkov and Scott 2014).

Additionally, the research adds to studies on conscientiousness by examining exposure to cuteness as an antecedent of low conscientiousness. This study is the first to investigate the link between exposure to cuteness and conscientiousness In particular, the current study extends the research stream on conscientiousness by identifying that cuteness leads individuals to become less conscientious toward risks around them (Berry and McArthur 1985; Nittono et al. 2016). Previous literature has shown the negative relationship between the level of conscientiousness and risk-seeking behavior; people with low levels of conscientiousness tend to be more likely to underestimate the chance of negative outcomes and to take risks (Chauvin et al. 2006; Hampson et al. 2000; Nicholson et al. 2005). Based on these prior works, this research extends this literature by demonstrating low conscientiousness as the underlying mechanism that explains the effects of cuteness on risk-seeking behavior.

The present research contributes to the literature on risk preference by advancing the understanding of the antecedents of risk-seeking behavior (Zou et al. 2020). Understanding consumers' risk preference has been an important topic of study in marketing, because consumers constantly face uncertainty in marketplaces when they make purchasing decisions 
(Mitchell and Greatorex 1989). Previous studies have shown the positive relationship between risk-seeking behavior, purchase intention, and actual purchase decision (Earl and Kemp 2002; Raghunathan et al. 2006). Because consumers' risk preference links to many behaviors, investigating exposure to cuteness as an antecedent to risk-seeking behavior should ultimately contribute to various consumer behavior research (Raghunathan et al. 2006). Cuteness as an antecedent of risk-seeking behavior regardless of observers' gender and risk domains is a novel concept that goes beyond the prior works that have analyzed the effects of cuteness from mainly a parental perspective (Borgi et al. 2014; Glocker et al. 2009a). The current study extends this literature through four experimental studies that show that consumers are more likely to engage in the risks associated with their health, finance, and safety after they are exposed to cuteness. Thus, the findings may benefit literature on risk preference in various contexts (Frey et al. 2020; Weber et al. 2002).

\section{Practical Implications}

Interestingly, although the use of cuteness in marketing has been ubiquitous (Jia et al. 2015; Kovarovic 2011), studies on cuteness in marketing have been scarce (Lee and Hsieh 2019; Schnurr 2019). Thus, the current paper carries important practical implications for practitioners, as it assists them in deciding when and how to use cuteness to promote their products and brands, as well as to avoid potential repercussions. First, the positive relationship between cuteness and risk-seeking behavior shown in the results can be applied to broaden markets by attracting new consumers. The current study recommends marketers who launch new products consider embedding cute elements in their marketing materials without facilitating caring motivation, as consumers are more likely to take the risk of trying new products after they are exposed to cuteness. Cuteness can be embedded in any setting, and become part of consumers' decision- 
making (Tan 2016). Therefore, the findings have a wide range of implications for marketers, especially for the practitioners who are interested in promoting innovative new products (Littler and Melanthiou 2006).

On the other hand, this research suggests that practitioners working for sharing economy businesses (e.g., Airbnb, Zipcar, Uber) should be cautious with the use of cuteness in their property. Exposure to cuteness lowers consumers' level of conscientiousness and increases consumers' risk-seeking behavior, which potentially results in careless and neglectful behavior towards sharing assets (Bogg and Roberts 2004; Nicholson et al. 2005). In other words, evoking low conscientiousness and risk-seeking behavior by using cute stimuli can be beneficial for some corporations but harmful for sharing businesses (Campbell and Winterich 2018). For example, the present research suggests that ridesharing companies such as Uber or Lyft may ask their drivers to exercise caution when employing cuteness in their cars because it could lead their passengers to be less conscientious and neglect to wear their seat belts (Roethe 1967). In sum, cuteness in marketing can be effectively employed when a company comprehends the desirability of consumers engaging in risk-seeking behavior (Marcus et al. 2017).

From consumers' perspective, the findings of this research would help them gain a better understanding of how exposure to cuteness could impact their decision-making. Particularly, the findings suggest that exposure to cuteness leads consumers to take more risks. Businesses often use cuteness in marketing to attract consumers (Olenski 2016). Correspondingly, consumers can easily identify cuteness in marketing communications (Chang and Li 2010). For example, 'Swimming With Pigs Tour' advertisements use pictures of cute pigs on its website to attract tourists to Bahamas (The islands of the Bahamas 2020). As a result, tourists do not critically analyze the hazards and ignore the health risks involved in swimming with pigs because the 
swimming pigs look adorable and cute (Hurtibise 2019). Furthermore, Dutch Boy Paint uses a cute boy trademark to mask the risk of lead in its paints, which in turn lowers consumers' uneasiness toward lead paint (Werth and Wright 2019). On the other hand, consumers who are aware of the effect of cuteness on risk preference can be better positioned to resist the appeal from risky products' advertisements coated with cute elements. Moreover, a better understanding of cuteness should help consumers facilitate self-control over potentially risky behaviors and beyond (Freeman and Muraven 2010; Nigg 2017; Wood et al. 1993).

\section{Caveats and Further Research Directions}

While the current study sheds light on the literature on cuteness by exploring its effect on risk-seeking behavior, it comes with limitations that future studies can explore. First, although the current study contributes to the emerging literature on cuteness by proposing a dual-process model to consolidate the mixed findings in the literature (Fischer and Hills 2012; Nenkov and Scott 2014), the literature on cuteness has exhaustive potential. Especially, although cuteemotion is unique and deserves greater attention, it has not been well-defined and widely studied in the literature (Buckley 2016; Steinnes et al. 2019). Thus, future studies can explore how the unique emotion triggered by cuteness (i.e., aww, cute-emotion) affects different judgments and decision-making. According to the Appraisal Tendency Framework (ATF), emotions often carry over and shape individuals' judgments and decision makings (Han et al. 2007; Lerner and Keltner 2000; Lerner and Keltner 2001; Motoki et al. 2018). Thus, I believe that cute emotion also affects consumers' decision-making in various ways on the basis of the Appraisal Tendency Framework (ATF).

Moreover, the current study presents the positive effect of cuteness on the limited domain contexts of risk-seeking behavior associated with health (study 1), financial decisions (Studies 
2and 3), and safety (Study 4). However, risk-seeking behaviors are domain-specific, and I did not include some other risk domains such as social risk (Zuckerman and Kuhlman 2000; Blais and Weber 2001). For example, studies on Domain-Specific Risk-Taking (DOSPERT) have assessed risk-seeking behaviors associated with different domains and found that consumers' risk-seeking behaviors are domain-specific (Blais and Weber 2006; Weber et al. 2002). Thus, future research could address some of this work's limitations and explore other interesting questions that stem from this work. For instance, to test the effects of cuteness on ethical riskseeking behavior, a study could explore whether a cute baby's photo inside of a missing wallet would motivate people to return it or take unethical actions (Blais and Weber 2001).

Furthermore, to test the effects of cuteness on recreational risk-seeking behavior, a study could ask if an amusement park that advertises its roller-coasters with a cute theme would increase the number of riders. I expect that the effects of cuteness on risk preference I show in the current study might differ in other risk domains, given that individuals' risk-seeking behavior is inconsistent across risk domains (Weber et al. 2002).

In addition, the current study solely considers visual cuteness stimuli that induce the perception of cuteness through seeing (Alley 1981). However, individuals might perceive cuteness through multiple senses such as hearing, smelling, tasting, and touching (Kringelbach et al. 2016). Given that cuteness is closely associated with youthfulness (Alley 1983), I expect that individuals might perceive younglings' voices, smells, or textures that are distinct from those of adults as cute. For instance, children have softer skin textures than adults do, because of vernix that coats a newborn baby's skin (WebMD 2003). Accordingly, future research could explore whether consumers perceive products or robots with childlike voices as cuter than their counterparts, and if they do, it can further examine whether the cuteness perception evoked by 
cute voice affects consumers' risk preference. In summary, whereas previous studies have mostly looked at the effects of cuteness perception generated by visual stimuli and neglected nonvisual senses, future work might examine how consumers perceive cuteness perception through multiple senses and address effects of cuteness evoked by nonvisual senses (Dydynski and Mäekivi 2018; Little 2012). 


\section{References}

Alley, T. R. (1981). Head shape and the perception of cuteness. Developmental Psychology, 17, 650.

Alley, T. R. (1983). Infantile head shape as an elicitor of adult protection. Merrill-Palmer Quarterly, 29, 411-427.

Aragón, O. R., Clark, M. S., Dyer, R. L., \& Bargh, J. A. (2015). Dimorphous expressions of positive emotion: Displays of both care and aggression in response to cute stimuli. Psychological Science, 26, 259-273.

Barrick, M. R., \& Mount, M. K. (1991). The big five personality dimensions and job performance: a meta-analysis. Personnel psychology, 44(1), 1-26.

Berman, P. W. (1980). Are women more responsive than men to the young? A review of developmental and situational variables. Psychological Bulletin, 88, 668.

Berry, D. S., \& McArthur, L. Z. (1985). Some components and consequences of a babyface. Journal of personality and social psychology, 48, 312.

Blais, A. R., and Weber, E. U. (2001). Domain-specificity and gender differences in decision making. Risk, Decision and Policy, 6, 47-69.

Blais, A. R., \& Weber, E. U. (2006). A domain-specific risk-taking (DOSPERT) scale for adult populations. Judgment and Decision Making, 1, 33-43.

Blekher, M., Danziger, S., \& Grinstein, A. (2020). Salient Volunteering Behavior Increases Monetary Risk-taking. Journal of Consumer Psychology, 30, 525-533.

Bogg, T., \& Roberts, B. W. (2004). Conscientiousness and health-related behaviors: a metaanalysis of the leading behavioral contributors to mortality. Psychological Bulletin, 130, 887. 
Bond, S. D., He, S. X., \& Wen, W. (2019). Speaking for "free": Word of mouth in free-and paidproduct settings. Journal of Marketing Research, 56, 276-290.

Borgi, M., Cogliati-Dezza, I., Brelsford, V., Meints, K., \& Cirulli, F. (2014). Baby schema in human and animal faces induces cuteness perception and gaze allocation in children. Frontiers in Psychology, 5, 411.

Branscombe, N. R., Weir, J. A., \& Crosby, P. (1991). A three-factor scale of attitudes toward guns. Aggressive Behavior, 17, 261-273.

Buckley, R. C. (2016). Aww: The emotion of perceiving cuteness. Frontiers in Psychology, 7 , 1740.

Campbell, M. C., \& Winterich, K. P. (2018). A Framework for the Consumer Psychology of Morality in the Marketplace. Journal of Consumer Psychology, 28, 167-79.

Chang, C., \& Li, H. (2010). Why are childlike portrayals appealing in East Asia?. International Journal of Advertising, 29, 451-72.

Chartrand, T. L., \& Bargh, J. A. (1996). Automatic activation of impression formation and memorization goals: Nonconscious goal priming reproduces effects of explicit task instructions. Journal of Personality and Social Psychology, 71.

Chauvin, B., Hermand, D., \& Mullet, E. (2007). Risk perception and personality facets. Risk Analysis: An International Journal, 27, 171-185.

Creyer, E., Ross, W., \& Evers, D. (2003). Risky recreation: an exploration of factors influencing the likelihood of participation and the effects of experience. Leisure Studies, 22, 239-253

Dale, J. P. (2016). Cute studies: An emerging field. East Asian Journal of Popular Culture, 2, 513.

de Braal, B. (2010). Encouraging baby talk!. Child Care, 7, 8-9. 
Dudley, N. M., Orvis, K. A., Lebiecki, J. E., \& Cortina, J. M. (2006). A meta-analytic investigation of conscientiousness in the prediction of job performance: examining the intercorrelations and the incremental validity of narrow traits. Journal of Applied Psychology, 91(1), 40.

Dydynski, J., \& Mäekivi, N. (2018). Multisensory perception of cuteness in mascots and zoo animals. International Journal of Marketing Semiotics, 6, 2-25.

Earl, P. E., \& Kemp, S. (Eds.). (2002). The Elgar companion to consumer research and economic psychology. Edward Elgar Publishing.

Esteky, S., Wineman, J. D., \& Wooten, D. B. (2018). The influence of physical elevation in buildings on risk preferences: Evidence from a pilot and four field studies. Journal of Consumer Psychology, 28, 487-494.

Fischer, D., \& Hills, T. T. (2012). The baby effect and young male syndrome: Social influences on cooperative risk-taking in women and men. Evolution and Human Behavior, 33, 530536.

Freeman, N., \& Muraven, M. (2010). Self-control depletion leads to increased risk taking. Social Psychological and Personality Science, 1, 175-181.

Frey, R., Richter, D., Schupp, J., Hertwig, R., \& Mata, R. (2020). Identifying robust correlates of risk preference: A systematic approach using specification curve analysis. Journal of Personality and Social Psychology.

Funke, D. (2016). The good, the bad and the weird: Mayhem and meet-ups after 'Pokemon Go' release. Los Angeles Times, July 13, 2016. Retrieved from https://www.latimes.com/nation/la-na-pokemon-go-roundup-20160713-snaphtmlstory.html 
Glocker, M. L., Langleben, D. D., Ruparel, K., Loughead, J. W., Gur, R. C., \& Sachser, N. (2009a). Baby Schema in Infant Faces Induces Cuteness Perception and Motivation for Caretaking in Adults. Ethology, 115, 257-63.

Glocker, M.L., Langleben, D.D., Ruparel, K., Loughead, J.W., Valdez, J.N., Griffin, M.D., Sachser, N. \& Gur, R.C. (2009b). Baby schema modulates the brain reward system in nulliparous women. Proceedings of the National Academy of Sciences of the United States of America, 106, 9115-9119.

Golle, J., Lisibach, S., Mast, F. W., \& Lobmaier, J. S. (2013). Sweet puppies and cute babies: Perceptual adaptation to babyfacedness transfers across species. PLoS One, 8, e58248.

Gorn, G. J., Jiang, Y., \& Johar, G. V. (2008). Babyfaces, trait inferences, and company evaluations in a public relations crisis. Journal of Consumer Research, 35, 36-49.

Griskevicius, V., Tybur, J. M., Delton, A. W., \& Robertson, T. E. (2011). The influence of mortality and socioeconomic status on risk and delayed rewards: a life history theory approach. Journal of Personality and Social Psychology, 100, 1015.

Griskevicius, V., Ackerman, J. M., Cantú, S. M., Delton, A. W., Robertson, T. E., Simpson, J. A., ... \& Tybur, J. M. (2013). When the economy falters, do people spend or save? Responses to resource scarcity depend on childhood environments. Psychological Science, 24, 197-205.

Gross, T. F. (1997). Children's perception of faces of varied immaturity. Journal of Experimental Child Psychology, 66, 42-63.

Hampson, S. E., Andrews, J. A., Barckley, M., Lichtenstein, E., \& Lee, M. E. (2000). Conscientiousness, perceived risk, and risk-reduction behaviors: A preliminary study. Health Psychology, 19, 496. 
Hayes, Andrew F. (2013). Introduction to Mediation, Moderation, and Conditional Process Analysis: A Regression-Based Approach. The Guilford Press.

Hellen, K., \& Sääksjärvi, M. (2013). Development of a scale measuring childlike anthropomorphism in products. Journal of Marketing Management, 29, 141-157.

Holly, R., Christine, E. P., Katherine, S. Y., Goodacre, T. E., Kringelbach, M. L., Bonaiuto, J. J., ... \& Murray, L. (2017). Effects of infant cleft lip on adult gaze and perceptions of “cuteness". The Cleft Palate-Craniofacial Journal, 54, 562-570.

Hurtibise, R. (2019). The Bahamas' swimming pig attractions are out of control, animal rights advocates say. SunSentinel, April 26, 2019. Retrieved from https://www.sunsentinel.com/business/fl-bz-bahamas-swimming-with-pigs-under-fire-20190426story.html

Jia, H. M., Park, C. W., \& Pol, G. (2015). Cuteness, nurturance, and implications for visual product design. The psychology of design: Creating consumer appeal, 168-179.

John, O. P., \& Srivastava, S. (1999). The Big Five trait taxonomy: History, measurement, and theoretical perspectives. Handbook of Personality: Theory and Research, 2, 102-138.

Junglas, I. A., Johnson, N. A., \& Spitzmüller, C. (2008). Personality traits and concern for privacy: an empirical study in the context of location-based services. European Journal of Information Systems, 17(4), 387-402.

Kovarovic, S. (2011). Hello Kitty: A brand made of cuteness. Journal of Culture and Retail Image, 4, 1-8.

Kringelbach, M. L., Stark, E. A., Alexander, C., Bornstein, M. H., \& Stein, A. (2016). On cuteness: Unlocking the parental brain and beyond. Trends in Cognitive Sciences, 20, $545-558$. 
LaGrange, R. L., \& Ferraro, K. F. (1989). Assessing age and gender differences in perceived risk and fear of crime. Criminology, 27, 697-720.

Lee, C. T., \& Hsieh, S. H. (2019). Engaging consumers in mobile instant messaging: the role of cute branded emoticons. Journal of Product \& Brand Management, 28.

Lehmann, V., Huis, E. M., \& Vingerhoets, A. J. (2013). The human and animal baby schema effect: Correlates of individual differences. Behavioural processes, 94, 99-108.

Leonhardt, J. M., Keller, L. R., \& Pechmann, C. (2011). Avoiding the risk of responsibility by seeking uncertainty: Responsibility aversion and preference for indirect agency when choosing for others. Journal of Consumer Psychology, 21, 405-413.

Li, Y., \& Yan, D. (2017). The Diverging Effects of Cuteness on Risk Preference: Moderating Role of Gender. ACR North American Advances, 45, 740-41.

Li, Y., \& Yan, D. (2021). Cuteness inspires men's risk seeking but women's risk aversion. Journal of Business Research, 126, 239-249.

Littler, D., \& Melanthiou, D. (2006). Consumer perceptions of risk and uncertainty and the implications for behaviour towards innovative retail services: the case of internet banking. Journal of Retailing and Consumer Services, 13, 431-443.

Lobmaier, J. S., Sprengelmeyer, R., Wiffen, B., \& Perrett, D. I. (2010). Female and male responses to cuteness, age and emotion in infant faces. Evolution and Human Behavior, $31,16-21$.

Loewenstein, G. F., Weber, E. U., Hsee, C. K., \& Welch, N. (2001). Risk as feelings. Psychological bulletin, 127, 267.

Loewenstein, G., \& Lerner, J. S. (2003). The role of affect in decision making. Handbook of Affective Science, 619, 3. 
Lorenz, K. (1943). Die angeborenen Formen möglicher Erfahrung [The innate forms of potential experience]. Zeitschrift für Tierpsychologie, 5, 233-519.

Lott, D. F. (1974). Sexual and aggressive behavior of adult male American bison (Bison bison). IUCN Publications new series, 24, 382-394.

Luo, L. Z., Li, H., \& Lee, K. (2011). Are children's faces really more appealing than those of adults? Testing the baby schema hypothesis beyond infancy. Journal of experimental child psychology, 110(1), 115-124.

Maestripieri, D., \& Pelka, S. (2002). Sex differences in interest in infants across the lifespan. Human Nature, 13, 327.

Marcus, A., Kurosu, M., Ma, X., \& Hashizume, A. (2017). Cuteness engineering: Designing adorable Products and services. Springer.

Mather, M., Mazar, N., Gorlick, M. A., Lighthall, N. R., Burgeno, J., Schoeke, A., \& Ariely, D. (2012). Risk preferences and aging: The "certainty effect" in older adults' decision making. Psychology and Aging, 27, 801.

Mayseless, O. (2015). The caring motivation: An integrated theory. Oxford University Press.

Miesler, L., Leder, H., \& Herrmann, A. (2011). Isn't It Cute: An Evolutionary Perspective of Baby-Schema Effects in Visual. International Journal of Design, 5, 17-30.

Minagawa-Kawai, Y., Matsuoka, S., Dan, I., Naoi, N., Nakamura, K., \& Kojima, S. (2009). Prefrontal Activation Associated with Social Attachment: Facial-Emotion Recognition in Mothers and Infants. Cerebral Cortex, 19, 284-92.

Mitchell, V. W., \& Greatorex, M. (1989). Risk reducing strategies used in the purchase of wine in the UK. European Journal of Marketing, 23, 31-46. 
Murthy, D. N. P., \& Djamaludin, I. (2002). New product warranty: A literature review. International Journal of Production Economics, 79, 231-60.

Myrick, J. G. (2015). Emotion regulation, procrastination, and watching cat videos online: Who watches Internet cats, why, and to what effect?. Computers in Human Behavior, 52, 168176.

Nenkov, G. Y., \& Scott, M. L. (2014). “So Cute I Could Eat It Up”: Priming Effects of Cute Products on Indulgent Consumption. Journal of Consumer Research, 41, 326-41.

Nicholson, N., Soane, E., Fenton-O'Creevy, M., \& Willman, P. (2005). Personality and domainspecific risk taking. Journal of Risk Research, 8, 157-76.

Nigg, J. T. (2017). Annual Research Review: On the relations among self-regulation, selfcontrol, executive functioning, effortful control, cognitive control, impulsivity, risktaking, and inhibition for developmental psychopathology. Journal of Child Psychology and Psychiatry, 58, 361-383.

Nittono, H., \& Ihara, N. (2017). Psychophysiological responses to kawaii pictures with or without baby schema. SAGE Open, 7, 2158244017709321.

Nittono, H., Fukushima, M., Yano, A., \& Moriya, H. (2012). The power of kawaii: Viewing cute images promotes a careful behavior and narrows attentional focus. PloS one, 7, e46362.

Olenski, S. (2016). How brands should use celebrities for endorsements. Forbes, July 20, 2016. Retrieved from www.forbes.com/sites/steveolenski/2016/07/20/how-brands-should-usecelebrities-for-endorsements/\#73fc5acd5593

Paulsen, D., Platt, M., Huettel, S. A., \& Brannon, E. M. (2011). Decision-making under risk in children, adolescents, and young adults. Frontiers in Psychology, 2, 72. 
Paulsen, D. J., Platt, M. L., Huettel, S. A., \& Brannon, E. M. (2012). From risk-seeking to riskaverse: the development of economic risk preference from childhood to adulthood. Frontiers in psychology, 3, 313.

Poniewozik, J. (2019). Baby Yoda Is Your God Now. The New York Times, December 12, 2019. Retrieved from https://www.nytimes.com/2019/12/12/arts/television/baby-yodamandalorian.html

Porcelli, A. J., \& Delgado, M. R. (2009). Acute stress modulates risk taking in financial decision making. Psychological Science, 20, 278-283.

Powell, M., \& Ansic, D. (1997). Gender differences in risk behaviour in financial decisionmaking: An experimental analysis. Journal of Economic Psychology, 18, 605-628.

Raghunathan, R., Naylor, R. W., \& Hoyer, W. D. (2006). The unhealthy tasty intuition and its effects on taste inferences, enjoyment, and choice of food products. Journal of Marketing, 70, 170-184.

Rhodes, N., \& Pivik, K. (2011). Age and gender differences in risky driving: The roles of positive affect and risk perception. Accident Analysis \& Prevention, 43, 923-931.

Riessland, A. (1998). Sweet spots: The use of cuteness in Japanese advertising, Japanstudien, 9(1), 129-154.

Roethe, J. W. (1967). Seat Belt Negligence in Automobile Accidents. Wis. L. Rev., 288.

Roh, E. H., Ahn, J. A., Park, S., \& Song, J. E. (2017). Factors influencing parenting efficacy of Asian immigrant, first-time mothers: A cross-sectional, correlational survey. Nursing \& health sciences, 19, 467-474.

Rossbach, K. A., \& Wilson, J. P. (1992). Does a Dog’s Presence Make a Person Appear More Likable?: Two Studies. Anthrozoös, 5, 40-51. 
Saad, G. (2013). Evolutionary consumption. Journal of Consumer Psychology, 23, 351-371.

Sanefuji, W., Ohgami, H., \& Hashiya, K. (2007). Development of preference for baby faces across species in humans (Homo sapiens). Journal of Ethology, 25, 249-254.

Schnurr, B. (2019). Too cute to be healthy: How cute packaging designs affect judgments of product tastiness and healthiness. Journal of the Association for Consumer Research, 4 , 363-375.

Scott, M. L., \& Nenkov, G. Y. (2016). Using consumer responsibility reminders to reduce cuteness-induced indulgent consumption. Marketing Letters, 27, 323-336.

Shen, L., Fishbach, A., \& Hsee, C. K. (2014). The motivating-uncertainty effect: Uncertainty increases resource investment in the process of reward pursuit. Journal of Consumer Research, 41, 1301-15.

Sherman, G. D., Haidt, J., \& Coan, J. A. (2009). Viewing cute images increases behavioral carefulness. Emotion, 9, 282-86.

Sherman, G. D., Haidt, J., Iyer, R., \& Coan, J. A. (2013). Individual differences in the physical embodiment of care: Prosocially oriented women respond to cuteness by becoming more physically careful. Emotion, 13, 151.

Stanton, S. J., Reeck, C., Huettel, S. A., \& LaBar, K. S. (2014). Effects of induced moods on economic choices. Judgment and Decision Making, 9, 167.

Stavropoulos, K. K., \& Alba, L. A. (2018). “It's so cute I could crush it!”: Understanding neural mechanisms of Cute Aggression. Frontiers in Behavioral Neuroscience, 12, 300.

Stavropoulos, K. M. (2019). Why is everyone in love with baby Yoda? Psychology Today, December 05, Retrieved from https://www.psychologytoday.com/us/blog/neurosciencein-translation/201912/why-is-everyone-in-love-baby-yoda 
Steinnes, K. K., Blomster, J. K., Seibt, B., Zickfeld, J. H., \& Fiske, A. P. (2019). Too Cute for Words: Cuteness Evokes the Heartwarming Emotion of Kama Muta. Frontiers in Psychology, 10, 387.

Sternglanz, S. H., Gray, J. L., \& Murakami, M. (1977). Adult preferences for infantile facial features: An ethological approach. Animal Behaviour, 25, 108-115.

Stoeckel, L. E., Palley, L. S., Gollub, R. L., Niemi, S. M., \& Evins, A. E. (2014). Patterns of brain activation when mothers view their own child and dog: An fMRI study. PloS one, 9, e107205.

Tait, A. (2019). How aggressively cute toys for adults became a $\$ 686$ million business. VOX August 13, 2019. Retrieved from https://www.vox.com/thegoods/2019/8/13/20798910/funko-pop-vinyl-figurines-collectibles

Tan, C. S. (2016). We Need to Look Cute! But Is It Really Effective?: The Adoption of Culture in Twitter by a Japanese CVS. In Managing Public Relations and Brand Image through Social Media (pp. 228-254). IGI Global.

Tan, X., Van Prooijen, J. W., Proulx, T., Wu, H., Van Beest, I., \& Van Lange, P. A. (2017). Reacting to unexpected losses in an uncertain world: High approach individuals become even more risk-seeking. Personality and individual differences, 109, 117-123.

The islands of the Bahamas (2020). Official home of the swimming pigs. Retrieved from https://www.bahamas.com/official-home-swimming-pigs

Tiedens, L. Z., \& Linton, S. (2001). Judgment under emotional certainty and uncertainty: The effects of specific emotions on information processing. Journal of Personality and Social Psychology, 81, 973-988. 
Tracey, L. (2020). There's a Mascot for That? Cute COVID-19 Education. JSTORE Daily, Retrieved from https://daily.jstor.org/theres-a-mascot-for-that-cute-covid-19-education/ Volk, A. A., Lukjanczuk, J. L., \& Quinsey, V. L. (2007). Perceptions of child facial cues as a function of child age. Evolutionary Psychology, 5, 147470490700500409.

Wang, T., Mukhopadhyay, A., \& Patrick, V. M. (2017). Getting Consumers to Recycle NOW! When and Why Cuteness Appeals Influence Prosocial and Sustainable Behavior. Journal of Public Policy \& Marketing, 36, 269-83.

Wallace, J. C., \& Vodanovich, S. J. (2003). Workplace safety performance: Conscientiousness, cognitive failure, and their interaction. Journal of occupational health psychology, 8(4), 316.

Weber, B. J., \& Chapman, G. B. (2005). Playing for peanuts: Why is risk seeking more common for low-stakes gambles?. Organizational Behavior and Human Decision Processes, 97, $31-46$.

Weber, E. U., Blais, A. R., \& Betz, N. E. (2002). A domain-specific risk-attitude scale: Measuring risk perceptions and risk behaviors. Journal of Behavioral Decision Making, $15,263-290$.

WebMD (2003). Secret to Baby-Like Soft Skin Revealed. WebMD Health News, May 5, 2003. Retrieved from https://www.webmd.com/parenting/baby/news/20030506/secret-to-babylike-soft-skin-revealed

Werth, C. \& Wright, K. (WNYC Studios) (2019, April 23) The People vs. Dutch Boy Lead [Audio podcast]. Retrieved from https://www.wnycstudios.org/podcasts/thestakes/episodes/the-stakes-people-vs-dutch-boy-lead 
Wida, E. C. (2019). Trader Joe's has been hiding stuffed animals in store aisles for years here's why. TODAY, November 6, Retrieved from https://www.today.com/food/traderjoe-s-has-been-hiding-stuffed-animals-store-aisles-t166611

Wood, P. B., Pfefferbaum, B., \& Arneklev, B. J. (1993). Risk-taking and self-control: Social psychological correlates of delinquency. Journal of Crime and Justice, 16, 111-130.

Woodford, M. (2018). Google ads rebranding: all Google logo changes. Key Principles, August 7, Retrieved from https://www.keyprinciples.co.uk/all-google-logo-changes/

Zhipeng, X., Tao, W., \& Jing, Z. (2018). A Literature Review of Cuteness in Marketing. Foreign Economics \& Management, 40, 56-68.

Zickfeld, J. H., Kunst, J. R., \& Hohle, S. M. (2018). Too sweet to eat: Exploring the effects of cuteness on meat consumption. Appetite, 120, 181-195.

Zou, X., Scholer, A. A., \& Higgins, E. T. (2020). Risk preference: How decision maker's goal, current value state, and choice set work together. Psychological Review, 127, 74.

Zuckerman, M., and Kuhlman, D. M. (2000). Personality and risk-taking: Common biosocial factors. Journal of Personality, 68, 999-1029. 


\section{Appendices}

\section{Appendix A}

Images of Marketing Campaigns Incorporating Cuteness

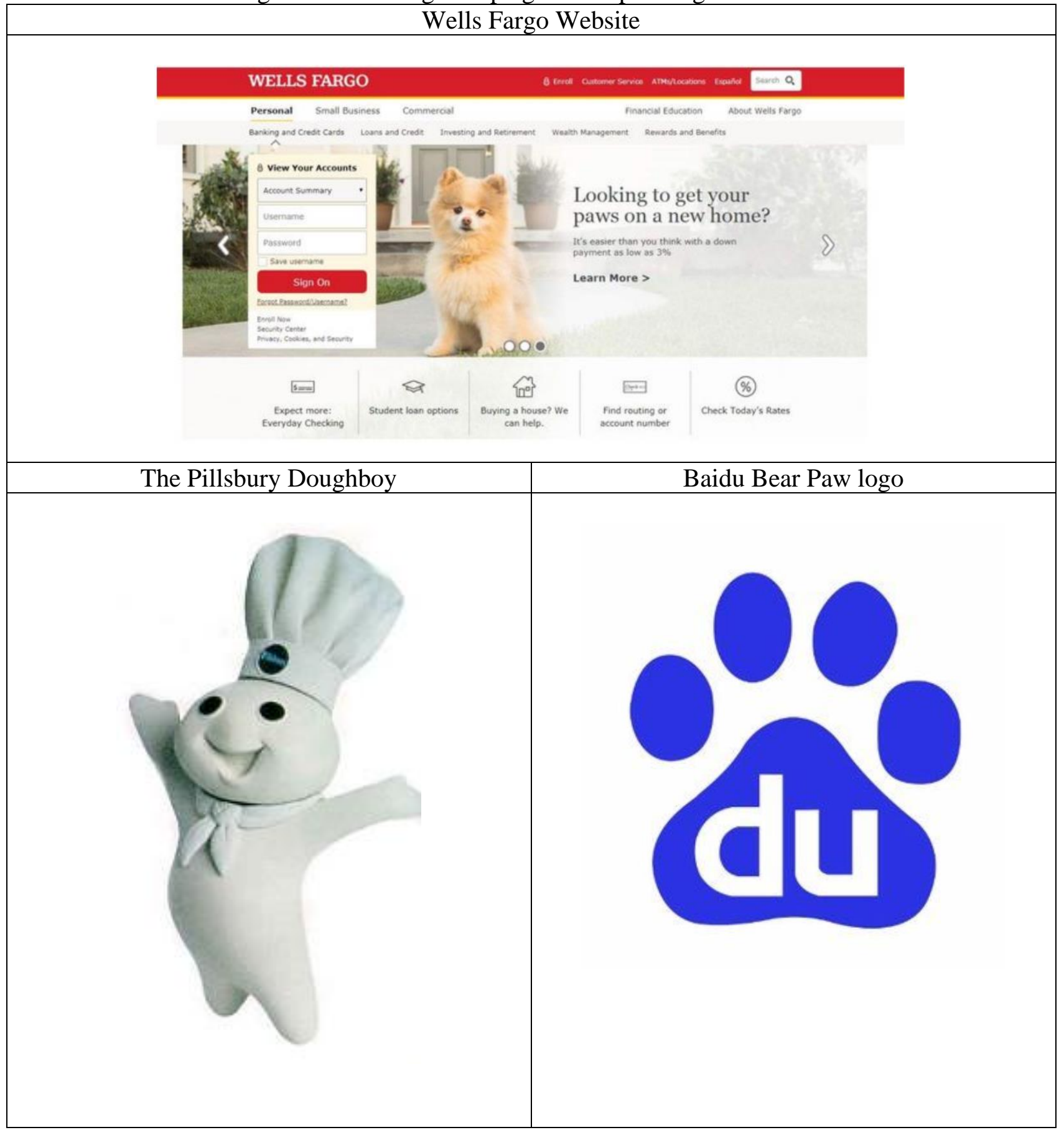


Methodological Details Appendix A

Study 1: Examples of Stimuli Images Used

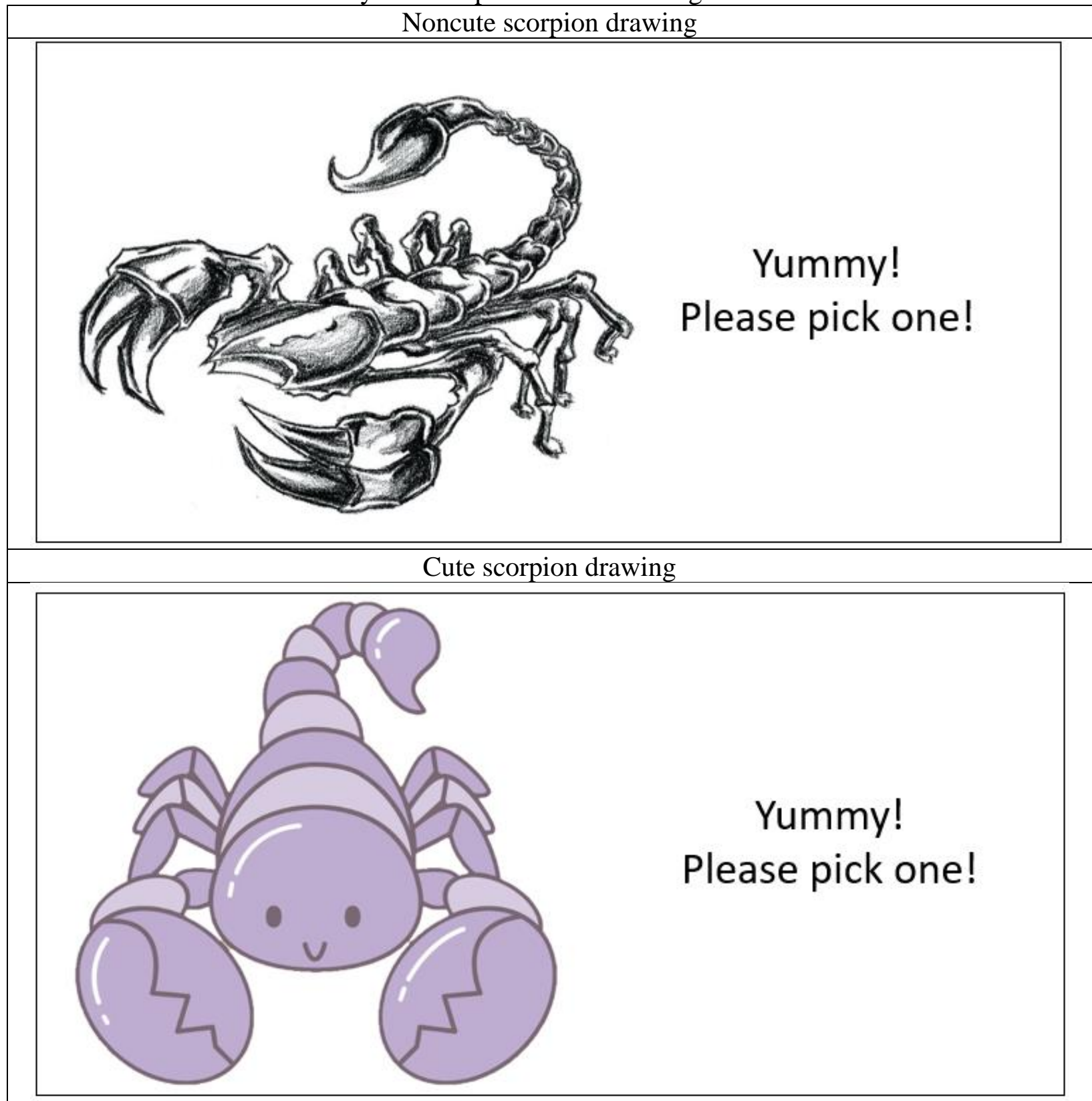


Methodological Details Appendix B

Study 1: Examples of lollipops

\begin{tabular}{|l|l|l|}
\hline Scorpion lollipop & \\
\hline Ordinary lollipop & \\
\hline
\end{tabular}


Methodological Details Appendix C

Study 2: Examples of Stimuli Images Used

\begin{tabular}{|c|c|}
\hline Neutral Gambling Stimuli & $\begin{array}{l}\text { Please select one } \\
\text { from the } \\
\text { following two } \\
\text { options. } \\
\text { GOOD LUCK! }\end{array}$ \\
\hline Cute Gambling Stimuli & $\begin{array}{l}\text { Please select one } \\
\text { from the } \\
\text { following two } \\
\text { options. } \\
\text { GOOD LUCK! } \\
\text { Please select one } \\
\text { from the } \\
\text { following two } \\
\text { options. } \\
\text { GOOD LUCK! } \\
\text { Please select one } \\
\text { of the following } \\
\text { two options. } \\
\text { GOOD LUCK! }\end{array}$ \\
\hline
\end{tabular}




\section{Methodological Details Appendix D}

Study 2 and 3: Examples of Gambling Game Options

\begin{tabular}{|c|c|c|}
\hline Sets & Option 1 (right side) & Option 2 (left side) \\
\hline 1 & $100 \%$ chance of gaining $\$ 0.60$ & $50 \%$ chance of gaining $\$ 1.20$ \\
\hline 2 & $50 \%$ chance of gaining $\$ 1.20$ & $100 \%$ chance of gaining $\$ 0.60$ \\
\hline 3 & $100 \%$ chance of losing $\$ 0.60$ & $50 \%$ chance of losing $\$ 1.20$ \\
\hline 4 & $50 \%$ chance of losing $\$ 1.20$ & $100 \%$ chance of losing $\$ 0.60$ \\
\hline 5 & $20 \%$ chance of gaining $\$ 3.00$ & $80 \%$ chance of gaining $\$ 0.75$ \\
\hline 6 & $80 \%$ chance of gaining $\$ 0.75$ & $20 \%$ chance of gaining $\$ 3.00$ \\
\hline 7 & $20 \%$ chance of losing $\$ 3.00$ & $80 \%$ chance of losing $\$ 0.75$ \\
\hline 8 & $80 \%$ chance of losing $\$ 0.75$ & $20 \%$ chance of losing $\$ 3.00$ \\
\hline 9 & $60 \%$ chance of gaining $\$ 1.00$ & $40 \%$ chance of gaining $\$ 1.50$ \\
\hline 10 & $40 \%$ chance of gaining $\$ 1.50$ & $60 \%$ chance of gaining $\$ 1.00$ \\
\hline 11 & $60 \%$ chance of losing $\$ 1.00$ & $40 \%$ chance of losing $\$ 1.50$ \\
\hline 12 & $40 \%$ chance of losing $\$ 1.50$ & $60 \%$ chance of losing $\$ 1.00$ \\
\hline
\end{tabular}

Three different probabilities (i.e., $80 \% / 20 \%, 60 \% / 40 \%, 10 \% / 90 \%$ ) were presented during the gambling game. The sets were presented in random order. For example, for the first set, a participant must choose between an option with a $20 \%$ chance to win $\$ 2$ or an option with an $80 \%$ chance to win $\$ 0.5$. The expected value for both options is $\$ 0.4$, but the first option (20\% chance) is riskier than the other ( $80 \%$ chance) due to higher uncertainty. 
Methodological Details Appendix E

Study 3: Examples of Stimuli Images Used

Babies $\begin{aligned} & \text { Please select one } \\ & \text { from the } \\ & \text { following two } \\ & \text { options. }\end{aligned}$


Methodological Details Appendix F

Study 4: Examples of Stimuli Images Used

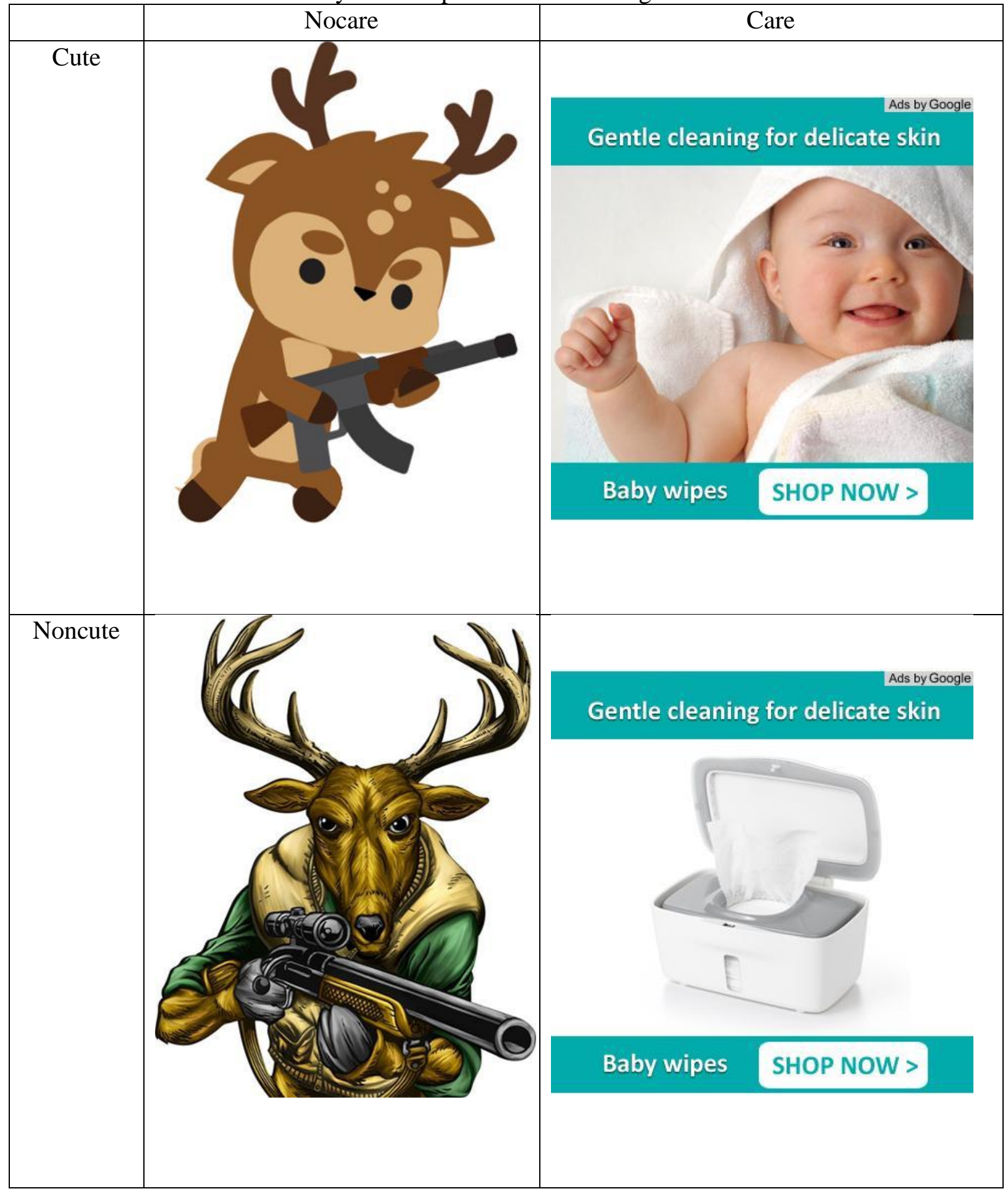




\section{DEATH TOLL RISES TO 50 IN NEW ZEALAND MOSQUE SHOOTINGS}

By John Anderson | March 26, 2019 02:26 PM

The staggering death toll from the mass shootings at two Christchurch mosques has climbed to 50, New Zealand police confirmed Sunday, as the country continued to grapple with the emotional fallout from the atrocity. The body of the $50 t h$ victim was discovered at the $\mathrm{Al}$ Noor mosque, where most victims were killed, when officials were removing the victims' bodies on Saturday, New Zealand Police

Commissioner Mike Bush said, told reporters on Sunday.

The victims' names were not made public. While a preliminary list of the victims has been shared with families, Bush said their bodies have not yet been released.
The number of wounded also increased to 50 , he said. Of those, 34 remain hospitalized in the Christchurch Hospital and | 12 are in critical condition, Greg Robertson, the hospital's chief of surgery, said.

\section{Place Stimuli Here}




\section{Methodological Details Appendix H}

Attitude toward gun measures (Branscombe et al. 1991)

( 1 = strongly disagree, 7 = strongly agree)

1) People should be allowed to have guns in their homes.

2) A ban on guns would be a violation of the U.S. Constitution.

3) The right to bear arms is an important freedom for Americans to retain.

4) Regardless of their potential for injury, it is each person's right to choose to own a gun or not.

5) People should be able to own guns because many people use them for sporting purposes.

6) I should be able to get a gun if I want one.

7) Gun ownership is a basic American value. 


\section{Essay 2: The Harmful Effect of Salesperson Babyface on Online Consumer Engagement}

\section{Introduction}

Online platforms offer great convenience and consumer engagement opportunities, especially amid COVID-19 (Wang et al., 2020; Hartmann and Lussier, 2020). To avoid in-person engagement or interaction, consumers are more likely to engage with salespeople online during the pandemic. Even before the pandemic, consumers often obtained information about salespeople before initiating traditional in-person exchanges (Catlin et al., 2016). For example, service provider websites such as Zillow.com (real estate), Rover (dog walking), and Preply.com (language learning) provide photo profiles of salespeople and service professionals and allow consumers to engage with them on the websites. Notably, the online presence of a salesperson's facial information provides consumers cues to assess the salesperson's emotional state, attractiveness, and trustworthiness; which in turn influences consumers' likelihood of contacting the salesperson, and eventually their satisfaction, loyalty, and service quality evaluations (Zhou, Lu, and Ding, 2020; Rezlescu et al., 2012).

The notion that people make inferences about others based on their appearance is not new (Bar, Neta, and Linz, 2006). Research has found that people form their first impression and make judgments of strangers' characteristics in half a minute based on their appearances (Ambady and Rosenthal, 1993). The feature that people focus on the most when making such inferences is a person's face (Stirrat and Perrett, 2010). In other words, even though there is a proverbial idiom that says, "Don't judge a book by its cover," consumers often do precisely that when they see salespeople's faces. These inferences are especially prevalent in sales contexts, and they have significant consequences. For example, salespeople's appearance eventually influences their 
service rating, consumers' decision-making confidence, and consumers' reactions to them (McElroy and DeCarlo, 1999; Wan and Wyer, 2015).

One of the most well-established facial inferences is the babyface overgeneralization effect theory, which indicates people generally assume that a person with babyish facial features possesses childlike characteristics (Zebrowitz and Franklin, 2014). This effect has been documented in multiple disciplines, including psychology, politics, and leadership studies. Having a babyface is found to influence the likelihood of being found less guilty in a court and winning elections (Chang et al., 2017; Zebrowitz and McDonald, 1991). Despite the extensive research showing the importance of babyface effects (Ahearne et al., 1999; Farmer and Tsakiris, 2012), little is known about its influences in business contexts. Thus, I find it urgent to understand salespeople's babyface effects in service business settings. The current paper aims to shed new light on a physical dimension — babyface - that has not received much attention in the sales and service literature (Berry and Landry, 1997; Rule and Ambady, 2008).

In the current service selling landscape, consumers frequently use the Internet as their primary source of information and are influenced by online content, primarily in the early stages of the purchase process (Holliman and Rowley, 2014). Especially, amid COVID-19 prompted citizen lockdown, consumers often have to find salespeople online because many in-person interactions or engagements are unavailable (Hollebeek et al., 2020). For example, consumers can easily find local State Farm insurance sales agents' profile photos with their contact information on a State Farm's website before having an in-person meeting. Salespeople often have their profile pictures online, and consumers' attention towards involving online content in the buying process prompts salespeople to maintain an online presence (Agnihotri et al., 2016). Consumer engagement is all about "building emotional bonds in relational exchanges" (Sashi, 
2012, p. 260) and consumer engagement represents salespeople's performance in online service settings, as consumer engagement often occurs when they are satisfied with services (Zhang et al., 2018). Therefore, the question of whether having a babyface helps or harms online consumer engagement is central to the intent of this paper.

The current study contributes to the service and sales literature in many ways. This study is the very first to demonstrate babyface overgeneralization effect theory in an online setting, bridge the babyface overgeneralization effects and sales, and suggest two moderators. The present study also extends the babyface overgeneralization effect theory by integrating gender stereotyping in service professions and the theory of consumer involvement into the studies (Chang and Chen, 2015; Chang et al., 2017). In particular, the current research documents that salespeople's gender and customers' level of involvement with the purchase interact with the effects of babyface on online engagement, thereby further increasing the implications of the present work.

In addition, current research makes a significant methodological contribution. To analyze salespeople's facial features, I adopted an artificial intelligence facial recognition software API, Azure, to objectively analyze 1,000 real estate agents' profiles on Zillow.com to examine the effects of salespeople's babyface on online engagement. Specifically, the artificial intelligence facial recognition API provides 27 facial landmarks for each real estate agent's profile picture. After obtaining the facial landmarks, I calculate each real estate agent's babyface score by using the methodology adapted from previous literature (Berry and McArthur, 1985; Borgi et al., 2014; Henderson et al., 2001). The current research is the first to empirically test the associations between salespeople's appearance and online engagement by using the number of real-world 
consumer reviews and photos of real salespeople with an artificial intelligence facial recognition API.

\section{Theoretical Background}

\section{Facial Inferences}

"The human face is perhaps the most salient source of interpersonal information, especially with strangers" (Stirrat and Perrett 2010, p. 349). Indeed, people often generate biased and quick inferences about others based on their faces (Gibson, 2014; Goldstein et al., 1984; Jack and Schyns, 2015). For instance, individuals decide whom to trust based on facial characteristics and find it easier to trust others whose faces look similar to their own (Debruine, 2002; Wilson and Eckel, 2006). Studies have also consistently shown a "halo effect" of facial attractiveness; for example, individuals assume that good-looking people are healthier and more successful (Cialdini, 1984; Zebrowitz and Montepare, 2008). On the flip side, people tend to make negative judgments about physically unattractive individuals (Griffin and Langlois, 2006). For example, unattractive criminals are found guilty more often than attractive ones (Efran, 1974), and people generally avoid interacting with individuals possessing disfigured facial features (Houston and Bull, 1994). In sum, these inferences are widespread, manifesting across various contexts (Dion and Walster, 1972) (See table 2).

To that end, it is not surprising that such inferences have also been documented in sales and service contexts (Chaker et al., 2019; Wan and Wyer, 2015). That is, consumers make inferences about salespeople based on their faces (Fergurson, 2017; McColl and Truong, 2013). For example, service and sales employees' facial attractiveness affects consumer citizenship behavior, consumers' perceptions of their communication ability, likability, and trustworthiness (Ahearne et al., 1999). However, when consumers are concerned about their self-presentation or 
have a low social interaction, they react less favorably to attractive salespeople (Li et al., 2019; Wen and Wyer, 2015).

Although previous studies have documented various impacts of a salespeople' faces, an important yet often overlooked facial feature is a salesperson's babyface. In the current study, I define babyface as the extent to which salespeople possess babyish facial features (Chang and Chen, 2015; Zebrowitz et al., 1993).

\section{Online Engagement}

Consumer engagement is referred to as "the intensity of an individual's participation and connection with the organization's offerings and activities initiated by either the consumer or the organization" (Vivek et al., 2012, p. 133). Especially, in today's modern selling landscape, online consumer engagement is important and unique as consumers cannot engage in-person amid COVID-19 (Karpen and Conduit, 2020). Highly engaged consumers not only purchase services, but also are committed to a brand, impact potential consumers' purchase behavior by posting reviews and referring businesses to others (Khan et al., 2019; Pansari and Kumar, 2017). In the context of personal selling and sales management, consumer engagement is an expanded domain of relationship marketing (Brodie et al., 2013). Marketing Science Institute identifies "consumer engagement" as one of the research priorities contributing to academic insight into interactive online environments that are particularly common today (Viglia et al., 2018). Relational value outcomes that should be assessed from both the buyer's and seller's point of view are expected to emerge through engaging consumers (Kumar et al., 2010). 
Table 2. Literature review on facial appearance in marketing

\begin{tabular}{|c|c|c|c|}
\hline Study & Construct & Data context & Findings \\
\hline $\begin{array}{l}\text { Gorn et al. } \\
(2008) ; \text { JCR }\end{array}$ & Babyface & $\begin{array}{l}\text { A pharmaceutical } \\
\text { company context. }\end{array}$ & Babyfaced (vs. maturefaced) CEOs have more benefits in a public relations crisis. \\
\hline $\begin{array}{l}\text { Wan \& Wyer } \\
(2015) ; \text { JCR }\end{array}$ & Attractiveness & $\begin{array}{l}\text { A health care } \\
\text { product context. }\end{array}$ & $\begin{array}{l}\text { When a self-presentation concern is made salient, consumers react less positively } \\
\text { to highly (vs. less) attractive retail store providers. }\end{array}$ \\
\hline $\begin{array}{l}\text { Dolmans et al. } \\
\text { (2016); JBR }\end{array}$ & Facial traits & $\begin{array}{l}\text { An invention } \\
\text { disclosure } \\
\text { context. }\end{array}$ & $\begin{array}{l}\text { Technology licensing officers at Carnegie I research universities perceive } \\
\text { inventions by more (vs. less) professional looking faculty members are more } \\
\text { likely to have commercial potentials. }\end{array}$ \\
\hline $\begin{array}{l}\text { Wang et al. } \\
(2017) ; \mathrm{JCR}\end{array}$ & $\begin{array}{l}\text { Smile } \\
\text { Intensity }\end{array}$ & $\begin{array}{l}\text { A crowdfunding } \\
\text { context } \\
\text { (Kickstarter.com) }\end{array}$ & $\begin{array}{l}\text { 1. Broad (vs. slight) smiles increase social support and low-cost helping behaviors, } \\
\text { such as Facebook shares and small-scale donations. } \\
\text { 2. Broad (vs. slight) smiles decrease pledges, and large-scale donations. }\end{array}$ \\
\hline $\begin{array}{l}\text { Canace et al. } \\
(2020) ; \mathrm{JBR}\end{array}$ & Facial traits & $\begin{array}{l}\text { S\&P } 500 \text { firms } \\
\text { context. }\end{array}$ & $\begin{array}{l}\text { More (vs. less) competent looking CEOs receive a higher salary but not higher } \\
\text { non-salary pay. }\end{array}$ \\
\hline $\begin{array}{l}\text { Cheng et al. } \\
\text { (2020); JCR }\end{array}$ & $\begin{array}{l}\text { Smile } \\
\text { Intensity }\end{array}$ & $\begin{array}{l}\text { Real estate sales } \\
\text { context. }\end{array}$ & $\begin{array}{l}\text { Salespeople with large Duchenne (vs. small) smiles signal greater intrinsic } \\
\text { motivation. }\end{array}$ \\
\hline $\begin{array}{l}\text { Mittal \& Silvera } \\
(2020) ; \text { JBR }\end{array}$ & Facial hair & $\begin{array}{l}\text { Online ad } \\
\text { campaign context } \\
\text { (Facebook) }\end{array}$ & $\begin{array}{l}\text { Salespeople with beards (vs. clean-shaven or other facial hairstyles) foster higher } \\
\text { perceptions of expertise, ratings of trustworthiness, and increase purchase } \\
\text { intention and service satisfaction. }\end{array}$ \\
\hline Current study & Babyface & $\begin{array}{l}\text { A real-estate } \\
\text { sales context } \\
\text { (Zillow) }\end{array}$ & $\begin{array}{l}\text { 1. Babyface (vs. maturefaced) salespeople induce less online engagement } \\
\text { when consumers' purchase involvement is high. } \\
\text { 2. Babyface (vs. maturefaced) salespeople induce more online engagement } \\
\text { when consumers' purchase involvement is low. } \\
\text { 3. The Babyface effect on online engagement attenuates for a female } \\
\text { salesperson. }\end{array}$ \\
\hline
\end{tabular}

Note: JCR: Journal of Consumer Research; JBR: Journal of Business Research 
Amid COVID-19 lockdowns, online consumer engagement has become more essential (Hollebeek et al., 2020). In an online context, consumer engagement is defined as the extent to which the consumers are active in using online platforms to support sales organizations (Guesalaga, 2016). Online consumer engagement has often been captured through consumers' referrals and consumers' reviews and feedback (Agnihotri, 2020). It has been argued that consumer-generated online content, online ratings, reviews create social-influence value for sellers (Brodie et al., 2013; Pansari and Kumar, 2017). However, it is unknown whether a positive (or negative) connection exists between salespeople's babyface features and online engagement. Thus, I aim to investigate the effects of salespeople's babyface on online engagement in the present work.

For salespeople, the internet facilitates new connections and relationships by providing alternate ways to connect with prospective consumers. For example, online platforms such as Zillow.com are gateways for real estate salespeople to connect with larger audiences and reach potential consumers. Through online platforms, prospects can initiate conversations with salespeople after appraising their online profiles. Online presence enables self-disclosure, which on the one hand, facilitates and supports social network development (Agnihotri et al., 2020), which may also trigger the biasing impact of appearances on human judgments and choices (Olivola et al., 2014). Accordingly, examining the link between salespeople's babyface and consumers' online engagement and associated boundary conditions is needed.

\section{Hypotheses Development}

Babyface has evolutionary significance, as younglings have developed similar facial features to gain support and help from adults for survival (Hildebrandt and Fitzgerald, 1979). Thus, babyface is a universally shared facet of facial appearance, even regardless of animal species 
(Buckley, 2016). Nobel laureate ethologist Konrad Lorenz first proposed the idea of a baby schema (Lorenz, 1943), which is the group of facial traits that babies possess, such as a round face, big eyes, small nose, small chin, and prominent forehead (Borgi et al., 2014; Zebrowitz and Franklin 2014). Consistent with prior research (e.g., Gorn et al., 2008; Zheng et al., 2018), the current research refers to individuals who possess many of these traits as "babyfaced individuals" and those who possess many of the opposite characteristics as "maturefaced individuals." In other words, maturefaced individuals tend to have broader chins, lower foreheads, and smaller eyes than babyfaced individuals (Berry and Landry, 1997; Glocker et al., 2009).

Prior work has documented a "babyface overgeneralization effect theory" whereby people impose the non-physical (e.g., mental ability, personality, etc.) traits of babies to babyfaced adults (Gorn et al., 2008; Zebrowitz, 1996). This type of stereotyping can either be positive or negative for the babyfaced individual (Berry and McArthur, 1985; Chang et al., 2017). On the positive side, babyfaced individuals are perceived as kind and warm (Friedman and Zebrowitz, 1992; Zebrowitz et al., 1997/2018). For example, consumers often prefer a babyfaced CEO (vs. maturefaced CEO) as a new CEO when a firm has a public crisis because they assume that babyfaced CEOs are warmer than maturefaced CEOs (Gorn et al., 2008). Similarly, patients assume that babyfaced health providers are kinder than their maturefaced counterparts (Chang and Chen, 2015). On the negative side, however, babyfaced individuals are perceived as childish, incompetent, and unintelligent (Berry and Landry, 1997; Rule and Ambady, 2008).

In contrast to babyfaced individuals, maturefaced individuals are often assumed to be responsible, competent, and intelligent (Berry and Brownlow, 1989; Zebrowitz et al., 1991). For example, in the political realm, voters believe that maturefaced candidates are more capable of 
leadership positions (Poutvaara et al., 2009). Leadership studies have also demonstrated that maturefaced individuals are more likely to succeed in high leadership positions (Berry and Landry, 1997; Rule and Ambady, 2008). Besides, maturefaced job candidates are evaluated more positively than babyfaced job candidates for positions that require significant intelligence and perceptiveness (Zebrowitz et al., 1991). Similarly, consumers should perceive maturefaced salespeople as more dependable and capable.

In sum, whereas consumers perceive babyfaced salespeople as warm and kind, they perceive maturefaced salespeople as competent and intelligent (Berry and Landry, 1997; Zebrowitz, 1996). Thus, it is unclear whether having a babyface should be expected to induce more or less online engagement (Eigenraam et al., 2018). That said, the current research proposes that babyface induces less online engagement compared to mature face, as a salesperson's intelligence is more important than warmness when consumers are highly involved in the purchase process. Consumers should be more likely to approach and be willing to build relationships with such salespeople from whom they can infer intelligence and competency (Reingen and Kernan, 1993; Xie and Kahle, 2014).

Prior research demonstrates that salespeople's competency is critical to their performance because it indicates their attentiveness and reflectiveness (Ricks et al., 2008). Indeed, consumers expect their salespeople to provide valuable and thoughtful solutions for them (Liu and Leach, 2001). Salespeople's competency drives consumer engagement by conveying to consumers their ability to help them choose the right services (Piercy et al., 2009). When consumers are highly involved in the purchase process, they will be more engaged with a salesperson who has high competency, as they can trust someone who can help with their purchase decision-making. On the other hand, salespeople's warmth and kindness should not be seen as essential because these 
qualities do not lead consumers to the exact solutions, services, and products that they seek. For example, when a consumer is in the market for a house, he/she should want to engage with an intelligent (vs. warm) salesperson. Therefore, consumers will look for a salesperson who they can infer competency, maturity, and intelligence from his/her face, assuming such a salesperson is more likely to help them find the ideal house (Johnson and Sohi, 2017).

To recap, the theorizing leads me to propose that babyface induces less online engagement than matureface because consumers i) expect babyfaced individuals to be less intelligent and ii) place a high weight on this consideration when evaluating salespeople. More formally, the current research hypothesizes:

\section{H1. Babyface is negatively associated with online engagement.}

I further extend the babyface overgeneralization theory by proposing a boundary condition related to a salesperson's gender as a moderator; that is, the negative effects of babyface on online engagement varies based on the gender of a salesperson due to gender stereotyping. Gender plays an important role in facial inference (Chiao et al., 2008). Not surprisingly, sales literature has also shown saleswomen's disadvantageous position due to gender role stereotyping (Lane and Crane, 2002). Men and women have distinctive facial features that allow individuals to accurately determine the gender of a human face (Burton et al., 1993). Women are more likely to have neotenic features such as narrower jaws, smaller noses, and rounder eyes than men (Friedman and Zebrowitz, 1992; Skorska et al., 2015). Estrogen, the hormone that develops and maintains female characteristics, tends to give women more babyish faces and youthful appearances (Jones et al., 1995). Thus, babyface features and feminine features are highly correlated (Paunonen et al., 1999). Indeed, when a person has big, round eyes, participants indicate that the person appears to have both feminine and babyish facial features 
(Marsh et al., 2005). For instance, when babies' genders are unknown, people typically

assume that those with a higher degree of babyface are girls (Zebrowitz, 1997/2018). Contrary to women, men are more likely to develop larger facial bones, such as wider jaws, than women because of men's higher testosterone levels, the dominant sex hormone in males (Penton-Voak and Chen, 2004; Swaddle and Reierson, 2002). Also, men have more prominent noses and skulls due to their larger lungs, which create gender differences in facial features (Holton et al., 2014).

In sum, women are more likely to have a babyface than men (Friedman and Zebrowitz, 1992). Given the high association between babyfaced features and feminine features, people often infer similar traits from babyfaced individuals' faces and women's faces in general (Jones et al., 1995). As most women already share features of a babyface in common, the difference between babyfaced women and maturefaced women is less prominent than that for men (Berry and McArthur, 1985). Thus, I expect that the negative impact of babyface on female salespeople' online engagement is weaker than for male salespeople, as most women already have babyface features and are viewed as warm but less competent (Fiske, 1998). This proposition is consistent with prior studies that have expected the effect of babyface is more pronounced for males (Gorn et al., 2008; Zebrowitz, 1997/2018).

\section{H2. The negative effect of babyface on online engagement attenuates for a female salesperson.}

Next, I propose a boundary condition related to the theory of consumer involvement; that is, the negative effect of babyface on online engagement varies based on the level of purchase involvement. In this study, a high involvement service refers to a service that most consumers invest a lot of time and effort into while making a purchase decision. For example, real estate could be an example of a high involvement service as most consumers engage in a complex 
decision-making process for real estate purchases (Gibler and Nelson, 2003). On the other hand, a low involvement service refers to a service that most consumers consider only a few variables and comparisons (Kuenzel and Musters, 2007). For instance, most consumers would not be involved in a highly complex decision-making process when purchasing an inexpensive prepaid phone plan service.

As I discussed previously, babyfaced people are perceived as warm and kind (Gorn et al., 2008; Zebrowitz, 1997/2018). In the domain of low involvement services, salespeople's warmth and kindness might play an especially important role relative to their product knowledge because low involvement services carry lesser risks if the services fail (Petty et al., 1983). That is, consumers do not need to rely on competent salespeople to make low-involvement service purchase decisions. Thus, consumers will be more likely to engage with warm and kind salespeople than skilled salespeople.

On the other hand, having a babyface could negatively affect sales performance on highinvolvement services since babyfaced people are perceived to be less competent (Rule and Ambady, 2008). Individuals presume babyfaced others to have more childlike traits (Zheng et al., 2018). Contrarily, maturefaced individuals are highly rated on their shrewdness (Zebrowitz et al., 1991). Individuals put a lot of time and effort when purchasing high involvement services as high involvement services carry greater risks if the services fail (Petty et al., 1983; Youn and Kim, 2018). Therefore, consumers might need and engage with salespeople who are knowledgeable and able to help them process a lot of information efficiently for high involvement service purchase decisions. Formally stated:

\section{H3. Purchase involvement moderates the negative effect of babyface on online engagement.}


The full conceptual model is presented in Figure 5.

Figure 5. Conceptual framework

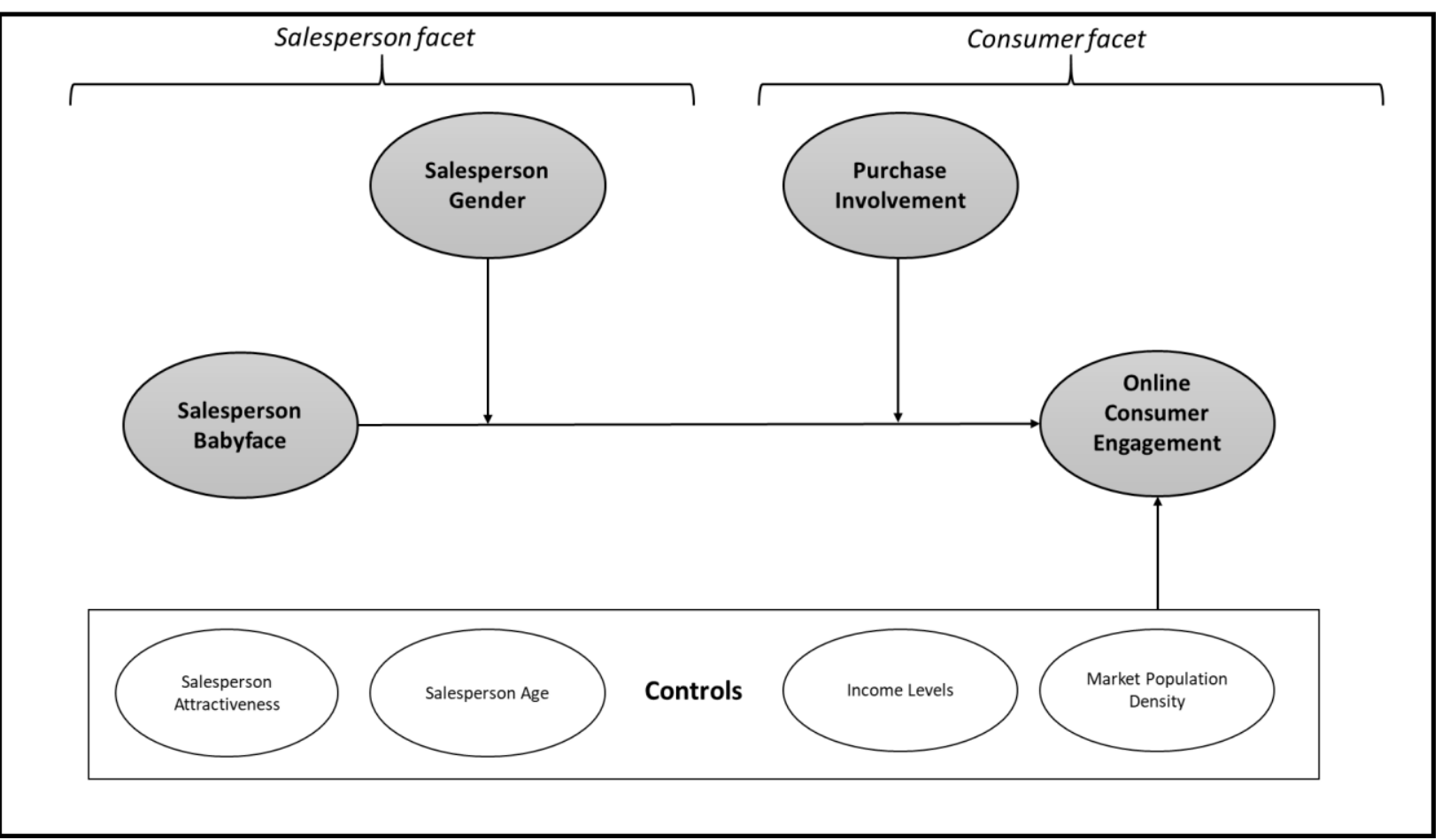

\section{Methodology and Findings}

\section{Study 1}

The goal of Study 1 is to examine hypotheses 1 and 2 . This study used the number of online reviews from a leading real estate website, Zillow.com, to test the effects of babyface on online engagement. I analyzed 1,000 real estate agents' profile photos on Zillow.com with an artificial intelligence facial recognition API, Azure, to determine each agent's level of babyface. After obtaining the babyface level (i.e., babyface score) for each agent, the current study used the babyface scores along with the number of online reviews written by consumers for each agent to examine the proposed negative relationship between babyface and online engagement. 
To test hypothesis 2 , the gender of the sales agents was identified using the artificial intelligence facial recognition API.

\section{Procedure}

I first randomly chose 100 zip codes through randomlist.com. The randomly selected zip codes included the zip codes from 33 states (see Appendix A). I selected the ten real estate agents who reported the highest recent sale numbers, according to Zillow.com, in each zip code for the analysis. The current study selected the ten real-estate agents who reported the highest recent sale numbers in each zip code on Zillow.com for the analysis because they are more likely to be active on Zillow.com than other agents, many of whom have reported "no recent sales."

Once I obtained the images of the 1,000 real estate agents (from their Zillow profiles), I used Microsoft's facial recognition service, Azure, to calculate babyface scores for the agents. Azure is a Microsoft cloud platform that allows users to employ its face API integrated with R. The program detects a human face in an image and places the face in the center of a rectangle. Then, a Cartesian coordinate plane is placed in the rectangle and 27 facial landmarks are developed from the horizontal (x) and vertical (y) coordinates (see Appendix B). The 27 landmarks of $\mathrm{x}$ and $\mathrm{y}$ coordinates include points around the mouth, the nose, the eyes, and the eyebrows. Azure's face API successfully provided all the 27 facial landmarks of the facial features of 766 agents. Azure's face API could not provide facial landmarks for 234 agents due to various issues associated with the photographs, such as company logos other than faces, multiple faces, image noise, blurry faces, and complicated backgrounds (see Appendix C). Thus, 234 agents were excluded from the analyses. After obtaining the 27 facial landmarks, the current study calculated the relative sizes of the various facial features, including the eyes, the nose, and 
the mouth, so that the present study could compute babyface scores and attractiveness scores for each agent.

\section{Measures}

Babyface. Each real estate agent's 'babyface score' was calculated by the following equation: Babyface $=1000 *(6 *$ Proportion of the eyes- $2 *$ Proportion of the nose- $1 *$ Proportion of the mouth) (see Appendix D). I multiple 1,000 because the sizes of the eyes, the noses, the mouth from each salespeople's profile pictures from Zillow.com were extremely small. The coefficients of the facial aspects were based on previous literature detailing the mean gaze time on different aspects of strangers' faces (Henderson et al., 2001). When viewing strangers' faces during facial recognition tasks, individuals focus on facial features proportionally within a designated time period; for every six times, they focus on the eyes, they focus twice on the nose and once on the mouth (Henderson et al., 2001). That is, consumers should look at a salesperson's eyes three times longer than they look at their nose and six times longer than they look at their mouth. The current study applied negative values to the nose and mouth coefficients because previous studies have shown that babyface is negatively related to the sizes of these aspects (Glocker et al., 2009). On the other hand, the current study applied a positive coefficient to the eyes because previous studies have shown that babyface is positively related to the size of this aspect (Berry and McArthur, 1985; Borgi et al., 2014).

Online engagement. The current study used the total number of online consumer reviews from Zillow.com as the measure of online engagement. Almost all the reviews on Zillow are 
positive; they are all written by verified, actual consumers; and neither the agents nor Zillow are able to remove them (Zillow, 2016; Zillow, 2020). ${ }^{1}$

Attractiveness. Salespeople's facial attractiveness affects consumers' perceptions toward them and beyond (Lin et al., 2018). Literature has demonstrated that facial symmetry and ideal proportions in the face determine facial attractiveness (Foo et al., 2017; Little, 2014; Schmid et al., 2008). Thus, the current study adapted the computation of a facial attractiveness index described in Schmid et al. (2008) (see Appendix E). The present study calculated the degrees of facial symmetry for the eyes, the nose, and the mouth, and four ideal proportions in the face and averaged these seven numbers to obtain an attractiveness score for each agent.

Gender. Facial recognition API, Microsoft Azure, provided the gender of each agent.

Age. Facial recognition API, Microsoft Azure, provided the age of each agent.

Median household income. The current study collected median household incomes from www.zipdatamaps.com based on the agents' listed zip codes on Zillow.com.

Population density. The current study collected population from www.zipdatamaps.com based on the agents' listed zip codes on Zillow.com.

\section{Results}

I first calculated the Variance Inflation Factor (VIF) for both attractiveness and babyface, to assess the multicollinearity of these two variables. The VIF for attractiveness was 1.02, and for babyface was 1.01, which are well below 5 as recommended by Hair et al. (1995). Thus, multicollinearity is not a concern in the current study.

\footnotetext{
${ }^{1}$ Zillow has a team of moderators that monitors every submitted review to ensure its validity and adherence to the company's review guidelines.
} 
Prior to analyzing the data, standardization of babyface and attractiveness was first performed to avoid multicollinearity (Dunlap and Kemery, 1987). The current study conducted a multiple regression, with the number of online consumer reviews as the dependent variable, and babyface, salespeople's gender, and their interactions as the independent variables, and salespeople's attractiveness, age, consumers' income levels, and population density as the control variable. Attractiveness was included as a control variable, as previous literature has shown that it affects consumers' attitudes toward salespeople (Ahearne et al., 1999; Lin et al., 2018). However, the current study did not find that attractiveness affects online engagement.

Consistent with hypothesis 1 , babyface was negatively related to the total number of online consumer reviews (see Table $3 ; \beta=-.18, \mathrm{t}(757)=-3.68, p<.001$ ) even after controlling for salespeople's attractiveness $(\beta=.02, \mathrm{t}(757)=.44, p=.66)$, age $(\beta=-.28, \mathrm{t}(757)=-$ $1.07, p=.28)$, median household income $(\beta=.15, \mathrm{t}(757)=4.2, p<.001)$, and population density $(\beta=.05, \mathrm{t}(757)=1.59, p=.11)$. Regarding the possible main effects of the other independent variables: Gender was related to the number of online consumer reviews $(\beta=-.11, \mathrm{t}(757)=-$ 3.01, $p=.003)$. Specifically, salesmen had a higher number of online reviews than saleswomen $\left(M_{\text {salesmen }}=82.1\right.$ vs. $\left.M_{\text {saleswomen }}=48.43\right)$.

Consistent with hypothesis 2 , there was a marginally significant interaction effect between babyface and gender $(\beta=.09, \mathrm{t}(757)=1.75, p=.08)$. For salesmen, babyface was negatively related to the number of online reviews $(\beta=-.14, \mathrm{t}(757)=-2.69 p=.01)$, whereas for saleswomen, there was no effect of babyface on the number of online reviews $(\beta=-.08, \mathrm{t}(757)=$ $-1.65, p=.1)$. 
These results provide evidence in support of the negative association between salespeople's babyface and online engagement and show that this effect is moderated by salespeople's gender. 
Table 3. Regression results for Study 1

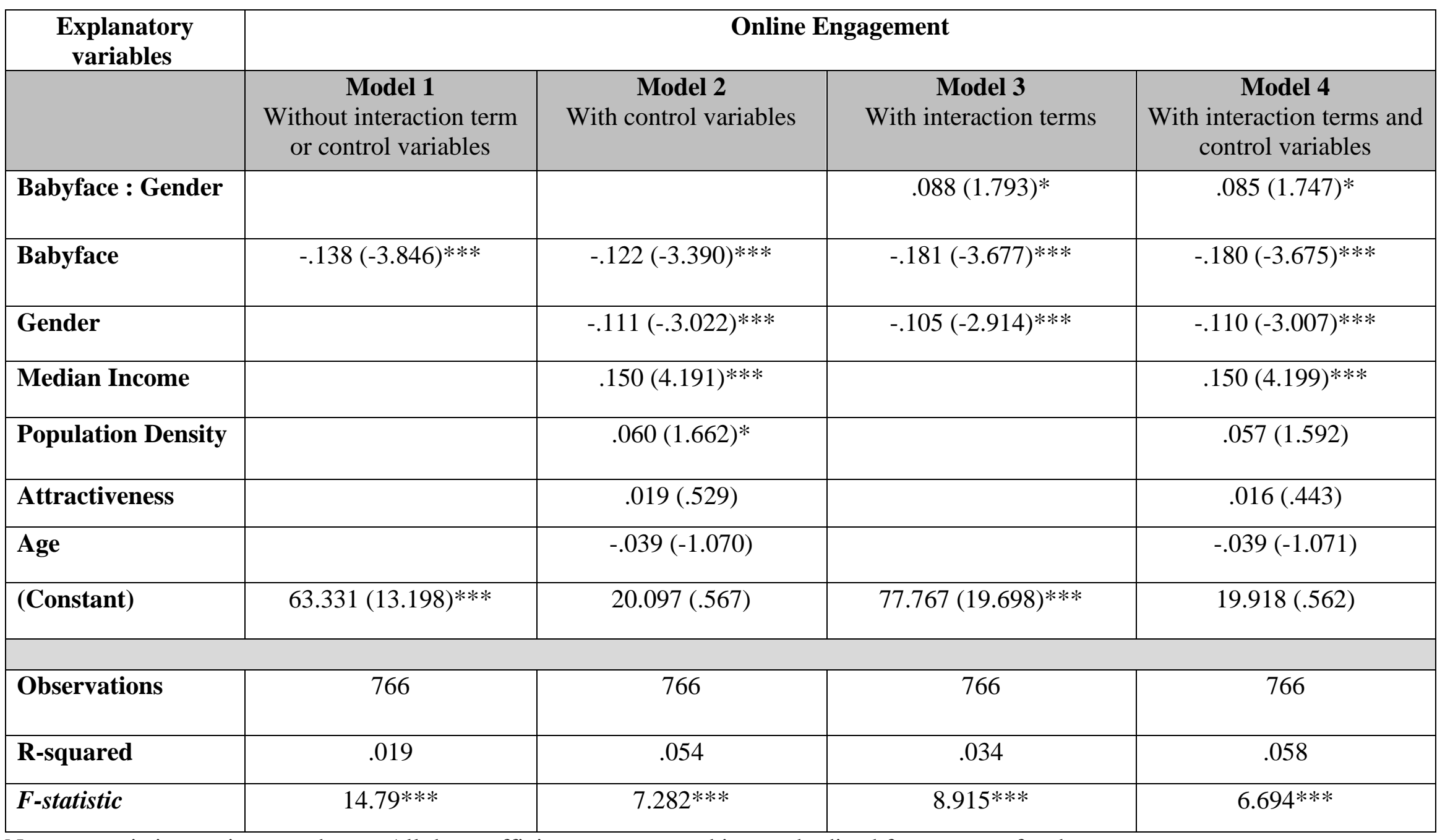

Notes: t-statistics are in parentheses. All the coefficients are reported in standardized form except for the constants.

$* p<.1, * * p<.05, * * * p<.001$ 


\section{Study 2}

The purpose of study 2 is to test hypothesis 3 . Participants in each condition viewed a morphed image of a salesperson and answered a questionnaire. I expect that a babyfaced salesperson will induce less online engagement than a maturefaced salesperson on sales of high involvement service, but he will induce more online engagement on sales of low involvement services than a counterpart.

\section{Participants and Procedure}

I recruited 339 participants in exchange for a small payment from Amazon's Mechanical Turk (MTurk) (33.3\% female, $\left.M_{a g e}=38.62\right)$. This experimental study excluded the participants who did not pass the attention check question or took less than 2 minutes or over 20 minutes to complete the study. This data cleaning process results in a total of 331 participants (33.5\% female, $M_{a g e}=38.63$ ). The study employed a 2 (salesperson's face types: babyface vs. mature face) x 2 (purchase involvement: low vs. high) between-subjects design. An image of a male salesperson's face was used because the effects of baby schema on faces are more likely to be prominent for men than for women (Gorn et al., 2008; Zebrowitz, 1997/2018).

Participants in the babyface (vs. mature face) condition viewed a picture of a salesperson's face that was manipulated to have a high baby schema (vs. low baby schema) (see fig. 6; adapted from Chang et al. 2018). Participants viewed a picture of the service being sold and a list of the service's features above the picture of the salesperson. For the high purchase involvement condition, I used a car insurance plan, and for the low purchase involvement condition, I used a prepaid phone plan. I chose these services because they differ in terms of price and importance (suggesting greater involvement on the part of the consumer), but are 
highly familiar for most consumers. Indeed, the manipulation check below suggests that I successfully manipulated product involvement.

Face type. This experimental study adopted salesperson's face types stimuli (babyface vs. mature face) from Chang et al. (2018), and conducted a pretest to ensure that the morphed images differ on the level of babyface. The current study recruited 159 participants on Amazon Mechanical Turk Participants (MTurk; 39.4\% female; $M_{\text {age }}=35.55$ ) to have them rate the level of babyface with seven-point scale scales $(1=$ not kind at all, $7=$ very kind; $1=$ not warm at all, $7=$ very warm; $1=$ not aggressive at all, $7=$ very aggressive (reverse-coded); $1=$ not strong at all, 7 = very strong $($ reverse-coded)). As expected, a pretest result showed that participants rated the babyfaced salesperson as cuter than the maturefaced salesperson $\left(M_{\text {babyface }}=4.86 \mathrm{vs}\right.$. $\left.M_{\text {matureface }}=5.21, F(1,157)=3.58, p=.01\right)($ see fig. 6$)$.

Purchase involvement. I conducted a pretest to ensure that the services differ on the level of purchase involvement. 159 participants on Amazon Mechanical Turk Participants (MTurk; $39.4 \%$ female; $\left.M_{\text {age }}=35.55\right)$ rated the importance of an inexpensive prepaid phone plan, and car insurance with a seven-point scale adapted from Zaichkowsky (1985) (1 = not important at all, 7 $=$ important). As expected, a pretest result showed that participants rated car insurance as more important than a cell phone plan $\left(M_{\text {high involvement }}=5.66\right.$ vs. $M_{\text {low involvement }}=5.24, t(330)=4.24, p$ $<.001$ ) (see fig. 6). 
Figure 6. Study 2: Experimental study stimuli

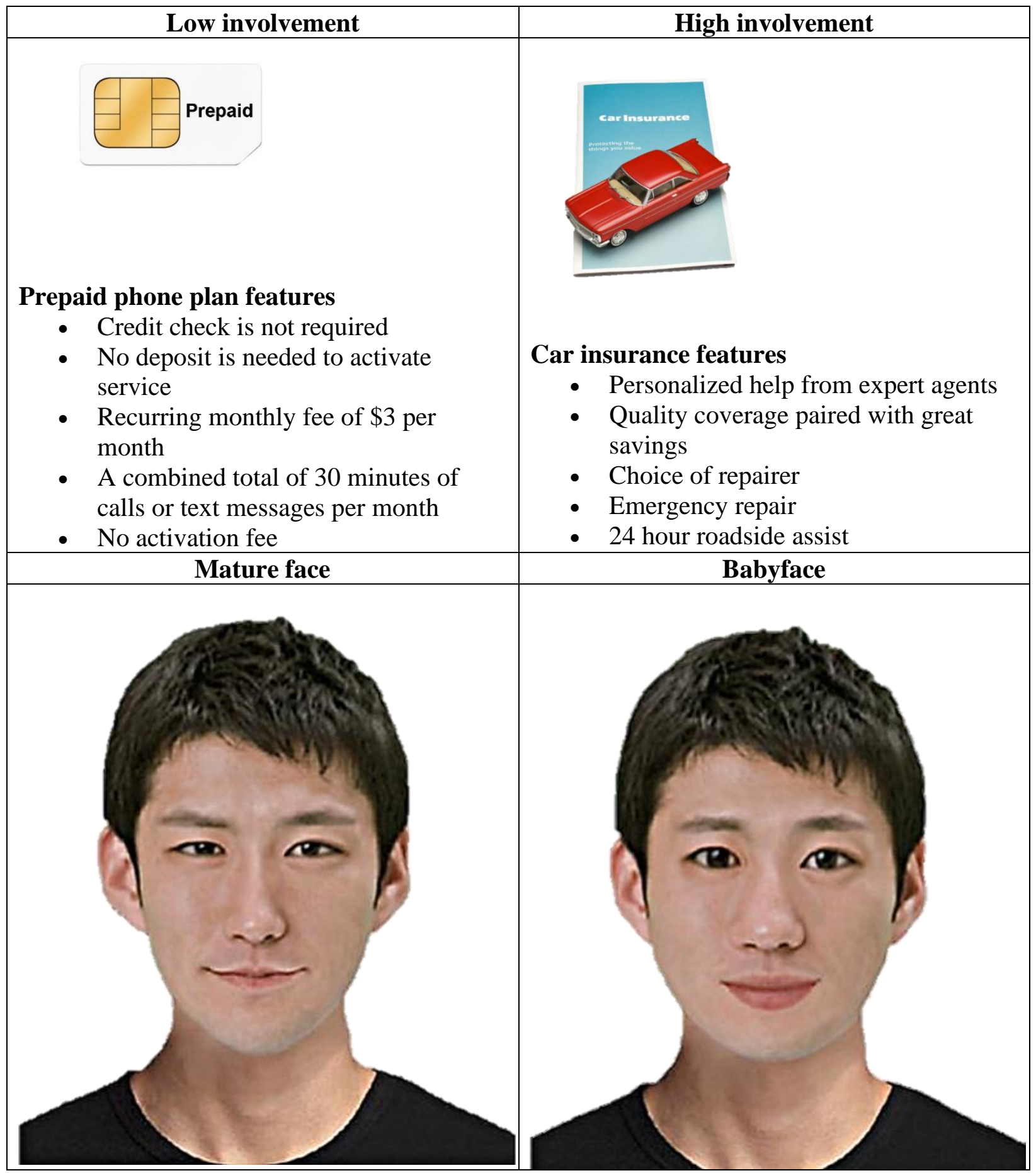


Online engagement. The current experimental study examined the online engagement by having participants respond to the following questions adapted from Maxham and Netemeyer (2002) to an online shopping context: (a) How likely are you to write an online review about the item? (b) How likely are you to post about the item online? (c) How likely are you to write an online review about the salesperson?, (d) How likely are you to post about the salesperson online? $(1=$ Extremely unlikely, 7 = extremely likely $)$.

Attitude toward the salesperson. Participants indicated their attitudes toward the salesperson based on the salesperson's appearance with using a seven-point scale $(1=$ bad, $7=$ good) adapted from Smith et al. (2007).

\section{Results}

To assess whether online engagement differs across salesperson's face types (babyfaced vs. maturefaced) and the purchase involvement (high vs. low), I ran an ANCOVA on online engagement as the dependent variable, with the face type, purchase involvement, and their interaction as the independent variables, and with attitude toward the salesperson as the covariate. The results revealed no main effects of either the face type $(F(1,326)=.002, p=.96)$ or purchase involvement $(F(1,326)=1.51, p=.22)$. However, importantly, there was a significant two-way interaction between face type and purchase involvement $(F(1,326)=7.97 p$ $=.01$ ) (see fig. 3). In the low involvement condition, maturefaced salesperson is less likely to induce online engagement than the babyfaced salesperson $\left(M_{\text {babyface }}=5.17\right.$ vs. $M_{\text {matureface }}=4.74$; $F(1,326)=3.94, p=.05)$. On the other hand, in the high involvement condition, maturefaced salesperson is more likely to induce online engagement than the babyfaced salesperson ( $M_{\text {babyface }}$ $=4.55$ vs. $\left.M_{\text {matureface }}=4.99 ; F(1,326)=4.02, p=.05\right)($ see Fig. 7$)$. 
The results of the study demonstrated that online engagement could vary depending on the service that a babyfaced salesperson was selling. I found that when a babyfaced salesperson sells a low involvement service, consumers are more likely to engage. On the other hand, the findings demonstrated when a babyfaced salesperson sells a high involvement service, consumers are less likely to engage, supporting hypothesis 3.

Figure 7. Study 2: Moderation effect of involvement on the relationship between salesperson face type and online engagement

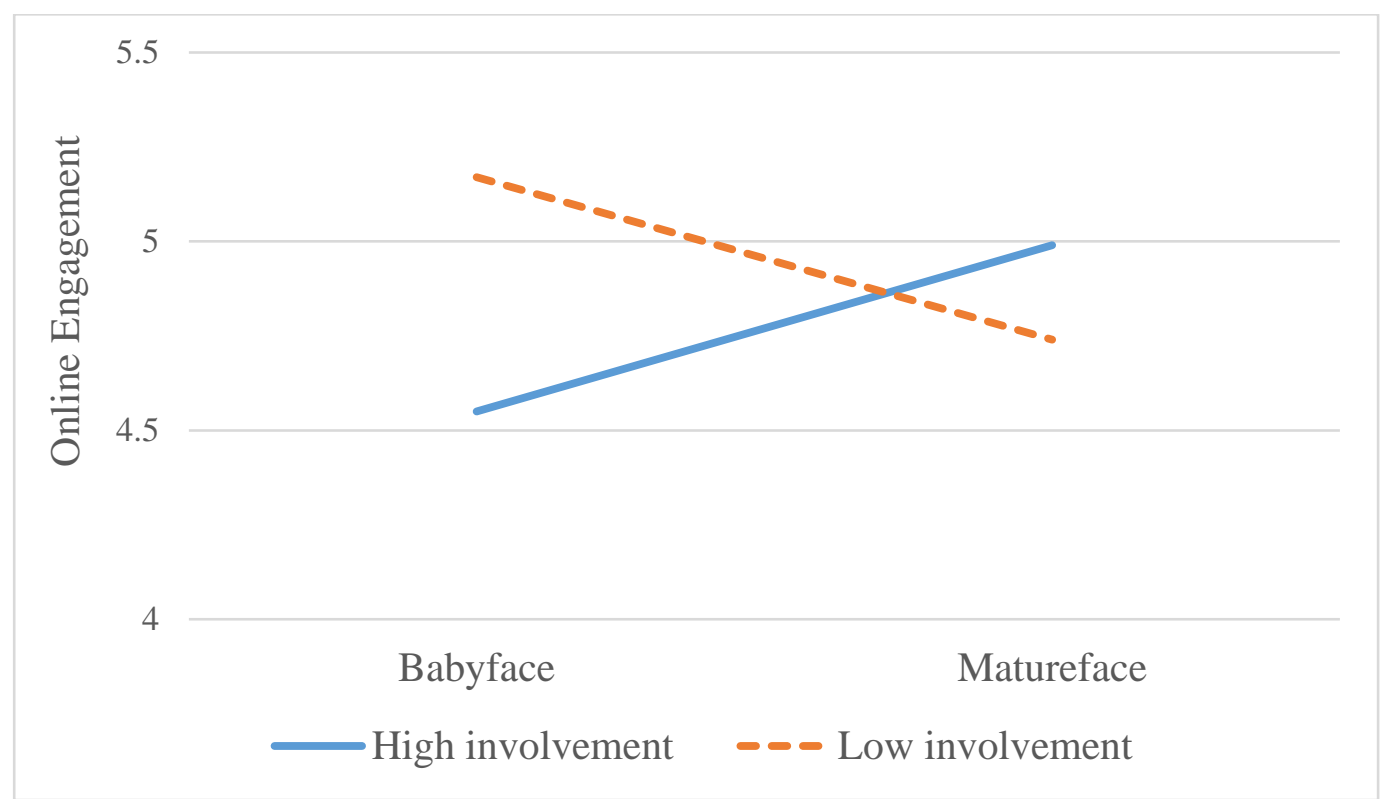

\section{General Discussion}

Study 1 explored real-world salespeople's profile pictures and the number of their online consumer reviews from Zillow.com to empirically test whether babyface impacts online engagement. The findings demonstrate that babyfaced salespeople induce less online engagement (i.e., online consumer review) than maturefaced salespeople on Zillow.com. 
However, salespeople's babyface's negative effect on online engagement was not as pronounced for saleswomen (vs. salesmen). Moreover, I test the effect with an experimental study in Study 2 and find that salespeople's babyface negatively affects online engagement in sales of a high involvement service but positively affects online engagement in sales of a low involvement service.

\section{Theoretical Contributions}

The current research contributes to service marketing literature by documenting a negative association between babyface and online engagement in services (Johnson et al., 2021). Whereas the various impacts of salespeople's and service professional's appearance have been explored (Verbeke et al., 2011; Vinchur et al., 1998), this study represents the first attempt to investigate the babyface overgeneralization effect on online engagement. Consistent with the chronic effects of babyface in various contexts (Zheng et al., 2016), the current research shows that babyface effects are also pervasive in the service contexts. In particular, the current research explores how salespeople's babyface induces less online engagement by utilizing real-world data and an experimental study.

Additionally, this work contributes to babyface literature (Chang and Chen, 2015; Zebrowitz et al., 1991; Zheng et al., 2016). Significantly, the current work extends the research stream by identifying two rarely explored moderators that attenuate the effects of a babyface. First, the results empirically demonstrate that babyface's negative influence is quite pronounced for a male salesperson but not as much for a female counterpart (Zebrowitz, 1997/2018). Also, the present research identifies that purchase involvement (high vs. low) moderates the effect of salespeople's babyface on online engagement. The findings may also benefit other disciplines that focus on stereotyping and social-psychological effects, such as psychology and 
management, as the current research broadens literature on babyface to service and sales literature (Livingston and Pearce, 2009; Zheng et al., 2018).

\section{Methodological Contribution}

The current work adds to the marketing literature by initiating a new methodology. This is the first study that investigates real-world salespeople's online profile pictures by utilizing an artificial intelligence facial recognition API to the best of my knowledge. Thus, the current paper aims to stimulate a methodological discussion by employing artificial intelligence-based technologies and real-world archival data. This unique approach allowed me to analyze thousands of images from Zillow.com in a short period. Besides, artificial intelligence-based technology provides more systematic and objective results than a survey or experiment would have (Russell, 1997; Russell and Norvig, 2009; Winston, 1992). In sum, the current work shows the use of artificial intelligence-based technology to test hypotheses as a new opportunity for marketing scholars.

\section{Managerial Implications}

Our research has important practical implications for vast online service industries such as Zillow.com or Freelancer.com and salespeople who want to encourage online consumer engagement. Salespeople's appearance has been shown to be one of the critical factors that affect online engagement and beyond, as consumers often judge salespeople's characteristics based on their appearance (Ahearne et al., 1999; Lin et al, 2018). Amid COVID-19, an online profile picture is the first one that consumers might find when they look for salespeople or service providers.

Our research identifies that salespeople should be encouraged to look more mature to enhance online engagement when consumers are highly involved in a service purchase process. 
On the other hand, they should be encouraged to look more babylike to enhance online engagement when consumers are not highly engaged in the service purchase process. The current work provides insights for babyfaced salespeople to consider applying different outfits, glasses, and makeup to make themselves look more mature to induce online engagement (Lieber-Milo and Nittono, 2019; Tung et al., 2019). Unlike physical attractiveness that could be highly subjective, babyface (vs. matureface) is a universally agreed upon and standardized facial feature (Hildebrandt and Fitzgerald, 1978). Thus, the negative association between salespeople's babyface and online engagement in high involvement sales should not be culture or age-specific, and thus salespeople can apply the suggestions from the present study regardless of their consumer segments (Berry and Landry, 1997; Glocker et al., 2009; McArthur and Berry, 1987).

\section{Limitations and Future Research Directions}

The present work aimed to shed light on the effects of babyface on online engagement, extending to various research directions. Although the current study extends the service marketing and sales literature in multiple ways, the study still has limitations. The current research attempts to gain both internal and external validity by using real-world data and experimental study. However, I was unable to obtain some information from the real-world data such as salespeople's years of experience. In addition, the online engagement number based on the Zillow.com realworld dataset was positively skewed, as top real estate agents induced hundreds of online consumer reviews, while most of other less successful agents did not have many online consumer reviews. Nonetheless, the results with robustness checks by using Poisson regression model still show that the harmful effect of babyface on online engagement (Anderson and Simester, 2008). In addition, the present study was only able to use three features that are 
associated with a high baby schema with the facial recognition artificial intelligent API. Thus, future research might be able to measure babyface more accurately.

\section{Conclusion}

In conclusion, the present study documents the harmful effect of babyface on online engagement, particularly for high involvement service sales. Consequently, the current research contributes to the personal selling literature by advancing the literature on antecedents of online engagement. This study indicates that babyfaced salespeople perform worse than maturefaced counterparts on Zillow.com by using an artificial intelligence facial recognition API to examine salespeople's babyface objectively. The current research hopes that it provides direction and variable insights for future research to utilize artificial intelligence-based technology and explore various impacts of salespeople's appearance in sales contexts. 


\section{References}

Agnihotri, R. (2020), "Social media, customer engagement, and sales organizations: A research agenda", Industrial Marketing Management, Vol. 90, pp. 291-299.

Agnihotri, R., Dingus, R., Hu, M. Y., and Krush, M. T. (2016), “Social media: Influencing customer satisfaction in B2B sales", Industrial Marketing Management, Vol. 53, pp. 172180.

Agnihotri, R., Mani, S., Chaker, N. N., Daugherty, P. J., and Kothandaraman, P. (2020), "Drivers and Performance Implications of Frontline Employees' Social Capital Development and Maintenance: The Role of Online Social Networks", Decision Sciences.

Ahearne, M., Gruen, T. W., and Jarvis, C. B. (1999), "If looks could sell: Moderation and mediation of the attractiveness effect on salesperson consumer engagement", International Journal of Research in Marketing, Vol. 16 No. 4, pp. 269284.

Ambady, N., and Rosenthal, R. (1993), "Half a minute: Predicting teacher evaluations from thin slices of nonverbal behavior and physical attractiveness", Journal of Personality and Social Psychology, Vol. 64 No. 3, p. 431.

Anderson, E. T. and Simester, D. I. (2008), "Research note—does demand fall when customers perceive that prices are unfair? The case of premium pricing for large sizes", Marketing Science, Vol. 27 No.3, pp. 492-500.

Bar, M., Neta, M., and Linz, H. (2006), “Very first impressions”, Emotion, Vol. 6 No. 2, p. 269.

Berry, D. S., and Brownlow, S. (1989), "Were the physiognomists right? Personality correlates of facial babyishness", Personality and Social Psychology Bulletin, Vol. 15 No. 2, pp. 266-279. 
Berry, D. S., and Landry, J. C. (1997), "Facial maturity and daily social interaction”, Journal of Personality and Social Psychology, Vol. 72 No. 3, p. 570.

Berry, D. S., and McArthur, L. Z. (1985), "Some components and consequences of a babyface", Journal of Personality and Social Psychology, Vol. 48 No. 2, p. 312.

Borgi, M., Cogliati-Dezza, I., Brelsford, V., Meints, K., and Cirulli, F. (2014), "Baby schema in human and animal faces induces cuteness perception and gaze allocation in children", Frontiers in Psychology, Vol. 5, p. 411.

Brodie, R. J., Ilic, A., Juric, B., and Hollebeek, L. (2013), "Consumer engagement in a virtual brand community: An exploratory analysis", Journal of Business Research, Vol. 66 No. 1, pp. 105-114.

Buckley, R. C. (2016), “Aww: The emotion of perceiving cuteness”, Frontiers in Psychology, Vol. 7, p. 1740.

Burton, A. M., Bruce, V., and Dench, N. (1993), "What's the difference between men and women? Evidence from facial measurement", Perception, Vol. 22 No. 2, pp. 153-176.

Catlin, T., Harrison, L., Plotkin, C. L., and Stanley, J. (2016), "How B2B digital leaders drive five times more revenue growth than their peers", McKinsey and Company.

Chaker, N. N., Walker, D., Nowlin, E. L., and Anaza, N. A. (2019), "When and how does sales manager physical attractiveness impact credibility: A test of two competing hypotheses", Journal of Business Research, Vol. 105, pp. 98-108.

Chang, C. T., and Chen, C. X. (2015), "Babyface effects: A double-edged sword in healthcare service evaluations", Asian Journal of Social Psychology, Vol. 18 No. 4, pp. 325-336. 
Chang, C. T., Huang, G. H., and He, M. L. (2018, May), "Cuteness Makes the Sale? How Consumer Responses are Affected by Message Framing and Crowding”, In Academy of Marketing Science Annual Conference (pp. 363-373), Springer, Cham.

Chang, C. T., Lee, Y. K., and Cheng, Z. H. (2017), "Baby face wins? Examining election success based on candidate election bulletin via multilevel modeling", Asian Journal of Social Psychology, Vol. 20 No. 2, pp. 97-112.

Chiao, J.Y., Bowman, N.E. and Gill, H. (2008), “The political gender gap: Gender bias in facial inferences that predict voting behavior", PloS one, Vol. 3 No. 10, p. e3666.

Cialdini, R. B. (1984), The Psychology of Persuasion. New York: Quill William Morrow. DeBruine, L. M. (2002), "Facial resemblance enhances trust", Proceedings of the Royal Society of London. Series B: Biological Sciences, Vol. 269 No. 1498, pp. 1307-1312.

Dion, K., Berscheid, E., and Walster, E. (1972), "What is beautiful is good", Journal of Personality and Social Psychology, Vol. 24 No. 3, p. 285.

Dunlap, W. P., and Kemery, E. R. (1987), "Failure to detect moderating effects: Is multicollinearity the problem?", Psychological Bulletin, Vol. 102 No. 3, pp. 418-420.

Efran, M. G. (1974), “The effect of physical appearance on the judgment of guilt, interpersonal attraction, and severity of recommended punishment in a simulated jury task", Journal of Research in Personality, Vol. 8 No. 1, pp. 45-54.

Eigenraam, A. W., Eelen, J., Van Lin, A., and Verlegh, P. W. (2018), “A consumer-based taxonomy of digital customer engagement practices", Journal of Interactive Marketing, Vol. 44, pp. 102-121.

Farmer, H., and Tsakiris, M. (2012), "The bodily social self: a link between phenomenal and narrative selfhood", Review of Philosophy and Psychology, Vol. 3 No. 1, pp. 125-144. 
Fergurson, J. R. (2017), “Self-Image Congruence: An Empirical Look at Consumer Behavior in Door-to-Door Sales!”, Journal of Managerial Issues, Vol. 29 No. 3, pp. 262-277.

Fiske, S. T. (1998), Stereotyping, prejudice, and discrimination. The handbook of social psychology, Vol. 2 No. 4, pp. 357-411.

Foo, Y. Z., Simmons, L. W., and Rhodes, G. (2017), "Predictors of facial attractiveness and health in humans", Scientific Reports, Vol. 7.

Friedman, H., and Zebrowitz, L. A. (1992), "The contribution of typical sex differences in facial maturity to sex role stereotypes", Personality and Social Psychology Bulletin, Vol. 18, pp. 430-438.

Gibler, K. and Nelson, S. (2003), "Consumer behavior applications to real estate education", Journal of Real Estate Practice and Education, Vol. 6 No. 1, pp. 63-83.

Gibson, J. J. (2014), The ecological approach to visual perception: classic edition, Psych Press, New York and London.

Glocker, M. L., Langleben, D. D., Ruparel, K., Loughead, J. W., Gur, R. C., and Sachser, N. (2009), "Baby schema in infant faces induces cuteness perception and motivation for caretaking in adults", Ethology, Vol. 115 No. 3, pp. 257-263.

Goldstein, A. G., Chance, J. E., and Gilbert, B. (1984), "Facial stereotypes of good guys and bad guys: A replication and extension", Bulletin of the Psychonomic Society, Vol. 22 No. 6, pp. 549-552.

Gorn, G. J., Jiang, Y., and Johar, G. V. (2008), "Babyfaces, trait inferences, and company evaluations in a public relations crisis", Journal of Consumer Research, Vol. 35 No. 1, pp. 36-49. 
Griffin, A. M., and Langlois, J. H. (2006), "Stereotype directionality and attractiveness stereotyping: Is beauty good or is ugly bad?", Social Cognition, Vol. 24 No. 2, pp. 187206.

Guesalaga, R. (2016), “The use of social media in sales: Individual and organizational antecedents, and the role of customer engagement in social media”, Industrial Marketing Management, Vol. 54, pp. 71-79.

Hair, J. F. (2009), Multivariate Data Analysis (7th ed), Upper Saddle River: Prentice Hall. Hartmann, N. N. and Lussier, B. (2020), "Managing the sales force through the unexpected exogenous COVID-19 crisis”, Industrial Marketing Management, Vol. 88, pp. 101-111.

Henderson, J. M., Falk, R., Minut, S., Dyer, F. C., and Mahadevan, S. (2001), “Gaze control for face learning and recognition by humans and machines", In fragments to objects: segmentation and grouping in vision, edited by Shipley, T., and P. Kellman, pp. 463-481, Amsterdam: Elsevier.

Hildebrandt, K. A., and Fitzgerald, H. E. (1978), “Adults' responses to infants varying in perceived cuteness", Behavioural Processes, Vol. 3 No. 2, pp. 159-172.

Hollebeek, L.D., Smith, D.L.G., Kasabov, E., Hammedi, W., Warlow, A. and Clark, M.K. (2020), “Customer brand engagement during service lockdown”, Journal of Services Marketing.

Holliman, G., and Rowley, J. (2014), “Business to business digital content marketing: marketers' perceptions of best practice", Journal of Research in Interactive Marketing.

Holton, N. E., Yokley, T. R., Froehle, A. W., and Southard, T. E. (2014), “Ontogenetic scaling of the human nose in a longitudinal sample: implications for genus Homo facial evolution", American Journal of Physical Anthropology, Vol. 153 No. 1, pp. 52-60. 
Houston, V., and Bull, R. (1994), "Do people avoid sitting next to someone who is facially disfigured?", European Journal of Social Psychology, Vol. 24 No. 2, pp. 279-284.

Jack, R. E., and Schyns, P. G. (2015), “The human face as a dynamic tool for social communication”, Current Biology, Vol. 25 No. 14, pp. R621-R634.

Johnson, C., Kaski, T., Karsten, Y., Alamäki, A. and Stack, S. (2021), “The role of salesperson emotional behavior in value proposition co-creation", Journal of Services Marketing.

Johnson, J. S., and Sohi, R. S. (2017), “Getting business-to-business salespeople to implement strategies associated with introducing new products and services", Industrial Marketing Management, Vol. 62, pp. 137-149.

Jones, D., Brace, C. L., Jankowiak, W., Laland, K. N., Musselman, L. E., Langlois, J. H., ... and Symons, D. (1995), "Sexual selection, physical attractiveness, and facial neoteny: crosscultural evidence and implications [and comments and reply]", Current Anthropology, Vol. 36 No. 5, pp. 723-748.

Karpen, I. O. and Conduit, J. (2020), "Engaging in times of COVID-19 and beyond: theorizing customer engagement through different paradigmatic lenses”, Journal of Service Management.

Khan, I., Hollebeek, L.D., Fatma, M., Islam, J.U. and Rahman, Z. (2019), “Brand engagement and experience in online services", Journal of Services Marketing, Vol. 34 No. 2, pp. $163-175$.

Kuenzel, J. and Musters, P. (2007), "Social interaction and low involvement products", Journal of Business Research, Vol. 60 No. 8, pp. 876-883. 
Kumar, V., Aksoy, L., Donkers, B., Venkatesan, R., Wiesel, T., and Tillmanns, S. (2010), "Undervalued or overvalued customers: capturing total customer engagement value", Journal of Service Research, Vol. 13 No. 3, pp. 297-310.

Lane, N. and Crane, A. (2002), "Revisiting gender role stereotyping in the sales profession”, Journal of Business Ethics, Vol. 40 No. 2, pp. 121-132.

Li, Y., Xie, L., Gao, T. and Guan, X., (2019), "Does being beautiful always help? Contingency effects of physical attractiveness of the service providers on customer response", Journal of Services Marketing. Vol. 33 No. 3, pp. 356

Lieber-Milo, S., and Nittono, H. (2019), "How the Japanese Term Kawaii Is Perceived Outside of Japan: A Study in Israel”, SAGE Open, Vol. 9 No. 3, 2158244019869904.

Lin, L., Hoegg, J., and Aquino, K. (2018), "When beauty backfires: the effects of server attractiveness on consumer taste perceptions", Journal of Retailing, Vol. 94 No. 3, pp. 296-311.

Little, A. C. (2014), "Facial attractiveness", Wiley Interdisciplinary Reviews: Cognitive Science, Vol. 5 No. 6, pp. 621-634.

Liu, A. H., and Leach, M. P. (2001), "Developing loyal customers with a value-adding sales force: Examining customer satisfaction and the perceived credibility of consultative salespeople”, Journal of Personal Selling and Sales Management, Vol. 21 No. 2, pp. 147156.

Livingston, R. W., and Pearce, N. A. (2009), “The teddy-bear effect: Does having a baby face benefit black chief executive officers?", Psychological Science, Vol. 20 No. 10, pp. 12291236. 
Lorenz, K. (1943), “Die angeborenen formen möglicher erfahrung”, Zeitschrift für Tierpsychologie, Vol. 5 No. 2, pp. 235-409.

Marsh, A.A., Adams Jr, R.B. and Kleck, R.E. (2005), "Why do fear and anger look the way they do? Form and social function in facial expressions", Personality and Social Psychology Bulletin, Vol. 31 No. 1, pp. 73-86.

Maxham III, J. G., and Netemeyer, R. G. (2002), “A longitudinal study of complaining customers' evaluations of multiple service failures and recovery efforts", Journal of Marketing, Vol. 66 No. 4, pp. 57-71.

McArthur, L. Z., and Berry, D. S. (1987), "Cross-cultural agreement in perceptions of babyfaced adults", Journal of Cross-cultural Psychology, Vol. 18 No. 2, pp. 165-192.

McColl, R., and Truong, Y. (2013), "The effects of facial attractiveness and gender on customer evaluations during a web-video sales encounter", Journal of Personal Selling and Sales Management, Vol. 33 No. 1, pp. 117-128.

McElroy, J. C., and DeCarlo, T. E. (1999), "Physical attractiveness on cognitive evaluations of saleswomen's consumer engagement", Journal of Marketing Theory and Practice, Vol. 7 No. 1, pp. 84-100.

Olivola, C. Y., Funk, F., and Todorov, A. (2014), "Social attributions from faces bias human choices", Trends in Cognitive Sciences, Vol. 18 No. 11, pp. 566-570.

Pansari, A., and Kumar, V. (2017), "Customer engagement: the construct, antecedents, and consequences", Journal of the Academy of Marketing Science, Vol. 45 No, 3, pp. 294311.

Paunonen, S. V., Ewan, K., Earthy, J., Lefave, S., and Goldberg, H. (1999), "Facial features as personality cues", Journal of Personality, Vol. 67 No. 3, pp. 555-583. 
Penton-Voak, I. S., and Chen, J. Y. (2004), "High salivary testosterone is linked to masculine male facial appearance in humans", Evolution and Human Behavior, Vol. 25 No. 4, pp. 229-241.

Petty, R. E., Cacioppo, J. T., and Schumann, D. (1983), “Central and peripheral routes to advertising effectiveness: The moderating role of involvement", Journal of Consumer Research, Vol. 10 No. 2, pp. 135-146.

Piercy, N. F., Cravens, D. W., and Lane, N. (2009), "Sales management control level and competencies: Antecedents and consequences", Industrial Marketing Management, Vol. 38 No. 4, pp. 459-467.

Poutvaara, P., Jordahl, H., and Berggren, N. (2009), "Faces of politicians: Babyfacedness predicts inferred competence but not electoral success", Journal of Experimental Social Psychology, Vol. 45 No. 5, pp. 1132-1135.

Reingen, P. H., and Kernan, J. B. (1993), "Social perception and interpersonal influence: Some consequences of the physical attractiveness stereotype in a personal selling setting”, Journal of Consumer Psychology, Vol. 2 No. 1, pp. 25-38.

Rezlescu, C., Duchaine, B., Olivola, C. Y., and Chater, N. (2012), "Unfakeable facial configurations affect strategic choices in trust games with or without information about past behavior", PloS one, Vol. 7 No. 3, p. e34293.

Ricks, Jr, J. M., Williams, J. A., and Weeks, W. A. (2008), "Sales trainer roles, competencies, skills, and behaviors: A case study", Industrial Marketing Management, Vol. 37 No. 5, pp. 593-609. 
Rule, N. O., and Ambady, N. (2008), “The face of success: Inferences from chief executive officers' appearance predict company profits”, Psychological Science, Vol. 19 No. 2, pp. 109-111.

Russell, S. and Norvig, P. (2009), Artificial Intelligence: A Modern Approach 3rd edition, Saddle River, NJ: Prentice Hall.

Russell, S. J. (1997), “Rationality and intelligence”, Artificial intelligence, Vol. 94 No. 1-2, pp. 57-77.

Sashi, C. M. (2012), “Customer engagement, buyer-seller relationships, and social media”, Management Decision, Vol. 50 No. 2, pp. 253-272.

Schmid, K., Marx, D., and Samal, A. (2008), "Computation of a face attractiveness index based on neoclassical canons, symmetry, and golden ratios”, Pattern Recognition, Vol. 41 No. 8, pp. $2710-2717$.

Skorska, M. N., Geniole, S. N., Vrysen, B. M., McCormick, C. M., and Bogaert, A. F. (2015), "Facial structure predicts sexual orientation in both men and women", Archives of Sexual Behavior, Vol. 44 No. 5, pp. 1377-1394.

Smith, R. E., MacKenzie, S. B., Yang, X., Buchholz, L. M., and Darley, W. K. (2007), "Modeling the determinants and effects of creativity in advertising", Marketing Science, Vol. 26 No. 6, pp. 819-833.

Stirrat, M., and Perrett, D. I. (2010), "Valid facial cues to cooperation and trust: Male facial width and trustworthiness", Psychological Science, Vol. 21 No, 3, pp. 349-354.

Swaddle, J.P. and Reierson, G.W. (2002), “Testosterone increases perceived dominance but not attractiveness in human males", Proceedings of the Royal Society of London. Series B: Biological Sciences, Vol. 269 No. 1507, pp. 2285-2289. 
Tung, C.W., Qie, N. and Rau, P.L.P., (2019), “Exploring Semantic Space for Kawaii Design”, In International Conference on Human-Computer Interaction, pp. 583-591. Springer, Cham.

Verbeke, W., Dietz, B., and Verwaal, E. (2011), “Drivers of sales performance: a contemporary meta-analysis. Have salespeople become knowledge brokers?", Journal of the Academy of Marketing Science, Vol. 39 No. 3, pp. 407-428.

Viglia, G., Pera, R., and Bigné, E. (2018), “The determinants of stakeholder engagement in digital platforms", Journal of Business Research, Vol. 89, pp. 404-410.

Vinchur, A. J., Schippmann, J. S., Switzer III, F. S., and Roth, P. L. (1998), “A meta-analytic review of predictors of job consumer engagement for salespeople", Journal of Applied Psychology, Vol. 83 No. 4, p. 586.

Vivek, S. D., Beatty, S. E., and Morgan, R. M. (2012), “Customer engagement: Exploring customer relationships beyond purchase", Journal of Marketing Theory and Practice, Vol. 20 No. 2, pp. 122-146.

Wan, L. C., and Wyer Jr, R. S. (2015), “Consumer reactions to attractive service providers: Approach or avoid?", Journal of Consumer Research, Vol. 42 No. 4, pp. 578-595.

Wang, Y., Hong, A., Li, X. and Gao, J. (2020), "Marketing innovations during a global crisis: A study of China firms' response to COVID-19", Journal of Business Research, Vol. 116, pp. 214-220.

Wang, Z., Mao, H., Li, Y. J., and Liu, F. (2017), "Smile big or not? Effects of smile intensity on perceptions of warmth and competence", Journal of Consumer Research, Vol. 43 No. 5, pp. $787-805$. 
Wilson, R. K., and Eckel, C. C. (2006), “Judging a book by its cover: Beauty and expectations in the trust game", Political Research Quarterly, Vol. 59 No. 2, pp. 189-202.

Winston, P. (1992), Artificial Intelligence, Reading, MA: Addison-Wesley.

Xie, G. X., and Kahle, L. R. (2014), “Approach or avoid? The effect of regulatory focus on consumer behavioural responses to personal selling attempts”, Journal of Personal Selling and Sales Management, Vol. 34 No. 4, pp. 260-271.

Youn, S., and Kim, H. (2018), “Temporal duration and attribution process of cause-related marketing: Moderating roles of self-construal and product involvement", International Journal of Advertising, Vol. 37 No. 2, pp. 217-235.

Zaichkowsky, J. L. (1985), "Measuring the involvement construct”, Journal of Consumer Research, Vol. 12 No. 3, pp. 341-352.

Zebrowitz, L. (1997/2018), Reading faces: Window to the soul?. Routledge.

Zebrowitz, L. A. (1996), "Physical appearance as a basis of stereotyping”, Stereotypes and Stereotyping, pp. 79-120.

Zebrowitz, L. A., and Franklin Jr, R. G. (2014), “The attractiveness halo effect and the babyface stereotype in older and younger adults: similarities, own-age accentuation, and older adult positivity effects", Experimental Aging Research, Vol. 40 No. 3, pp. 375-393.

Zebrowitz, L. A., and Montepare, J. M. (2008), "Social psychological face perception: Why appearance matters", Social and Personality Psychology Compass, Vol. 2 No. 3, pp. 1497-1517.

Zebrowitz, L. A., Olson, K., and Hoffman, K. (1993), "Stability of babyfaceness and attractiveness across the life span", Journal of Personality and Social Psychology, Vol. 64 No. 3, p. 453. 
Zebrowitz, L. A., Tenenbaum, D. R., and Goldstein, L. H. (1991), “The impact of job applicants' facial maturity, gender, and academic achievement on hiring recommendations", Journal of Applied Social Psychology, Vol. 21 No. 7, pp. 525-548.

Zebrowitz, L.A. and McDonald, S.M. (1991), “The impact of litigants' baby-facedness and attractiveness on adjudications in small claims courts", Law and human behavior, Vol. 15 No. 6, pp.603-623.

Zhang, T., Lu, C., Torres, E. and Chen, P. J. (2018), "Engaging customers in value co-creation or co-destruction online", Journal of Services Marketing, Vol. 32 No. 1, pp. 57-69.

Zheng, W., Luo, T., Hu, C. P., and Peng, K. (2018), “Glued to which face? Attentional priority effect of female babyface and male mature face", Frontiers in Psychology, Vol. 9, p. 286.

Zheng, W., Yang, Q., Peng, K., and Yu, F. (2016), "What's in the Chinese babyface? Cultural differences in understanding the babyface", Frontiers in Psychology, Vol. 7, p. 819.

Zhou, Y., Lu, S., and Ding, M. (2020), “Contour-as-Face Framework: A Method to Preserve Privacy and Perception", Journal of Marketing Research.

Zillow (2016), "Review Guidelines”, available at: https://www.zillow.com/z/info/reviewguidelines/ (accessed June 29, 2020)

Zillow (2020), “Zillow 101: Past and Recent Sales”, available at: https://www.zillow.com/agentresources/blog/zillow-101-past-and-recent-sales/ (accessed August 31, 2020) 


\section{Appendices}

Appendix A

100 randomly selected zip codes

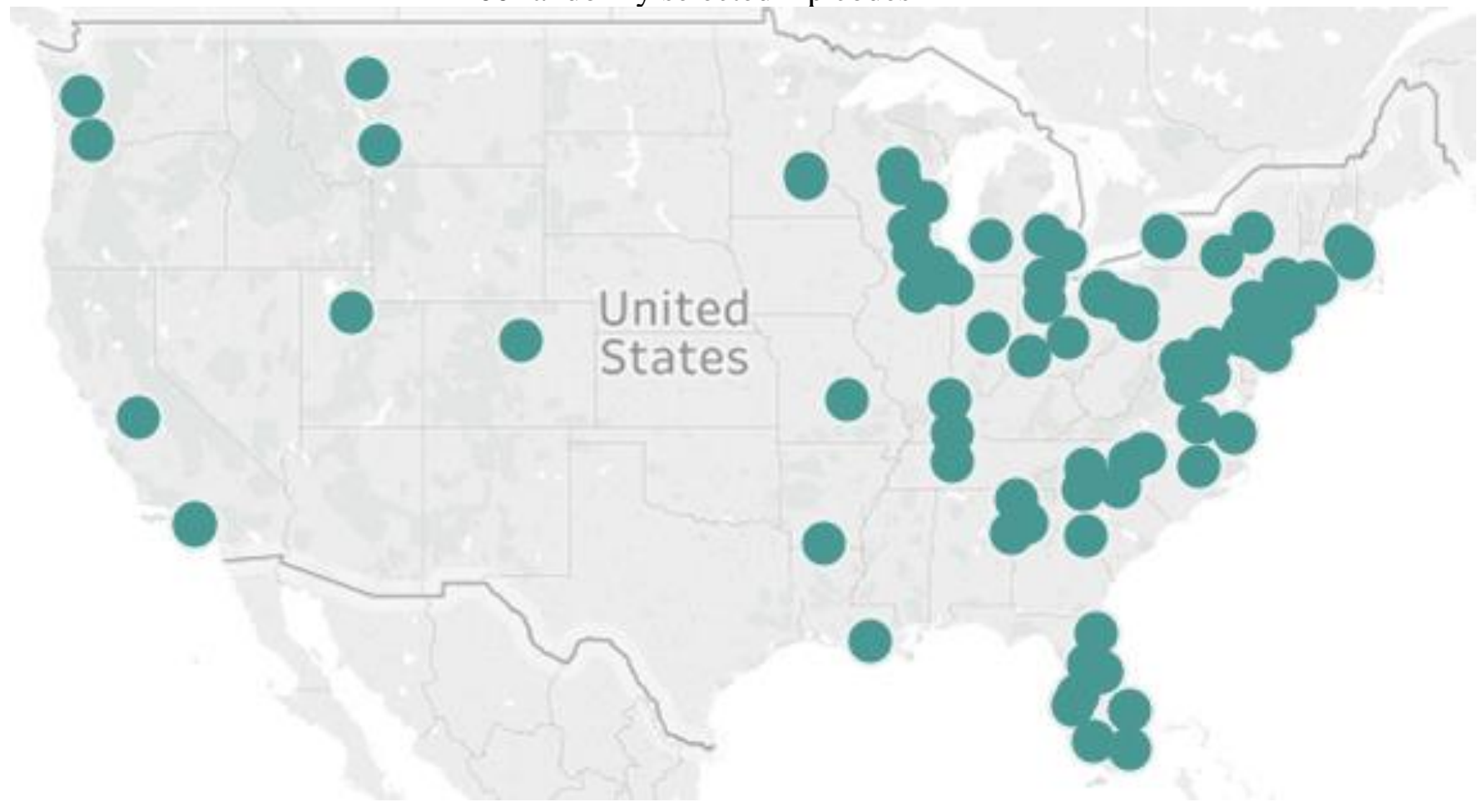


Appendix B

27-point facial landmarks from Microsoft Azure

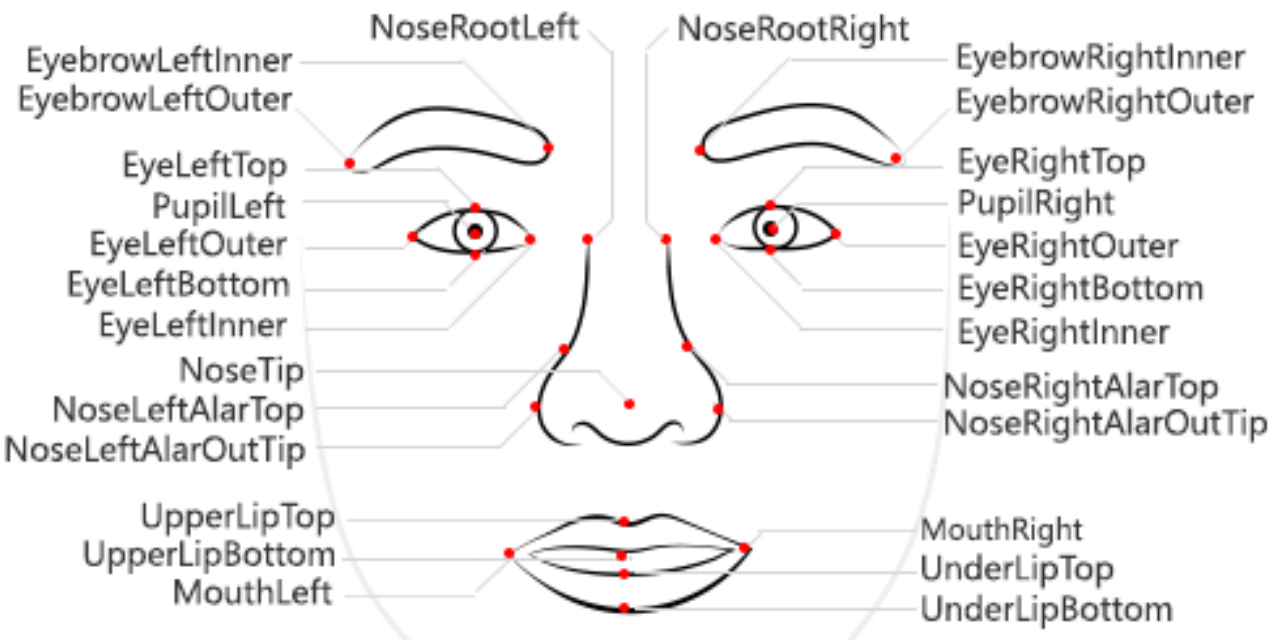


Appendix C

Examples of facial recognition analyses

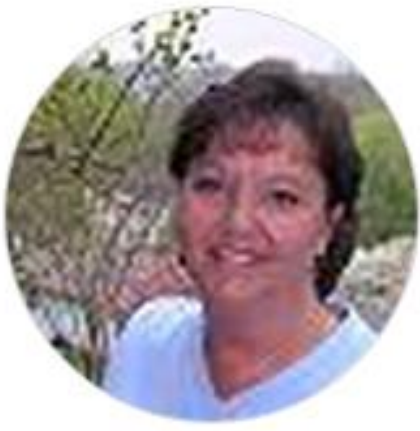

Unsuccessful facial recognition analysis

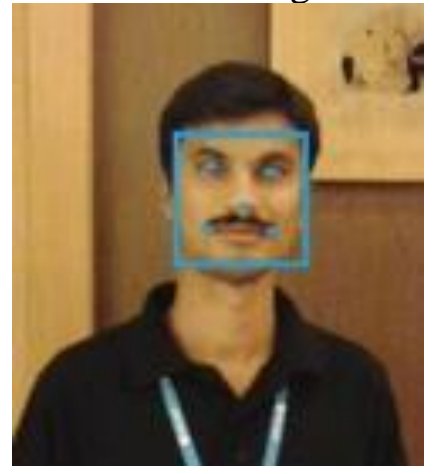

Successful facial recognition analysis 


\section{Appendix D}

Babyface illustration and babyface index

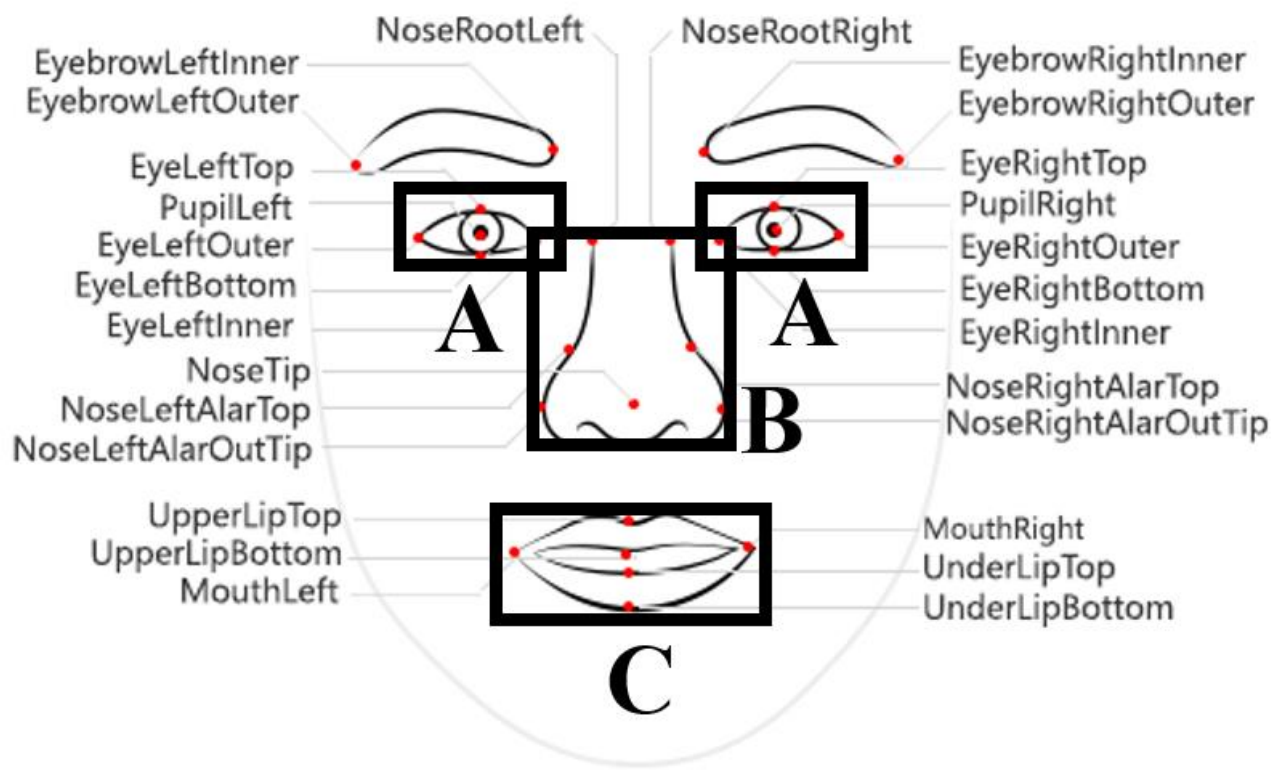

(A) Proportion of the eyes $=(($ Eye width_right*Eye length_right $)+($ Eye width_left*Eye length_left))/2

1. Eye width_right: $\operatorname{sqrt}\left((\text { eyeRightOuter.x-eyeRightInner.x })^{\wedge} 2+(\right.$ eyeRightOuter.yeyeRightInner.y $\left.)^{\wedge} 2\right) /($ faceRectangle.height*faceRectangle.width)

2. Eye length_right: $\operatorname{sqrt}\left((\text { eyeRightTop.x- eyeRightBottom.x })^{\wedge} 2+\right.$ eyeRightTop.yeyeRightBottom.y $\left.)^{\wedge} 2\right) /($ faceRectangle.height*faceRectangle.width)

3. Eye width_left: sqrt((eyeLeftOuter.x-eyeLeftInner.x $)^{\wedge} 2+($ eyeLeftOuter.yeyeLeftInner.y $\left.)^{\wedge} 2\right) /($ faceRectangle.height*faceRectangle.width)

4. Eye length_left: $\operatorname{sqrt}\left((\text { eyeLeftTop.x- eyeLeftBottom.x })^{\wedge} 2+(\right.$ eyeLeftTop.yeyeLeftBottom.y $\left.)^{\wedge} 2\right) /($ faceRectangle.height*faceRectangle.width)

(B) Proportion of the nose $=(($ Nose width $) *($ Nose height $)) / 2$

1. Nose width: $\operatorname{sqrt}\left((\text { noseLeftAlarOutTip.x-noseRightAlarOutTip.x })^{\wedge} 2+\right.$ (noseLeftAlarOutTip.ynoseRightAlarOutTip.y $\left.)^{\wedge} 2\right) /($ faceRectangle.height*faceRectangle.width)

2. Nose height: $\operatorname{sqrt}\left((\text { nosemid.x- noseTip. } x)^{\wedge} 2+(\right.$ nosemid.ynoseTip.y $\left.)^{\wedge} 2\right) /($ faceRectangle.height* faceRectangle.width)

(C) Proportion of the mouth $=$ Mouth width*Mouth height

1. Mouth width: $\operatorname{sqrt}\left((\text { mouthLeft.x-mouthRight. } x)^{\wedge} 2+(\right.$ mouthLeft.ymouthRight.y $\left.)^{\wedge} 2\right) /($ faceRectangle.height*faceRectangle.width)

2. Mouth height: $\operatorname{sqrt}\left((\text { upperLipTop.x-underLipBottom.x })^{\wedge} 2+(\right.$ upperLipTop.yunderLipBottom.y $\left.)^{\wedge} 2\right) /($ faceRectangle.height*faceRectangle.width) 


\section{Appendix E}

A facial attractiveness index

\begin{tabular}{|c|c|}
\hline Facial symmetry & Neoclassical cannons \\
\hline 1. Eyes symmetry & 4. Interocular distance $=$ right eye width \\
\hline $\begin{array}{c}-\mid(\text { noserootleft.x-eyeleftouter.x }) /(\text { eyerightouter.x - } \\
\text { noserootright.x })-1 \mid\end{array}$ & $\begin{array}{c}-\mid(\text { eyerightinner.x- } \\
\text { eyeleftinner.x }) /(\text { eyerightouter.x - } \\
\text { eyerightinner.x })-1 \mid\end{array}$ \\
\hline 2. Nasal symmetry & 5. Interocular distance $=$ left eye width \\
\hline $\begin{array}{c}-\mid(\text { nosetip.x- } \\
\text { noseleftalarouttip.x)/(noserightalarouttip.x - } \\
\text { nosetip.x })-1 \mid\end{array}$ & $\begin{array}{c}-\mid(\text { eyerightinner.x- } \\
\text { eyeleftinner.x)/(eyeleftinner.x - } \\
\text { eyeleftouter.x })-1 \mid\end{array}$ \\
\hline 3. Lip symmetry & 6. Mouth width $=1.5$ nosewidth \\
\hline \multirow[t]{3}{*}{$\begin{array}{c}-\mid(\text { upperlipbottom.x-mouthleft.x }) /(\text { mouthright.x - } \\
\text { upperlitbottom.x })-1 \mid\end{array}$} & $\begin{array}{c}-\mid \text { (mouthright.x- } \\
\text { mouthleft.x)/1.5(noserightalarouttip.x - } \\
\text { noseleftalarouttip.x })-1 \mid\end{array}$ \\
\hline & 7. Interocular distance $=$ nose width \\
\hline & $\begin{array}{c}-\mid(\text { eyerightinner.x- } \\
\text { eyeleftinner.x)/(noserightalarouttip.x - } \\
\text { noseleftalarouttip.x })-1 \mid\end{array}$ \\
\hline
\end{tabular}

Note: The value closer to 0 indicates higher attractiveness (Schmid et al. 2008) 


\section{Essay 3: Cute Voice: Definition and Conceptualization}

\section{Introduction}

From young children asking their parents for snacks to adults negotiating for deals, individuals regularly use their voices to communicate with others. In the marketplace, marketers, brand managers, salespeople, robots and even virtual assistants use their voices to inform and communicate with consumers (Peterson 1995; Shiomi et al. 2013). For example, salespeople usually respond by using their voice when a consumer asks about a newly launched laptop in the store. Likewise, in virtual settings, Google Assistant, Amazon Alexa, and Apple Siri also reply to consumers' requests with their voices (Deighton 2021; Google Assistant Help 2020).

Although consumers are exposed to different voices constantly, the literature on the effects of voice on consumer behavior has been scarce (Lowe et al. 2018). Importantly, voice also affects individuals' perception of others (Surawski and Ossoff 2006). For example, politicians with lower-pitched voice are perceived as more attractive and receive more votes (Tigue et al. 2012). Consequently, the current research aims to explore a type of voice with evolutionary importance - cute voice, which I define as quality of voice being attractive in a childlike, youthful, or adorable way (Borkowska and Pawlowski 2011; Kuraguchi et al. 2015). Prior studies on cuteness have shown that cuteness has evolutionary importance because younglings have developed certain features inducing the perception of cuteness to gain adults' support and help (Hildebrandt and Fitzgerald 1979; Hinde and Barden 1985). Accordingly, adults respond to cuteness features that enhance offspring survival (Glocker et al. 2009). Thus, a number of studies have recently shown significant biological, emotional and behavioral effects of cuteness induced by visual cuteness stimuli that Nobel Laureate Konrad Lorenz proposed 
(1943). For example, exposure to visual cuteness stimuli evokes heartwarming emotion and modulates multiple brain regions (Glocker et al. 2009; Steinnes et al. 2019).

While previous studies on cuteness have mostly focused on the physical appearance of cuteness in which visual stimuli induce the perception of cuteness (Borgi and Cirulli 2016; Schnurr 2019), individuals might also perceive cuteness through other senses (Kringelbach et al., 2016; Shin and Mattila 2021). Thus, in the current study, I aim to find the answer to the question regarding what makes a voice sound cute? To answer this question, I define cute voice and test the antecedents of cute voice.

Notably, the current research adds to the emerging literature on cuteness by conceptualizing, and proposing antecedents of cute voice (Parsons et al. 2011; Schnurr 2019). Cuteness has evolutionary importance for offspring survival, and thus exposure to it changes brain activities, emotions, behaviors, and biological responses (Buckley 2016; Holly et al. 2017). However, to the best of my knowledge, this is the first study that defines cute voice and examines the antecedents of it with a controlled experimental study. Especially, understanding antecedents of cute voice is critical to further discovering its consequences in consumer behavior, given the importance of behavioral and biological influences of cuteness (Buckley 2016; Nenkov and Scott 2014). The next section discusses the theoretical background and hypotheses.

\section{What is Cute Voice?}

\section{Theoretical Background}

Consistent with previous literature, the present paper defines cute voice as a quality of voice being attractive in a childlike, youthful or adorable way (Hellen and Sääksjärvi 2011). For the evolutionary purpose, younglings have developed a variety of childlike features that assist them to gain support from adults, and adults have responded to the younglings with those features 
accordingly (Buckley 2016; Miesler et al. 2011). As a result, children's unique physical appearance, smell, and sound facilitate compassion, caregiving behavior, and activate a region of the midbrain (Darwin 1877; Parsons et al. 2014; Kringelbach et al. 2016).

For the physical appearance of cuteness, Lorenz proposed the concept of baby schema, which is a set of childlike physical appearances, including large and round eyes, a round face, and a small head-to-body ratio (Lorenz 1943). Since then, a large number of studies have shown that baby schema induces the perception of cuteness and its effect on changes in behaviors, brain activities and emotions (Esposito et al. 2014; Lorenz 1943). Although previous studies have consistently shown that visual baby schema induces the perception of cuteness and its effects, little is known about auditory stimuli which induce the perception of cuteness (Borgi et al. 2014; Lv et al. 2021; Shin and Mattila 2021).

People perceive similar traits from voices and faces that share similarities (Young et al. 2020). For example, both masculine faces and voices are perceived as strong and dominant (Neave and Shields 2008; Wolff and Puts 2010), whereas both childlike faces and voices are perceived as weak, submissive, naive, honest, warm and incompetent (Berry and McArthur 1985; Berry 1990; Berry 1992; Gorn et al. 2008; Montepare and Zebrowitz-McArthur 1987; Zebrowitz-McArthur and Montepare 1989). Both higher facial and vocal maturity are positively associated with perceived dominance and less agreeableness, which are opposite traits of children (Zuckerman et al. 1995).

A recent theoretical development called multimodal hypothesis argues that multiple stimuli including sight, sound or smell of infants facilitate caregiving behaviors (Kringelbach et al. 2016). Drawing on the multimodal hypothesis, individuals might also recognize the perception of cuteness through multiple senses (Parsons et al. 2013; Porter et al. 1983). 
Moreover, a recent empirical study has shown that individuals indicated infants' laughing sounds and baby animals' images as cute (Shin and Mattila 2021). Besides, individuals exhibited prosocial behaviors after exposure to cute sounds or cute images (Shin and Mattila 2021).

Based on the aforementioned arguments, I expect that individuals will perceive childlike voice as cute because people perceive childlike appearances as cute (Baumann and Hadelich 2003; Borkowska and Pawlowski 2011; Shigeno 2017; Zebrowitz-McArthur and Montepare 1989). Additionally, building on the multimodal hypothesis, I also expect that both childlike visual and auditory stimuli will induce similar perceptions (Kringelbach et al. 2016; Shin and Mattila 2021).

Despite the scholarly interest in cuteness and its effects elicited by visual stimuli (Glocker et al. 2009; Scott and Nenkov 2016), I am not aware of any study that systematically examined whether certain vocal elements induce the perception of cuteness (Nenkov and Scott 2016; Wang et al. 2017). Thus, to fill the gap, the present research proposes that vocal elements that are associated with the characteristics of children's voices yield the perception of cute voice (Moore 1991). More specifically, I posit that the two vocal elements, higher pitch and faster tempo, yield the perception of cute voice.

\section{Pitch and Tempo}

Pitch. Many studies have shown that there is a definite relationship between pitch and body size (Mondloch et al. 2004; Walker et al. 1985). Pitch refers to the highness and lowness of voice (Patel and Balaban 2001). Pitch and the body size of the object producing voice are negatively correlated (Bien et al. 2012). Thus, not surprisingly, children generally have a higher voice pitch than adults, as children have smaller larynxes than adults do (Moore 1991; Zuckerman et al. 1995). Voice comes from the larynx, the muscular organ located halfway down of the neck 
(Cunningham 1903). The larynx manipulates pitches and volumes (Zhang 2019), and the bigger the larynx is, the deeper and thicker the voice is (Dowshen 2015).

When children grow older, their voices become deeper and heavier because their larynxes grow bigger. Consequently, individuals perceive others with higher-pitched voices as childlike young and immature (Collins and Missing 2003; Zebrowitz-McArthur and Montepare 1989). On the other hand, individuals perceive others with deeper and heavier pitched voices as mature (Zuckerman et al. 1995). As I mentioned earlier, people perceive traits that are associated with childlikeness as cute (Glocker et al. 2009). Thus, I expect that the individuals perceive highpitched voice cuter than low-pitched voice.

\section{H1. Higher pitch is positively associated with cute voice.}

Tempo. Similar to that of the pitch, there might be a relationship between tempo and the perceived cuteness of voice. Tempo refers to a person's speaking rate or rate of speech within a given amount of time (Markel et al. 1973). Individuals' tempo varies depending on speakers' age, gender, dialect, language, articulatory energy, importance of contexts, emotions and perceptual clarity for listeners (Banse and Scherer 1996; Spieler and Griffin 2006; Verhoeven et al. 2004). In particular, individuals' age is negatively correlated to their speech tempo due to the aging process (Smith et al. 1987).

A number of studies have shown that younglings speak faster than older adults (Burke et al. 1991; Quené 2007). Aging makes people become slower, and the physical conditions of older adults make them more likely to make errors when they speak and they are more likely to fail word retrieval (Barresi et al. 2000; Feyereisen et al 1998). As a result, older adults tend to speak slower than younglings in general (Jacewicz et al. 2009). As I mentioned previously, people perceive traits representing youthfulness as cute (Gross 1997). Thus, I posit that individuals 
perceive voice with fast tempo as cute, because fast tempo indicates childlikeness (Horton et al. 2010).

\section{H2. Faster tempo is positively associated with cute voice.}

\section{Methodology and Findings}

This experimental study seeks evidence for hypotheses 1 and 2 that the two vocal elements, higher pitch and faster tempo, individually elicit the perception of cute voice. In this study, participants are asked to choose a cuter voice between twelve pairs of voice choices. I predict that participants choose higher pitch voice as cuter than lower pitch voice, and faster tempo voice as cuter than slower tempo voice.

\section{Method}

Seventy-eight adults were recruited from Amazon Mechanical Turk to participate in the study for monetary payment. Participants first listened to the voice reading four numbers to test their speakers and indicated the numbers to which they listened. Participants who indicated the correct numbers they listened to could continue to participate in the study. I used a text-to-speech online app, NaturalReader, to obtain six voice clips that were either female or male voice reading one of the three phrases. The three phrases included "an apple a day keeps the doctor away", "actions speak louder than words", and "don't judge a book by its cover" (Bloom et al. 1999). NaturalReader makes available about 10 male and 10 female voice options. I chose the Guy's voice option for the male voice, and I chose the Jessa's voice option for the female voice, because their voices sound more natural than the others.

After I downloaded MP3 voice files from NaturalReader, I converted them to WAV files because WAV files are uncompressed (Arbour 2011). I either increased or decreased the tempo or the pitch of each voice clip by using Audacity software. The manipulations of pitch or tempo 
of each voice clip result in twenty-four voice clips ( 2 genders of voice (male vs. female) x 3 phrases ("apple keeps a doctor away" vs. "actions speak louder than words" vs. "don't judge a book by its cover") x 2 vocal elements (pitch vs. tempo) x 2 manipulations (high vs. low)).

Cuteness Manipulation. I manipulated the obtained voice clips to produce $15 \%$ higher (vs. lower) pitch or $20 \%$ faster (vs. slower) tempo voices using Audacity software.

Cute Voice Choice. To assess cute voice, I asked participants to choose a cuter voice between two voice choices. Participants read the statement, "Please listen to the following two audio clips and select the one that sounds cuter. Feel free to listen to these clips as many times as you need to make a choice," and listened to a pair of two voice choices presented in random order. After participants listened to two voice choices, they chose a voice clip that sounds cuter than the other one. Each participant listened to the twelve paired voices and chose cuter vice twelve times in total.

\section{Results and Discussion}

Seventy-eight adults from Amazon Mechanical Turk participated in the study $(57.7 \%$

female; $\left.M_{\mathrm{age}}=42.29\right)$. As predicted, participants indicated that higher pitch voices $(89.1 \%)$ sounded cuter than lower pitch voices $\left(10.9 \%\right.$; difference $=89.1 \% \chi^{2}(1, N=468)=$ 286.231, $p<.001$ ) (see Figure 8). In addition, participants indicated that faster tempo voices $(56.4 \%)$ sounded cuter than slower tempo voices $\left(43.6 \%\right.$; difference $=12.8 \%, \chi^{2}(1, N=468)=$ 7.69, $p=.01)($ see Figure 9). 
Figure 8. Study 1: The effect of pitch on the perception of cute voice

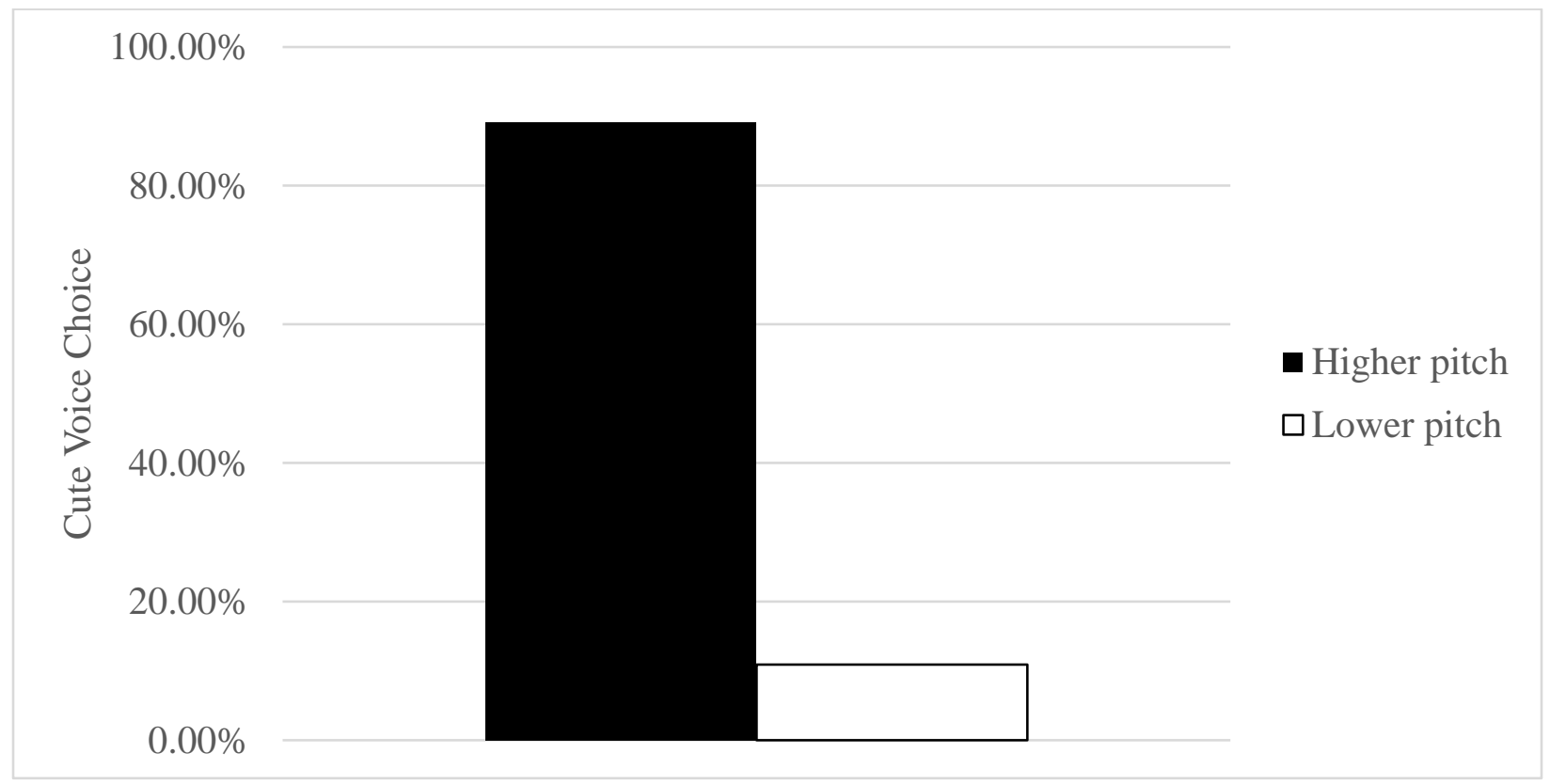

Figure 9. Study 1: The effect of tempo on the perception of cute voice

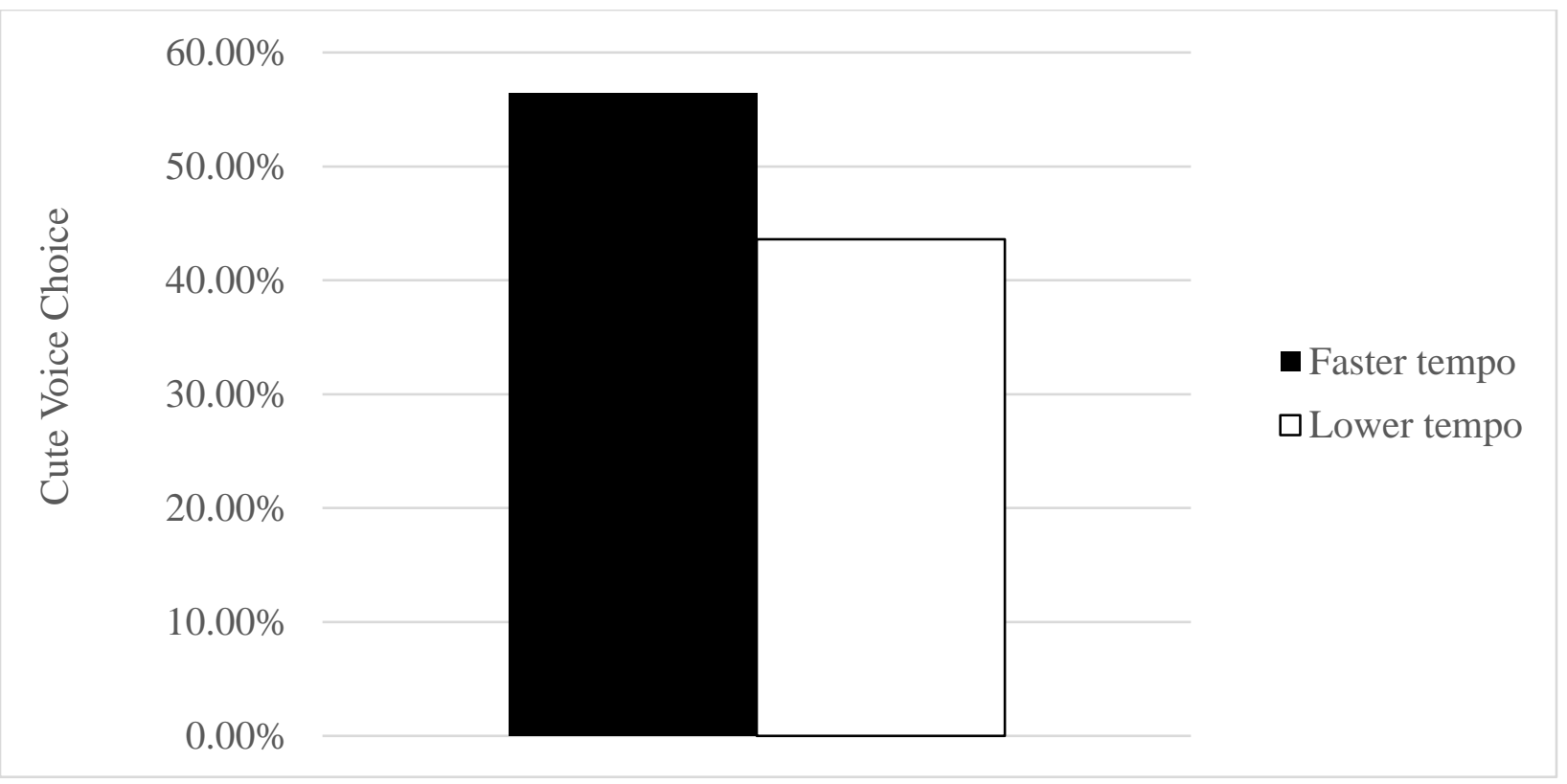

Participants' cute voice choice was further examined via generalized estimating equations to test the effects of tempo and pitch on cute voice choice. As expected, analyses revealed main effects of pitch $\left(\chi^{2}(1, N=468)=59.57, p<.001\right)$, and tempo $\left(\chi^{2}(1, N=468)=5.63, p=.02\right)$ on cute voice choice even after controlling for the genders of voice, phrases, and their interactions. 
These results suggest that a higher pitch and a faster tempo voice leads to the perception of cute voice, in support of hypotheses 1 and 2.

\section{General Discussion}

This research defines cute voice and investigates the antecedents of cute voice. Building on the findings from previous research that childlike traits such as baby schema lead to the perception of cuteness, I propose that voice with high pitch and fast tempo creates the perception of cute voice. An empirical study provides evidence for this theorizing by using both male and female voices speaking various phrases. The present theorizing and findings contribute to the understanding of consumer behavior and provide several practical implications.

\section{Theoretical Contributions}

The present research proposes a novel construct, cute voice that induces the perception of cuteness through auditory cues and examines the antecedents of cute voice. Thus, the current study contributes to the growing literature on cuteness by adding a new dimension of cuteness (Lee et al. 2018; Schnurr 2019). Nobel laureate Konrad Lorenz proposed baby schema - a set of babyish visual stimuli that create the perception of cuteness. Since then, studies on cuteness have shown various effects of cuteness involving visual cuteness stimuli (Batra et al. 2015; Glocker et al. 2009; Lorenz 1943). For instance, individuals who view cute images become more physically careful and more indulgent (Nenkov and Scott 2014; Sherman et al. 2013). Although recent research speculated auditory cuteness cues (Shin and Mattila 2021), none of the previous studies has systematically and empirically explored auditory cuteness stimuli that create the perception of cuteness. The current study extends such inquiry to define cute voice: a sound that creates the perception of cuteness, and proposed antecedents of cute voice. 
The current study also broadens the literature on auditory marketing and sensory marketing in consumer behavior by illustrating auditory stimuli that induce the perception of cuteness (André et al. 2016; Chattopadhyay et al. 2003; Ludden and Schifferstein 2007; Jung et al. 2017). Previous studies on auditory marketing have shown the significant effects of auditory stimuli on consumers' emotions and behavior (Lowe et al. 2018; Kellaris 2008). Although consumers are consistently exposed to sounds, consumer behavior studies involve auditory stimuli have been scarce, and the majority of consumer behavior research still involves visual stimuli (Grewal et al. 2019; Smith et al. 2020; Wu et al. 2017). To fill the void, the current study defines and proposes auditory stimuli that create the perception of cuteness that has evolutionary importance. As far as I know, this is the first study that examines the link between vocal elements, tempo and pitch, and cuteness.

\section{Practical Implications}

Research findings from this study indicate that voices with a higher pitch and faster tempo induce the perception of cuteness. Understanding auditory cuteness stimuli can assist businesses to attempt to use the stimuli to induce effects of cuteness in various contexts (Glocker et al. 2009; Nenkov and Scott 2014).

First, the current study has important managerial implications for marketers and advertisers. Advertisers can easily utilize the findings on the antecedents of cute voice to manipulate voice to sound cute in their advertisements (North et al. 2004). Findings in the current study suggest that an advertiser can simply manipulate any voice to sound cuter by increasing pitch and/or tempo. For example, advertisers interested in launching an advertisement campaign similar to Erste's cute Christmas advertisement can increase the pitch and/or tempo of advertisement characters' voices to make them sound cuter (Erste Group 2018). 
In addition, the findings on the antecedents of cute voice will assist new product developers. Product developers for AI assistants and robots can manipulate their voices to be cuter or less cute depending on their functions by simply increasing (vs. decreasing) pitch and/or tempo (Niculescu et al. 2013; McGinn and Torre 2019). For example, a robotic product developer for cute entertainment robots such as Cozmo can increase the pitch and the tempo of a robot's voice to match its functions and voices (Pierce 2016). On the other hand, a robotic product developer for military robots such as Atlas can decrease the pitch and/or the tempo of a robot's voice to reinforce the threatening perception of the military robot (Wall 2013).

The current research can also assist salespeople in consumer engagement and sales performance (Ogilvie et al. 2018; Peterson et al. 1995). Findings from this research would suggest that if salespeople want to be perceived as cute, they can easily speak faster and use higher-pitched voices when communicating with consumers. For example, drawing on the findings from the second essay, salespeople selling low involvement services such as prepaid phone plans can manipulate their voices to have a higher pitch and a faster tempo than usual to increase consumer engagement. On the other hand, salespeople selling high involvement services such as real estate or car insurance can manipulate their voices to have a lower pitch and a slower tempo than usual to increase consumer engagement.

\section{Limitations and Future Research Directions}

While the current study introduces and defines cute voice and its antecedents, there are many potential future extensions of the present work. First of all, future studies can explore the consequences of exposure to cute voice. Also, future studies can be conducted in a real-world setting with non-hypothetical scenarios. The current study only tested the hypotheses in a 
controlled experimental setting. However, a field study would uncover whether the findings are adjustable and generalizable in a real-world setting.

Previous literature on cuteness involving visual cuteness stimuli has shown two dimensions of cuteness, which are baby schema cuteness and whimsical cuteness (Lee et al. 2018; Scott and Nenkov 2016). While exposure to baby schema cuteness elicits prosocial and caretaking responses (Glocker et al. 2009; Shin and Mattila 2021), exposure to whimsical cuteness induces indulging behavior (Nenkov and Scott 2014). However, the current study did not take the different dimensions of cuteness into account. Thus, future studies can explore whether auditory cuteness also has different dimensions similar to the distinct dimensions that previous studies using visual cuteness stimuli have shown (Ahmed Rizvi et al. 2018; Schnurr 2019).

One might expect that auditory cuteness stimuli also induce similar effects of cuteness triggered by visual cuteness stimuli (Parsons et al. 2014; Kringelbach et al., 2016). A recent study has found both visual cuteness stimuli and auditory cuteness stimuli increase prosocial behavior (Shin and Mattila 2021). Thus, it would be interesting to test whether exposure to auditory cuteness stimuli also increases careful behavior (Glocker et al. 2009), indulging behavior (Nenkov and Scott 2014), and narrows attentional focus (Nittono et al. 2012). Furthermore, future studies can explore multisensory marketing effects by testing the interaction effects of visual cuteness stimuli and auditory cuteness stimuli (Joy and Sherry 2003; Spence et al. 2014; Yoganathan et al.2019). It would be meaningful to test whether the effects of cuteness are strengthened or weakened when multiple cuteness stimuli are used simultaneously.

In the first essay, I found the positive effect of visual cuteness stimuli on risk-seeking behavior. Similarly, future studies can explore the relationship between auditory cuteness stimuli 
and risk preference, and test whether auditory cuteness stimuli also increase risk-seeking behavior. Previous risk preference literature has rich findings on various risk-seeking antecedents, including individuals’ personalities and traits (Gambetti and Giusberti 2012; Nicholson et al. 2005; Mitchell 1999; Kim 2010). For example, studies have shown that promotion-focused or positive individuals are more likely to take risk (Grable and Roszkowski 2008; Loewenstein and Lerner 2003; Zou et al. 2014). While a majority of studies on risk preference have focused on individuals' inherited characteristics as antecedents of risk-seeking behavior (Bruyneel et al. 2009; Donohew et al. 2000), future studies can look at auditory cuteness stimuli as an antecedent of risk-seeking behavior. 


\section{References}

Ahmed Rizvi, S., G Moore, S., \& Richard Messinger, P. (2018). G4. That's So Sweet: Baby Cuteness Semantically Activates Sweetness to Increase Sweet Food Preference. ACR North American Advances.

André, V., Petr, C., André, N., Hausberger, M., \& Lemasson, A. (2016). Voice features of telephone operators predict auditory preferences of consumers. Interaction Studies, 17(1), 70-90.

Arbour, G. (2011, Feb 9). When to use .WAV files - when to use MP3 files? What is the difference between the two formats?. The Beat. Retrieved from https://www.premiumbeat.com/blog/when-to-use-wav-files-when-to-use-mp3-files-whatis-the-difference-between-the-two-formats

Banse, R., \& Scherer, K. R. (1996). Acoustic profiles in vocal emotion expression. Journal of personality and social psychology, 70(3), 614.

Batra, R., Seifert, C., \& Brei, D. (Eds.). (2015). The psychology of design: Creating consumer appeal. Routledge.

Baumann, S., \& Hadelich, K. (2003). Accent type and givenness: an experiment with auditory and visual priming. Proceedings of the 15th ICPhS, Barcelona, Spain, 1811-1814.

Berry, D. S. (1990). Vocal attractiveness and vocal babyishness: Effects on stranger, self, and friend impressions. Journal of Nonverbal Behavior, 14(3), 141-153.

Berry, D. S. (1992). Vocal types and stereotypes: Joint effects of vocal attractiveness and vocal maturity on person perception. Journal of Nonverbal Behavior, 16(1), 41-54.

Berry, D. S., \& McArthur, L. Z. (1985). Some components and consequences of a babyface. Journal of Personality and Social Psychology, 48(2), 312. 
Bien, Nina, Sanne ten Oever, Rainer Goebel, and Alexander T. Sack (2012), "The Sound of Size: Crossmodal Binding in Pitch-Size Synesthesia: A Combined TMS, EEG and Psychophysics Study,” NeuroImage, 59 (1), 663-72.

Block, S., \& Kellen, D. (1996). Speech rates of Australian English-speaking children and adults. Australian Journal of Human Communication Disorders, 24, 39-44.

Bloom, K., Zajac, D. J., \& Titus, J. (1999). The influence of nasality of voice on sex-stereotyped perceptions. Journal of Nonverbal Behavior, 23(4), 271-281.

Borgi, M., \& Cirulli, F. (2016). Pet face: Mechanisms underlying human-animal relationships. Frontiers in psychology, 7, 298.

Borgi, M., Cogliati-Dezza, I., Brelsford, V., Meints, K., \& Cirulli, F. (2014). Baby schema in human and animal faces induces cuteness perception and gaze allocation in children. Frontiers in Psychology, 5, 411.

Borkowska, B., \& Pawlowski, B. (2011). Female voice frequency in the context of dominance and attractiveness perception. Animal Behaviour, 82(1), 55-59.

Bruyneel, S. D., Dewitte, S., Franses, P. H., \& Dekimpe, M. G. (2009). I felt low and my purse feels light: Depleting mood regulation attempts affect risk decision making. Journal of Behavioral Decision Making, 22(2), 153-170.

Buckley, R. C. (2016). Aww: The emotion of perceiving cuteness. Frontiers in Psychology, 7 , 1740.

Chattopadhyay, A., Dahl, D. W., Ritchie, R. J., \& Shahin, K. N. (2003). Hearing voices: The impact of announcer speech characteristics on consumer response to broadcast advertising. Journal of Consumer Psychology, 13(3), 198-204. 
Collins, S. A., \& Missing, C. (2003). Vocal and visual attractiveness are related in women. Animal Behaviour, 65(5), 997-1004.

Cunningham, D. J. (Ed.). (1903). Text-book of Anatomy. William Wood.

Deighton, K. (2021, Feb 24). Tech Firms Train Voice Assistants to Understand Atypical Speech. The Wall Street Journal. Retrieved from https://www.wsj.com/articles/tech-firms-trainvoice-assistants-to-understand-atypical-speech-11614186019

Donohew, L., Zimmerman, R., Cupp, P. S., Novak, S., Colon, S., \& Abell, R. (2000). Sensation seeking, impulsive decision-making, and risky sex: Implications for risk-taking and design of interventions. Personality and individual differences, 28(6), 1079-1091.

Dowshen, S. (2015). Your Changing Voice. KidsHealth, Retrieved from https://kidshealth.org/en/kids/changingvoice.html\#: :text=As\%20you\%20go\%20through\%20puberty,lasts $\% 20$ only $\% 20 \mathrm{a} \% 20 \mathrm{few}$ $\% 20$ months

Erste Group (2018). Erste Christmas Ad 2018: What would Christmas be without love?. Retrieved from https://www.youtube.com/watch?v=Icx7hBWeULM

Esposito, G., Nakazawa, J., Ogawa, S., Stival, R., Kawashima, A., Putnick, D. L., \& Bornstein, M. H. (2014). Baby, you light-up my face: culture-general physiological responses to infants and culture-specific cognitive judgements of adults. PloS one, 9(10), e106705.

Gambetti, E., \& Giusberti, F. (2012). The effect of anger and anxiety traits on investment decisions. Journal of Economic Psychology, 33(6), 1059-1069.

Glocker, M. L., Langleben, D. D., Ruparel, K., Loughead, J. W., Gur, R. C., \& Sachser, N. (2009). Baby schema in infant faces induces cuteness perception and motivation for caretaking in adults. Ethology, 115(3), 257-263. 
Google Assistant Help (2021). Choose the voice of your Google Assistant. Retrieved from https://support.google.com/assistant/answer/7544506?co=GENIE.Platform\%3DAndroid\& $\mathrm{hl}=\mathrm{en}-\mathrm{GB}$

Gorn, G. J., Jiang, Y., \& Johar, G. V. (2008). Babyfaces, trait inferences, and company evaluations in a public relations crisis. Journal of Consumer Research, 35(1), 36-49.

Grable, J. E., \& Roszkowski, M. J. (2008). The influence of mood on the willingness to take financial risks. Journal of Risk Research, 11(7), 905-923.

Grewal, L., Hmurovic, J., Lamberton, C., \& Reczek, R. W. (2019). The self-perception connection: Why consumers devalue unattractive produce. Journal of Marketing, 83(1), 89-107.

Gross, T. F. (1997). Children's perception of faces of varied immaturity. Journal of Experimental Child Psychology, 66(1), 42-63.

Hellen, K., \& Sääksjärvi, M. (2013). “Development of a Scale Measuring Childlike Anthropomorphism in Products," Journal of Marketing Management, 29(1-2), 141-57.

Hildebrandt, K. A., \& Fitzgerald, H. E. (1979). Adults' perception of infant sex and cuteness. Sex Roles, 5, 471-481.

Hinde, R. A., \& Barden, L. A. (1985). The evolution of the teddy bear. Animal Behaviour, 33, $1371-1373$.

Holly, R., Christine, E. P., Katherine, S. Y., Goodacre, T. E., Kringelbach, M. L., Bonaiuto, J. J., .. \& Murray, L. (2017). Effects of infant cleft lip on adult gaze and perceptions of “cuteness". The Cleft Palate-Craniofacial Journal, 54(5), 562-570.

Jacewicz, E., Fox, R. A., O’Neill, C., \& Salmons, J. (2009). Articulation rate across dialect, age, and gender. Language variation and change, 21(2), 233. 
Joy, A., \& Sherry Jr, J. F. (2003). Speaking of art as embodied imagination: A multisensory approach to understanding aesthetic experience. Journal of Consumer Research, 30(2), $259-282$.

Jung, K., Garbarino, E., Briley, D. A., \& Wynhausen, J. (2017). Blue and red voices: Effects of political ideology on consumers' complaining and disputing behavior. Journal of Consumer Research, 44(3), 477-499.

Kellaris, James J. (2008), “Music and Consumers,” in Marketing and Consumer Psychology Series: Vol. 4: Handbook of Consumer Psychology, ed. Curtis P. Haugtvedt, Paul M. Herr, and Frank R. Kardes, New York: Taylor \& Francis/Erlbaum, 837-856.

Kim, I. (2010). Consumers' rankings of risk reduction strategies in e-shopping. International Journal of Business Research, 10(3), 143-148.

Kringelbach, M. L., Stark, E. A., Alexander, C., Bornstein, M. H., \& Stein, A. (2016). On cuteness: Unlocking the parental brain and beyond. Trends in cognitive sciences, 20(7), $545-558$.

Lee, H. C., Chang, C. T., Chen, Y. H., \& Huang, Y. S. (2018). The spell of cuteness in food consumption? It depends on food type and consumption motivation. Food Quality and Preference, 65, 110-117.

Loewenstein, G., \& Lerner, J. S. (2003). The role of affect in decision making.

Lorenz, Konrad (1943), “Die angeborenen Formen mo“glicher Erfahrung” [The innate forms of potential experience], Zeitschrift für Tierpsychologie, 5, 233-519.

Lowe, M. L., Loveland, K. E., \& Krishna, A. (2019). A quiet disquiet: Anxiety and risk avoidance due to nonconscious auditory priming. Journal of Consumer Research, 46(1), 159-179. 
Ludden, G. D., \& Schifferstein, H. N. (2007). Effects of visual-auditory incongruity on product expression and surprise. International Journal of Design, 1(3).

Lv, X., Liu, Y., Luo, J., Liu, Y., \& Li, C. (2021). Does a cute artificial intelligence assistant soften the blow? The impact of cuteness on customer tolerance of assistant service failure. Annals of Tourism Research, 87, 103114.

MacKay, D. G. (1968). Metamorphosis of a critical interval: Age-linked changes in the delay in auditory feedback that produces maximal disruption of speech. The Journal of the Acoustical Society of America, 43(4), 811-821.

Markel, N. N., Bein, M. F., \& Phillis, J. A. (1973). The relationship between words and tone-ofvoice. Language and Speech, 16(1), 15-21.

McGinn, C., \& Torre, I. (2019, March). Can you tell the robot by the voice? an exploratory study on the role of voice in the perception of robots. In 2019 14th ACM/IEEE International Conference on Human-Robot Interaction (HRI) (pp. 211-221). IEEE.

Miesler, L., Leder, H., \& Herrmann, A. (2011). Isn’t it cute: An evolutionary perspective of babyschema effects in visual product designs. International Journal of Design, 5(3).

Mitchell, V. W. (1999). Consumer perceived risk: conceptualisations and models. European Journal of marketing.

Mondloch, Catherine J. and Daphne Maurer (2004), “Do Small White Balls Squeak? Pitch-Object Correspondences in Young Children," Cognitive, Affective, \& Behavioral Neuroscience, 4(2), 133-136.

Montepare, J. M., \& Zebrowitz-McArthur, L. (1987). Perceptions of adults with childlike voices in two cultures. Journal of Experimental Social Psychology, 23(4), 331-349. 
Moore, R. S. (1991). Comparison of children's and adults' vocal ranges and preferred tessituras in singing familiar songs. Bulletin of the Council for Research in Music Education, 13-22.

Neave, N., \& Shields, K. (2008). The effects of facial hair manipulation on female perceptions of attractiveness, masculinity, and dominance in male faces. Personality and Individual Differences, 45, 373-377

Nenkov, G. Y., \& Scott, M. L. (2014). “So cute I could eat it up": Priming effects of cute products on indulgent consumption. Journal of Consumer Research, 41(2), 326-341.

Nicholson, N., Soane, E., Fenton-O'Creevy, M., \& Willman, P. (2005). Personality and domainspecific risk taking. Journal of Risk Research, 8(2), 157-176.

Niculescu, A., van Dijk, B., Nijholt, A., Li, H., \& See, S. L. (2013). Making social robots more attractive: the effects of voice pitch, humor and empathy. International journal of social robotics, 5(2), 171-191.

Nittono, H., Fukushima, M., Yano, A., \& Moriya, H. (2012). The power of kawaii: Viewing cute images promotes a careful behavior and narrows attentional focus. PloS one, 7(9), e46362.

North, A. C., Mackenzie, L. C., Law, R. M., \& Hargreaves, D. J. (2004). The Effects of Musical and Voice "Fit" on Responses to Advertisements 1. Journal of Applied Social Psychology, 34(8), 1675-1708.

Ogilvie, J., Agnihotri, R., Rapp, A., \& Trainor, K. (2018). Social media technology use and salesperson performance: A two study examination of the role of salesperson behaviors, characteristics, and training. Industrial Marketing Management, 75, 55-65.

Parsons, C. E., Young, K. S., Joensson, M., Brattico, E., Hyam, J. A., Stein, A., ... \& Kringelbach, M. L. (2014). Ready for action: a role for the human midbrain in responding to infant vocalizations. Social cognitive and affective neuroscience, 9(7), 977-984. 
Parsons, C. E., Young, K. S., Kumari, N., Stein, A., \& Kringelbach, M. L. (2011). The motivational salience of infant faces is similar for men and women. PloS one, 6(5), e20632.

Patel, A. D., \& Balaban, E. (2001). Human pitch perception is reflected in the timing of stimulusrelated cortical activity. Nature neuroscience, 4(8), 839-844.

Peterson, R. A., Cannito, M. P., \& Brown, S. P. (1995). An exploratory investigation of voice characteristics and selling effectiveness. Journal of Personal Selling \& Sales Management, 15(1), 1-15.

Pierce, D. (2016). Meet the Smartest, Cutest AI-Powered Robot You've Ever Seen, Retrieved from https://www.wired.com/2016/06/anki-cozmo-ai-robot-toy/

Porter, R. H., Cernoch, J. M., \& McLaughlin, F. J. (1983). Maternal recognition of neonates through olfactory cues. Physiology \& behavior, 30(1), 151-154.

Quené, H. (2007). On the just noticeable difference for tempo in speech. Journal of Phonetics, 35(3), 353-362.

Robb, M., Gilbert, H., Reed, V., \& Bisson, A. (2003). A preliminary study of speech rates in young Australian English-speaking children. Contemporary Issues in Communication Science and Disorders, 30(Spring), 84-91.

Schnurr, B. (2019). Too cute to be healthy: How cute packaging designs affect judgments of product tastiness and healthiness. Journal of the Association for Consumer Research, 4(4), $363-375$.

Scott, M. L., \& Nenkov, G. Y. (2016). Using consumer responsibility reminders to reduce cuteness-induced indulgent consumption. Marketing Letters, 27(2), 323-336. 
Sherman, G. D., Haidt, J., Iyer, R., \& Coan, J. A. (2013). Individual differences in the physical embodiment of care: prosocially oriented women respond to cuteness by becoming more physically careful. Emotion, 13(1), 151.

Shigeno, S. (2017). Effects of Auditory and Visual Priming on the Identification of Spoken Words. Perceptual and Motor Skills, 124(2), 549-563.

Shin, J., \& Mattila, A. S. (2021). Aww effect: Engaging consumers in "non-cute” prosocial initiatives with cuteness. Journal of Business Research, 126, 209-220.

Shiomi, M., Shinozawa, K., Nakagawa, Y., Miyashita, T., Sakamoto, T., Terakubo, T., ... \& Hagita, N. (2013). Recommendation effects of a social robot for advertisement-use context in a shopping mall. International Journal of Social Robotics, 5(2), 251-262.

Smith, R. K., Vandellen, M. R., \& Ton, L. A. N. (2020). Makeup Who You Are: Self-Expression Enhances the Perceived Authenticity and Public Promotion of Beauty Work. Journal of Consumer Research.

Spence, C., Puccinelli, N. M., Grewal, D., \& Roggeveen, A. L. (2014). Store atmospherics: A multisensory perspective. Psychology \& Marketing, 31(7), 472-488.

Spieler, D. H., \& Griffin, Z. M. (2006). The influence of age on the time course of word preparation in multiword utterances. Language and Cognitive Processes, 21(1-3), 291321.

Steinnes, K. K., Blomster, J. K., Seibt, B., Zickfeld, J. H., \& Fiske, A. P. (2019). Too cute for words: Cuteness evokes the heartwarming emotion of kama muta. Frontiers in psychology, 10, 387.

Surawski, M. K., \& Ossoff, E. P. (2006). The effects of physical and vocal attractiveness on impression formation of politicians. Current Psychology, 25(1), 15-27. 
Tigue, C. C., Borak, D. J., O'Connor, J. J., Schandl, C., \& Feinberg, D. R. (2012). Voice pitch influences voting behavior. Evolution and Human Behavior, 33(3), 210-216.

Verhoeven, J., De Pauw, G., \& Kloots, H. (2004). Speech rate in a pluricentric language: A comparison between Dutch in Belgium and the Netherlands. Language and Speech, 47(3), 297-308.

Vrij, A., Akehurst, L., Soukara, S., \& Bull, R. (2004). Detecting deceit via analyses of verbal and nonverbal behavior in children and adults. Human Communication Research, 30(1), 841.

Walker, Peter and Sylvia Smith (1985), "Stroop Interference Based on the Multimodal Correlates of Haptic Size and Auditory Pitch,” Perception, 14(6), 729-736.

Wall, M. (2013). Pentagon-funded Atlas robot refuses to be knocked over, Retrieved from https://www.bbc.com/news/technology-24427821.

Wang, T., Mukhopadhyay, A., \& Patrick, V. M. (2017). Getting consumers to recycle NOW! When and why cuteness appeals influence prosocial and sustainable behavior. Journal of Public Policy \& Marketing, 36(2), 269-283.

Wolff, S. E., \& Puts, D. A. (2010). Vocal masculinity is a robust dominance signal in men. Behavioral Ecology and Sociobiology, 64(10), 1673-1683.

Wu, F., Samper, A., Morales, A. C., \& Fitzsimons, G. J. (2017). It's too pretty to use! When and how enhanced product aesthetics discourage usage and lower consumption enjoyment. Journal of Consumer Research, 44(3), 651-672.

Yoganathan, V., Osburg, V. S., \& Akhtar, P. (2019). Sensory stimulation for sensible consumption: Multisensory marketing for e-tailing of ethical brands. Journal of Business Research, 96, 386-396. 
Young, A. W., Frühholz, S., \& Schweinberger, S. R. (2020). Face and voice perception: Understanding commonalities and differences. Trends in Cognitive Sciences.

Zebrowitz-McArthur, L., \& Montepare, J. M. (1989). Contributions of a babyface and a childlike voice to impressions of Moving and Talking Faces. Journal of Nonverbal Behavior, 13(3), $189-203$.

Zhang, Y. S., Takahashi, D. Y., Liao, D. A., Ghazanfar, A. A., \& Elemans, C. P. (2019). Vocal state change through laryngeal development. Nature Communications, 10(1), 1-12.

Zou, X., Scholer, A. A., \& Higgins, E. T. (2014). In pursuit of progress: Promotion motivation and risk preference in the domain of gains. Journal of Personality and Social psychology, 106(2), 183.

Zuckerman, M., Miyake, K., \& Elkin, C. S. (1995). Effects of attractiveness and maturity of face and voice on interpersonal impressions. Journal of Research in Personality, 29(2), 253272. 